Aus der Abteilung Präventive Zahnmedizin, Parodontologie und Kariologie (komm. Leiter: Prof. Dr. med. dent. M. Hülsmann) im Zentrum Zahn-, Mund- und Kieferheilkunde der Medizinischen Fakultät der Universität Göttingen

\title{
Eine Nachuntersuchung von parodontal behandelten Recallpatienten in einer privatzahnärztlichen Praxis
}

\section{INAUGURAL-DISSERTATION}

zur Erlangung des Doktorgrades

für Zahnheilkunde

der Medizinischen Fakultät

der Georg-August-Universität zu Göttingen

vorgelegt von

Michael Wieslaw Jablonski

aus Ratibor / Polen

Göttingen 2010 
Dekan:

1. Berichterstatter:

2. Berichterstatter/in:

3. Berichterstatter/in:

Tag der mündlichen Prüfung:
Prof. Dr. med. C. Frömmel

Prof. Dr. med. dent. R. F. Mausberg

Prof. Dr. med., Dr. med. dent. Engelke

25. Mai 2011 


\section{Inhaltsverzeichnis}

1. Einleitung 5

2. Literaturübersicht

2.1 Parodontitis $\quad 7$

2.1.1 Definition $\quad 7$

$\begin{array}{ll}2.1 .2 \text { Klassifikation } & 7\end{array}$

2.1.2.1 Gingivopathien 8

2.1.2.2 Chronische Parodontitis 8

2.1.2.3 Aggressive Parodontitis 9

2.1.2.4 Parodontitis als Manifestation systemischer Erkrenkungen 9

2.1.3 Epidemiologie 10

2.1.4 Ätiologie und Pathogenese $\quad 11$

2.1.4.1 Plaque/ Biofilm 11

2.1.4.2 Bakterien 11

2.1.4.3 Pathogenese von Parodontalläsionen 12

2.1.4.4 Plaquehypothesen 14

2.1.5 Risikofaktoren 14

2.1.5.1 Patientenbezogene Risikofaktoren 14

2.1.5.1.1 Alter 15

2.1.5.1.2 Ethnische Unterschiede 16

$\begin{array}{ll}\text { 2.1.5.1.3 Geschlecht } & 17\end{array}$

2.1.5.2 Soziale und Verhaltensfaktoren 17

$\begin{array}{ll}\text { 2.1.5.2.1 Mundhygiene } & 17\end{array}$

$\begin{array}{ll}\text { 2.1.5.2.2 Ernährung } & 17\end{array}$

2.1.5.2.3 Rauchen 18

2.1.5.2.4 Stress 20

2.1.5.3 Systemische Faktoren 20

2.1.5.3.1 Alkohol 20

2.1.5.3.2 Diabetes mellitus $\quad 20$

$\begin{array}{ll}2.1 .5 .3 .3 \text { Osteoporose } & 21\end{array}$

2.1.5.3.4 HIV/ AIDS 22

2.1.5.4 Genetische Faktoren 22

$\begin{array}{ll}\text { 2.1.5.4.1 IL-1 Polymorphismus } & 22\end{array}$ 
2.1.5.5 Mikrobiologische Faktoren 23

2.1.5.5.1 Bakterien 23

2.1.5.5.2 Viren 23

2.1.5.6 Sozioökonomischer Status 24

2.1.5.7 Lokale Faktoren 24

2.1.6 Klinisches Bild und Verlauf 25

2.1.6.1 Gingivitis - Die Initialläsion 25

2.1.6.2 Gingivitis - Die Frühläsion 25

2.1.6.3 Gingivitis - Die etablierte Läsion 26

2.1.6.4 Parodontitis - Die fortgeschrittene Läsion 26

2.1.7 Systematik der Parodontitistherapie $\quad 27$

2.1.7.1 Initialtherapie/ Hygienephase $\quad 27$

2.1.7.1.1 Die mechanische Parodontitistherapie 28

2.1.7.1.1.1 Handinstrumente 28

$\begin{array}{ll}\text { 2.1.7.1.1.2 Ultraschallinstrumente } & 28\end{array}$

- Magnetostriktives Prinzip 28

- Piezoelektrisches Prinzip 29

- Vector® - System 29

- Wirkungsweise der Ultraschallgeräte 29

- Wirkung auf die Zahnhartsubstanzen 30

- Wundheilung nach Ultraschalltherapie 31

- Mikroflora 31

- Arbeitsweise 32

- Aerosolentwicklung 32

2.1.7.1.1.3 Weitere Verfahren zur Parodontitistherapie 32

2.1.7.1.1.4 Wundheilung nach der Parodontitistherapie 32

2.1.7.2 Unterstützende Parodontitistherapie 33

3. Material und Methode 35

3.1 Administrative Vorbereitungen 35

3.1.1 Untersuchungsort und - Zeitraum 35

3.2 Auswahl der Probanden 35

3.3 Screening der Patientendaten $\quad 37$

3.4 Einteilung der Patienten in Risikogruppen 39

3.5 Prognoseeinteilung der Zähne 39 
3.6 Zahnärztliche Nachuntersuchung 40

3.6.1 Untersucher 40

$\begin{array}{ll}\text { 3.6.2 Anamnese } & 40\end{array}$

3.6.3 Zahnärztlicher Befund $\quad 40$

$\begin{array}{ll}3.7 \text { Statistik } & 41\end{array}$

4. Ergebnisse 43

4.1 Ergebnisse Zahnverlust 43

4.1.1 Zahnverlust innerhalb der Zahngruppen 44

4.2 Ergebnisse Sondierungstiefen 45

4.2.1 Sondierungstiefen innerhalb der Zahngruppen 46

4.3 Ergebnisse Attachmentlevel 48

4.3.1 Attachmentlevel innerhalb der Zahngruppen 49

4.4 Ergebnisse Patientenrisiko 51

4.5 Ergebnisse Zahnprognosen 52

4.6 Anamnese 54

4.6.1 Sondierungstiefen innerhalb der Anamnesegruppen 54

4.6.2 Attachmentlevel innerhalb der Anamnesegruppen 55

4.7 Raucher und ihre Rauchgewohnheiten 56

4.7.1 Zahnverlust beim Raucher, ehemaligen Raucher und Nichtraucher 56

4.7.2 Sondierungstiefen beim Nichtraucher, ehemaligen Raucher und Raucher $\quad 57$

4.7.3 Attachmentlevel beim Nichtraucher, ehemaligen Raucher und Raucher $\quad 57$

4.7.4 Sondierungstiefen im Vergleich mit den Rauchgewohnheiten 58

4.7.5 Attachmentlevel im Vergleich mit den Rauchgewohnheiten 58

5. Diskussion 60

$\begin{array}{ll}5.1 \text { Bewertung des Studiendesigns } & 60\end{array}$

$\begin{array}{ll}5.2 \text { Bewertung der Studienergebnisse } & 61\end{array}$

5.2.1 Zur Geschlechterverteilung 61

5.2.2 Zum Alter der Studienteilnehmer 61

5.2.3 Bewertung des Zahnverlustes 62

5.2.4 Bewertung der Sondierungstiefen $\quad 64$

5.2.5 Bewertung des Attachmentlevels 66 
5.2.6 Bewertung der Einflussnahme der Allgemeinerkrankungen auf die Parodontitis

5.2.7 Bewertung der Zahnprognose/ des Patientenrisikos

5.2.8 Bewertung des Rauchverhaltens auf den Krankheitsverlauf 70

6. Zusammenfassung

7. Anhang:

7.1 Patienten Erfassungsbogen

7.2 Bogen zur Auswertung von Röntgenbildern

7.3 Anamnese 78

7.4 Patientenaufklärung 79

7.5 Anschreiben an die Patienten 80

7.6 Einwilligung zur Untersuchung 81

8. Literaturverzeichnis 82 


\section{Einleitung}

Karies und Parodontopathien gehören zu den weltweit meist verbreiteten Erkrankungen überhaupt. Über 95\% der Bevölkerung der zivilisierten Länder sind davon betroffen. Um Erkrankungen wie Karies, Gingivitis und Parodontitis zu vermeiden bzw. ein Fortschreiten zu verhindern, gewinnt die präventiv orientierte zahnmedizinische Betreuung von Patienten zunehmend an Bedeutung. Verlust von Zähnen bedeutet ein Defizit an Funktionalität und Ästhetik, was immer einen Verlust an Lebensqualität für den Betroffenen mit sich bringt. Mit steigender Lebenserwartung steigt jedoch die Forderung nach gesunden Zähnen bis ins hohe Alter. Regelmäßige zahnärztliche Kontrolluntersuchungen und eine Zunahme an vorsorglichen Fissurenversiegelungen haben maßgeblichen Beitrag zum Rückgang der Karies geleistet. Kinder (12-jährige) haben im Durchschnitt 0,7 Zähne mit Karieserfahrung, Jugendliche (15-jährige) 1,8, Erwachsene (35- bis 44-jährige) 14,5 und Senioren (65- bis 74-jährige) 22,1 Zähne mit Karieserfahrung (DMS IV 2006). Zudem tragen die gesundheitliche Eigenverantwortlichkeit, eine bessere Aufklärung und das zunehmende Schönheitsempfinden des Patienten dazu bei, dass die Kariesprävalenz stetig abnimmt. Die Konsequenz ist, dass erhaltene Zähne mit zunehmendem Lebensalter ein höheres Risiko für Parodontopathien aufweisen. Mittelschwere und schwere Parodontalerkrankungen haben bei den Erwachsenen und Senioren seit der DMS III von 1997 um 26,9 bzw. 23,7 Prozent zugelegt (DMS IV 2006).

Die Parodontitis ist eine durch Bakterien verursachte Erkrankung des Zahnhalteapparates. Zahlreiche Untersuchungen zeigen, dass durch eine entsprechende Mundhygiene und eine gezielte Aufklärung des Patienten die Parodontitis vermeidbar ist. Die Qualität und Quantität der supragingivalen Plaque ist unmittelbar mit der subgingivalen Plaque vergesellschaftet und das gezielte Entfernen lindert oder heilt die Erkrankung (Smulow et al. 1983).

Keine andere Erkrankung im Mundraum hat so weitreichende Fernwirkung auf den Organismus wie die Parodontitis. Bei schweren Entzündungen kommt es zur Bakteriämie. Über die Zahnfleischtaschen werden ständig hochaktive Bakterien in den Blutkreislauf ausgeschwemmt. Somit stehen Erkrankungen, wie z.B. Herzinsuffizienz, rheumatische Arthritis, sowie Erkrankungen des kardiovaskulären Systems als auch erhöhtes Frühgeburtenrisiko in Assoziation zur Parodontitis (Chun et al. 2005, López et al. 2005b, Manau et al. 2008). Rauchen und ein vorhandener Diabetes mellitus gelten als Hauptrisikofaktoren für eine Parodontitis (Grossi et al. 1994, 
Albandar 2002b), damit sinken die Erfolgsaussichten für eine erfolgreiche Parodontaltherapie und die Rezidivgefahr bei aktiven Rauchern steigt (Grossi et al. 1997a). Als Ursache spielt die Nikotineinwirkung auf Abwehrzellen und die Minderdurchblutung der Gingiva eine Rolle (Salvi et al. 1997). Behandlungen bei bestehendem bzw. schlecht eingestelltem Diabetes mellitus verlaufen verhältnismäßig schlechter als bei gut eingestellten Diabetikern oder bei gesunden Patienten (Taylor et al. 1998). Häufig ist der Schweregrad der Entzündung und das Ausmaß des Alveolarknochenverlustes unverhältnismäßig groß. Medikamente und andauernde Stressbelastungen können zudem die Durchblutung reduzieren und somit die Immunabwehr im Entzündungsgebiet negativ beeinflussen. Das Risiko, an koronaren Herzerkrankungen oder an thromboembolischen Komplikationen zu erkranken, steigt. Das Apoplexrisiko steigt bei einer unbehandelten Parodontitis (Dörfer et al. 2004).

Es gibt unterschiedliche Vorgehensweisen bei der Parodontitistherapie, beispielsweise Handscaling, Ultraschallscaling, Laser etc. Diese Arten der Behandlung sind zwar behandlerabhängig, unterscheiden sich aber vom Behandlungserfolg nicht (Osterwaal et al. 1987, Petersilka \& Flemming 2005, Guarnelli et al. 2008, Schwarz et al. 2008, loannou et al. 2009). Das Ziel einer Parodontaltherapie ist der Erhalt der Gesundheit, Funktion und Ästhetik der Zähne über einen langen Zeitraum. Patienten sollten nach erfolgter Parodontaltherapie in ein Nachsorgeprogramm (UPTUnterstützende Parodontaltherapie) eingegliedert werden. Nur so ist mit einem langfristigen Therapieerfolg zu rechnen (Axelsson et al. 2004). Wichtige Stützpfeiler der Therapie sind neben der Befunderhebung (Parodontalen-Screening-Index) die Individualprophylaxe, später die therapiebegleitende Prophylaxe, sowie die Reinigung der infizierten Zahnfleischtaschen.

Ziel der geplanten Untersuchung ist, den Behandlungserfolg von parodontal behandelten Patienten, nach geschlossener Kürettage mit Ultraschall und mehrjähriger unterstützender Parodontitistherapie ( $\geq 3$ Jahre) in einer zahnärztlichen Praxis, hinsichtlich des langfristigen Zahnerhalts zu untersuchen. Daneben werden Veränderungen der Taschentiefe und des Attachmentlevels verglichen. 


\subsection{Parodontitis}

\subsubsection{Definition}

Als Parodontitis wird eine entzündliche multifaktoriell bedingte Infektionskrankheit des Zahnhalteapparates bezeichnet. Sie ist durch einen progressiven Verlust der Haltefunktion des Parodontiums (Attachmentverlust) und der Degeneration des Alveolarknochens gekennzeichnet. Klinische Symptome sind Blutung und gelegentlicher Pusaustritt bei Sondierung der Taschen. Kennzeichnend ist der bei der Parodontitis vorhandene, röntgenologisch nachweisbare Knochenabbau, mit und ohne Rezessionen. Durch die irreversible Schädigung des Zahnhalteapparats kommt es langfristig zur Lockerung und ggf. Zahnstellungsänderung der betroffenen Zähne. Langfristig droht der Zahnverlust (Plagmann 1998).

\subsubsection{Klassifikation}

Seit dem „International Workshop for a Classification of Periodontal Diseases and Conditions“ im Jahre 1999 werden die Parodontitiden wie folgt unterschieden (Armitage 1999):

1. Gingivopathien

2. Chronische Parodontitis

3. Aggressive Parodontitis

4. Parodontitis als Manifestation systemischer Erkrankungen

5. Nekrotisierende parodontale Erkrankungen

6. Abszesse des Parodonts

7. Parodontitis im Zusammenhang mit endodontalen Läsionen

8. Entwicklungsbedingte oder erworbene Deformationen und Zustände.

Im Folgenden soll nur auf die Punkte 1.-4. näher eingegangen werden. 


\subsubsection{Gingivopathien}

Typische klinische Symptome einer Gingivitis sind Rötung, Schwellung des Zahnfleisches, vermehrte Exsudatbildung und Blutung auf vorsichtiges Sondieren. Im Gegensatz zur Parodontitis heilt die Gingivitis bei Beseitigung der entzündungsverursachenden bakteriellen Beläge (Plaque) vollständig ab. Man unterscheidet die Gingivitiden in Plaque-induzierte und nicht durch dentale Plaque verursachte Gingivopathien. Zu den Plaque-induzierten Gingivitiden zählt man neben den ausschließlich durch Plaque verursachten Formen auch diejenigen, die durch systemische Faktoren, Medikamente und Mangelernährung moduliert werden. Systemische Faktoren wie z.B. hormonelle Umstellungen, die während der Pubertät, des Menstruationszyklus oder der Schwangerschaft auftreten, können den Verlauf der Gingivitis beeinflussen. Medikamente wie Antikonvulsiva (z.B. Phenytoin), Immunsuppressiva (z.B. Ciclosporine) und Kalziumkanalblocker (z.B. Nefidepin), können zu einer Gingivahyperplasie und somit zur Pseudotaschenbildung führen. Bei Mangelernährung ist im Wesentlichen Skorbut (Vitamin-C-Mangel) für einen negativen Krankheitsverlauf verantwortlich. Die nicht Plaque-induzierten Gingivitiden beruhen auf spezifischen bakteriellen Pilz- oder Virusinfektionen. Systemische Erkrankungen, allergische Reaktionen oder traumatische Läsionen können ebenfalls Auslöser für eine Gingivitis sein (Mariotti 1999, Plagmann 1998).

\subsubsection{Chronische Parodontitis}

Die chronische Parodontitis äußert sich in einem langsamen, überwiegend horizontal stattfindenden Knochenabbau. Es handelt sich um die am häufigsten diagnostizierte Parodontitisform. Sie tritt bei Erwachsenen etwa ab der 4. Lebensdekade auf, kann aber auch bei Kindern und Jugendlichen in Erscheinung treten. Das Ausmaß der Progression ermöglicht eine Unterteilung in eine „lokalisierte Form“, wenn weniger als $30 \%$ der Zahnflächen betroffen sind, und in eine „generalisierte Form“ ,bei einem Befall von mehr als $30 \%$ der Zahnflächen. Der Schweregrad der Erkrankung, gemessen am Ausmaß des Attachmentverlustes, gestattet die Einteilung in eine leichte (1-2 mm), moderate (3-4 mm) und schwere Form ( >5 mm) (Müller 2001). 


\subsubsection{Aggressive Parodontitis}

Die aggressive Parodontitis beschreibt eine Form der Erkrankung, die bei meist jüngeren Patienten (Beginn zwischen Pubertät und ca. 30 Lebensjahr) oftmals mit einem sehr raschen Verlauf vergesellschaftet ist. Auffällig ist die familiäre Häufung bei sonst gesunden Patienten. Weitere Merkmale können zum einen die Diskrepanz zwischen schwerer parodontaler Destruktion und den relativ geringen PlaqueAnsammlungen sein und zum anderen ein vermehrtes Auftreten von Actinobacter actinomycetemcomitans (A.a.) und Porphyromonas gingivalis (P.g.). Hinzu kommen Abnormalitäten der Phagozytenfunktion, als auch ein hyperaktiver Makrophagenphänotyp. In einigen Fällen ist sie eine selbstlimitierende Erkrankung. Die aggressive Parodontitis wird ebenfalls in eine lokalisierte und generalisierte Form unterteilt. Die lokalisierte Form manifestiert sich während der Pubertät, bei der erhöhte Serumkonzentrationen an A.a. und / oder P.g. zu finden sind. Erkrankt sind meistens die 1. Molaren und Inzisivi der bleibenden Zähne. Die generalisierte Form beginnt meist vor dem 30. Lebensjahr, wobei auch spätere Entwicklungen möglich sind. Sie kann mit einer phasenweisen Progression verbunden sein. Es sind mindestens 3 Zähne, die nicht die 1. Molaren/Inzisiven sind, vom approximalen Attachmentverlust betroffen (Brunner et al. 2002).

\subsubsection{Parodontitis als Manifestation systemischer Erkrankungen}

Diverse hämatologische Erkrankungen, wie Neutropenien und Leukämie, sowie genetisch bedingte Erkrankungen, wie z.B. das Down-Syndrom, das Papillon-LefévreSyndrom oder aber auch das Chediak-Higashi-Syndrom, können das Entstehen einer Parodontitis begünstigen. Ernährungsstörungen und Diabetes mellitus sollten in diesem Zusammenhang ebenfalls erwähnt werden (siehe Seite 17 und 20)

(Plagmann 1998, Mariotti 1999). 


\subsubsection{Epidemiologie}

Karies und Parodontopathien gehören zu den am häufigsten auftretenden Erkrankungen des Menschen weltweit. Schwerwiegende Erkrankungsformen sind aber eher selten, während leichte bis moderate Verläufe häufiger bei Erwachsenen diagnostiziert werden (Sheiham 1991). Es gibt zahlreiche Untersuchungen zu Prävalenzen der Parodontitis weltweit. Im Rahmen der großen National Health and Nutrition Examination Survey (NHANES III) vom Jahre 1988-1994 wurden 30.818 Personen untersucht. Es wurde festgestellt, dass etwa 35\% der Erwachsenen in den USA an einer Form der chronischen Parodontitis leiden. In der Gruppe der Dreißigjährigen erkrankten $3.1 \%$ an einer fortgeschrittenen, 9,5\% an einer moderaten und $21,8 \%$ an einer milden Form der Parodontitis (Albandar 2002a). Bei etwa 82\% der erwachsenen US-Amerikaner wurde eine Gingivitis mit Zahnfleischbluten festgestellt (Albandar \& Rams 2002). Studien, die das Vorkommen der Parodontitis in Europa untersuchen, sprechen von Zahlen zwischen 13-54\% in der Gruppe der 35-44 Jährigen mit 3,3-5,5mm tiefen Taschen. In Ost-Europa liegen die Werte bei $45 \%$ und in West-Europa durchschnittlich bei $36 \%$. Die Prävalenz für die fortgeschrittene $\mathrm{Pa}-$ rodontitis (Taschentiefe $>5,5 \mathrm{~mm}$ ) liegt in den westlichen europäischen Staaten bei $10 \%$ und in den östlichen bei 30-40\%. Das Auftreten der Gingivitis liegt im Vergleich zu den USA mit 80\% ähnlich hoch (Sheiham \& Netuveli 2002).

Die aktuellste Untersuchung für das Auftreten der Parodontitis in Deutschland liefert die vierte deutsche Mundgesundheitsstudie (DMS IV 2006) aus dem Jahre 2006. Die Ergebnisse zeigen, dass unter den 15-jährigen Jugendlichen 12,6\% an einer mittelschweren und immerhin 0,8\% an einer schwer verlaufenden Parodontitis leiden. Bei den Erwachsenen sind 52,7\% der 35- bis 45-jährigen an einer mittelschweren $\mathrm{Pa}$ rodontitis erkrankt und 20,5\% leiden an einer schweren Ausprägung des Krankheitsbildes. Die Seniorengruppe (65-74 Jahre) ist am Häufigsten (ca. 88\%) von der Erkrankung betroffen. Hier leiden 48,0\% unter einer mittelschweren und 39,8\% unter einer schweren Form. Vergleicht man die erhobenen Daten zur Prävalenz der Parodontitis mit der dritten deutschen Mundgesundheitsstudie (DMS III) von 1997, ist ein Punktanstieg von $26,9 \%$ bei Erwachsenen und $23,1 \%$ bei Senioren zu verzeichnen. Ein Grund für die Zunahme der Parodonthopathien ist die Tatsache, dass weniger Zähne durch Karies verloren gehen mit der Konsequenz, dass das Risiko im zunehmendem Lebensalter für Parodontitis steigt (DMS IV 2006). 


\subsection{4 Ätiologie und Pathogenese}

\subsubsection{Plaque/Biofilm}

„Die Plaque ist eine nicht mineralisierte Ansammlung von Bakterien, die fest an Zahnoberflächen und Restaurationen haftet. Sie zeigt strukturelle Organisation mit vorwiegend filamentförmigen Bakterien in einer organischen Matrix, aus Speichelglykoproteinen und extrazellulären Bakterienprodukten. Sie lässt sich durch Mundspülungen oder Wasserspray nicht entfernen“ (Plagmann 1998, S. 41).

\subsubsection{Bakterien}

Vor zirka 200 Jahren beschrieb Antony van Leeuwenhoek als erster Bakterien in der Mundhöhle. Seit der Bekanntgabe der Koch'schen Postulate jedoch ist bekannt, dass nicht die Gesamtheit aller Bakterien Karies und Parodontopathien verursacht, sondern eine mikrobiologische Spezifität bezüglich der Erkrankungen besteht (Christersson et al. 1991, Loomer 2004). Studien zeigen, dass nur ein kleiner Teil der etwa 500 Arten von Mikroorganismen der Mundhöhle mit Parodontitis assoziiert ist. Bestimmte Bakterien sind mit der Parodontitis oder mit der Progressionsrate vergesellschaftet (Wolff et al. 1994). So wird Actinobacter actinomycetemcomitans oft bei Patienten mit aggressiver Parodontitis gefunden (Slots \& Ting 1999). Albandar et al. (1997) verwendeten DNA-Sonden, um mögliche pathogene Mikroorganismen bei Patienten mit aggressiver Parodontitis zu entdecken. Sie fanden eine hohe Prävalenz für Porphyromonas gingivalis, Prevotella intermedia, Fusobacterium nucleatum, Campylobacter rectus und Treponema denticola, aber nur eine geringe für A. actinomycetemcomitans (Albandar et al. 1997). In einer weiteren Untersuchung bei Patienten mit einer aggressiven Parodontitis konnten Albandar und Kollegen einen erhöhten Serumspiegel von IgG- und IgA- Antikörpern gegen P. gingivalis und A. actinomycetemcomitans, sowie IgA gegen $P$. intermedia, im Vergleich zu gesunden Kontrollpersonen, nachweisen. Die hohen Antikörpertiter geben Anlass für die Vermutung, dass P.g., A.a. und P.i. eine entscheidende Rolle in der Pathogenese der Parodontitis spielen (Albandar et al. 2001). Bei einer retrospektiven Studie von Aass et al. konnte A. actinomycetemcomitans in etwa 50\% der Zahnfleischtaschen mit Knochenverlust identifiziert werden (Aass et al. 1994). Spezifische genetische Varianten von A.a. konnten mit der aggressiven Parodontitis in Bezug gebracht werden 
(DiRienzo et al. 1994, Haubek et al. 1996). Eine Studie von Grossi et al. über Risikoindikatoren für Knochenverlust, kam zu dem Ergebnis, dass Vorkommen von Porphyromonas gingivalis und Tannerella forsythia in der subgingivalen Flora mit einer Odds Ratio von 1,6 (für P.g.) und 2,5 (für T.f.) verbunden ist (Grossi et al. 1994, Grossi et al. 1995). Das Wissen über die Unterschiede in der Plaquezusammensetzung ist ausschlaggebend für das Management von parodontalen Erkrankungen (van Winkelhoff \& de Graaff 1991).

\subsubsection{Pathogenese von Parodontalläsionen}

Die Entstehung einer entzündlich bedingten Parodontitis wird durch mehrere Faktoren begünstigt. Als primäre Ursache werden die Bakterien angesehen. In der Mundhöhle existieren mehr als 500 verschiedene Bakterienspezies. Durch ihre bloße Anwesenheit allein wird aber noch keine Parodontitis verursacht, da sie auch in parodontal gesunden Bereichen nachweisbar sind.

Eine besondere Rolle in der Etablierung der Parodontitis spielt die Fähigkeit von Mikroorganismen zur Organisation in Biofilmen. Diese Eigenschaft ermöglicht es innen, sich erfolgreich der Wirtsabwehr zu widersetzen. Er hemmt beispielweise die Chemotaxis von polymorphkernigen, neutrophilen Granulozyten (PMN) oder blockiert die Phagozytoseprozesse, sowie die gegen sich gerichteten Immunglobuline.

Flüssigkeitskanäle innerhalb des Biofilms erlauben einen Austausch von Stoffwechselprodukten zwischen Bakterieninseln. Durch die Bildung einer extrazellulären Matrix ist der Biofilm resistenter gegenüber Austrocknung und zugeführten Chemotherapeutika, wie Chlorhexidin oder Antibiotika (Marsh 2004).

Zu Beginn der Plaquebildung bildet sich das erworbene Pellikel aus Glykoproteinen des Speichels. Es entsteht innerhalb von wenigen Minuten bis zwei Stunden, nach gründlicher Zahnreinigung, auf der Zahnoberfläche. Diese Struktur bildet die Grundlage für die Besiedlung mit Pionierkeimen, v. a. grampositive Kokken, aber auch Neisseria ssp. und Actinomyces ssp. Diese bilden extrazelluläre Polysaccharide, welche die Adhärenz weiterer Arten erleichtern. Die Anzahl an Streptokokken nimmt $a b$, wobei fakultative und anaerobe Aktinomyzeten, gramnegative Kokken und Stäbchen zunehmen (Page 1986).

Mit der Etablierung des Biofilms beginnt die marginale Infektion. Die ödematöse Schwellung der Gingiva und die Vertiefung des Sulcus gingivae sind Reaktionen auf 
die Infektion und ermöglichen die Migration in den subgingivalen Bereich. Diese Region bietet den Bakterien sehr günstige Bedingungen. Sie bietet Schutz vor Mundhygienemaßnahmen und der Spülwirkung des Speichels. Das entzündliche Gingivaexsudat enthält essentielle Wachstumsfaktoren für zahlreiche Parodontalpathogene. Durch den sinkenden Sauerstoffpartialdruck, infolge des Dickenwachstums und der Ausbreitung in den subgingivalen Bereich, wird die Besiedlung obligat anaerober Keime begünstigt. So kann sich subgingival neben der adhärenten Plaque eine „schwimmende“ Plaque etablieren, welche virulenter ist und bei aggressiven $\mathrm{Pa}$ rodontitiden dominiert (Plagmann 1998).

Aus dem Plaquefilm werden kontinuierlich Produkte und Bestandteile der Mikroorganismen freigesetzt. Da wären zum Beispiel Lipopolysaccharide (LPS), toxische Metabolite, wie organische Säuren, Ammoniak, Schwefelwasserstoff und zahlreiche proteolytische Enzyme zu nennen. In den angrenzenden Geweben werden daraufhin u.a. die Zytokine Interleukin-1 (IL-1) und TNF-a gebildet, die eine Entzündungsreaktion fördern. Die Durchblutung im parodontalen Gewebe steigt (Hyperämie) und die Gefäßpermeabilität erhöht sich, wodurch die Sulkusfließrate steigt. Es kommt zur massiven und zielgerichteten Einwanderung verschiedener immunkompetenter Zellen (PMN, Makrophagen, T-Lymphozyten und Plasmazellen) auf chemotaktische Reize hin. Das Komplementsystem wird aktiviert. Während der Phagozytose werden Granula freigesetzt, die u.a. Hydrolasen und Proteasen enthalten. Dadurch werden Bestandteile der bakteriellen Zellmembran, aber auch körpereigenes Kollagen und Fibrinogen gespalten. Die Produktion von Matrixmetalloproteinasen führt zur Destruktion der extrazellulären Matrix der Gingiva und des Desmodonts . Zudem setzen Granulozyten auch Lysozyme, sowie Entzündungsmediatoren (Prostaglandine und Leukotriene) frei, die erneut die Permeabilität der Gefäße steigern. Im Wechsel mit den zytotoxischen Substanzen und den aggressiven Enzymen aus Plaquebakterien, wird so die Kollagenolyse vorangetrieben. Dies führt zu einem bindegewebigen Attachmentverlust und durch Osteoklastenaktivierung zu Knochenabbau und Tiefenproliferation des Saumepithels mit Taschenbildung (Page 1986, Page 1991). 


\subsubsection{Plaquehypothesen}

Lange galten unterschiedliche Auffassungen über die krankheitsauslösenden Faktoren und deren Behandlungsstrategien.

Die unspezifische Plaquehypothese geht davon aus, dass die gesamte Plaque zur Gingivitis bzw. Parodontitis führt, wenn eine gewisse Toleranzschwelle des Wirts überschritten wird. Unterhalb dieser Schwelle ist der Körper selbst in der Lage die Bakterien abzuwehren. Folgen für die Therapie sind: Beseitigung der Plaque, dauerhafte Therapie.

Die spezifische Plaquehypothese hingegen geht davon aus, dass die Qualität der Plaque einen Einfluss auf die Erkrankung hat. Nur bestimmte Keime lösen die Erkrankung aus. Folgen für die Therapie sind: eine gezielte Erregerdiagnostik und Erregerbeseitigung sind erforderlich. Die Therapie endet mit dem Heilerfolg.

Die opportunistische Plaquehypothese geht nicht nur von der Anwesenheit bestimmter pathogener Keine aus, sondern auch von einem günstigen Milieu für deren Entstehung. Modulierende Einflüsse können z.B. veränderte Immunabwehr, hormonelle Einflüsse oder Spezifität der Bakterien sein. Dabei kann auch die Abwesenheit bestimmter, die Plaque stabilisierender Bakterien als mögliche Ursache für parodontale Destruktion angesehen werden.

Die Therapiefolgen werden im Weiteren erläutert.

\subsubsection{Risikofaktoren}

\subsubsection{Patientenbezogene Risikofaktoren}

Die Parodontitis ist eine multifaktoriell bedingte Erkrankung. Als Primäre Ursache gilt die mikrobielle Besiedlung der Mundhöhle. Darüber hinaus haben viele Faktoren einen unterschiedlich starken Einfluss auf die Progression der Parodontitis. Die Abbildung 1 zeigt die Ätiologie und Pathogenese unter Berücksichtigung Einfluss nehmender Faktoren (Page \& Kornman 1997). 

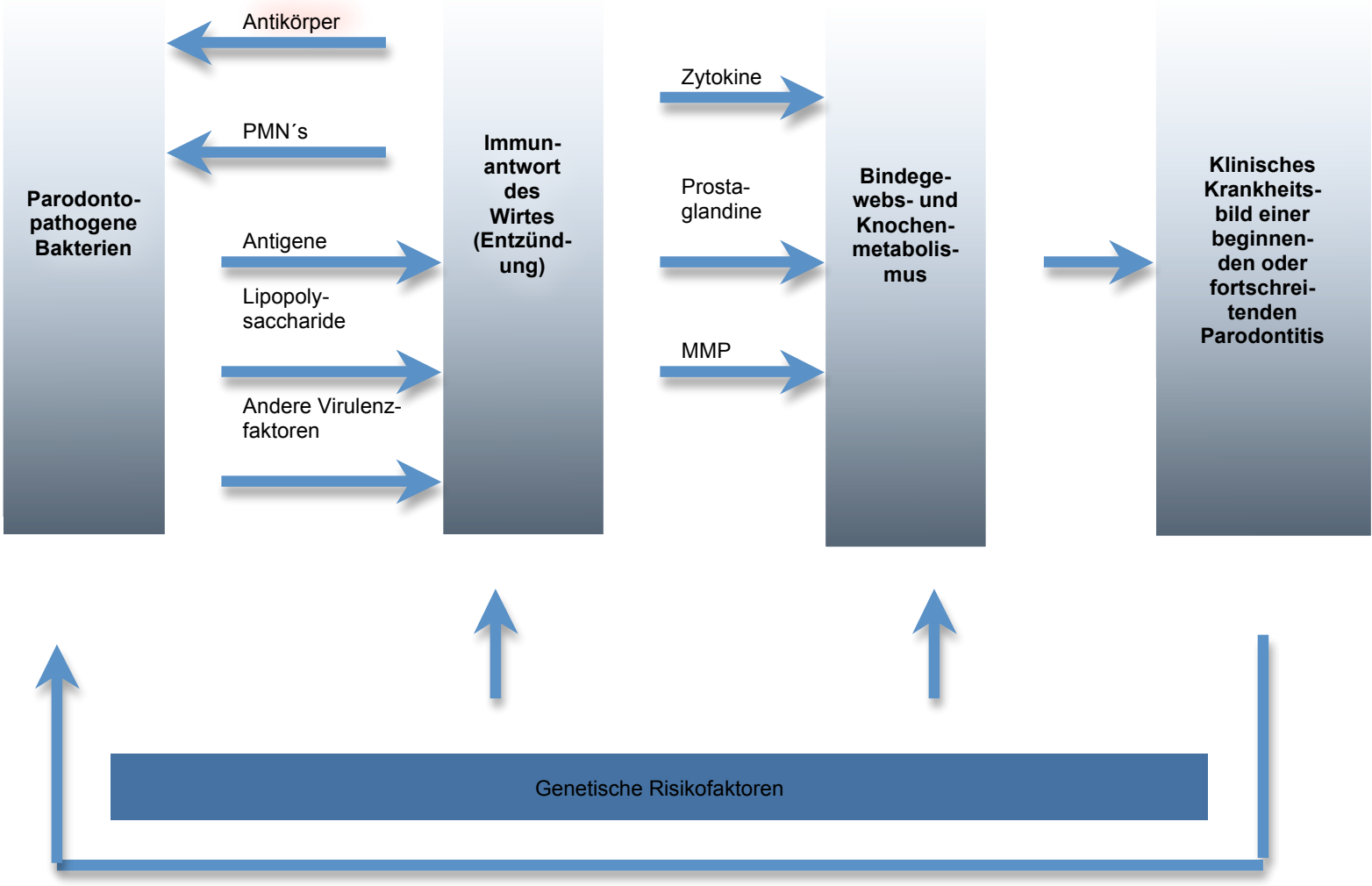

Abb. 1 Ätiologie und Pathogenese der Parodontitis modifiziert nach Page \& Kornman 1997 (S. 10)

\subsection{Alter}

Bei dem Einfluss des Alters auf das Parodontium sollte zwischen der Alterung der Körpergewebe, der Veränderung von Abwehr- und Regenerationsfähigkeit und dem Alter als der Zeitspanne, in der die vorhandene Plaque sich auswirken kann, unterschieden werden (Plagmann 1998).

Querschnittsstudien deuten auf einen möglichen Zusammenhang zwischen der Prävalenz von Parodontopathien und dem zunehmenden Alter hin (Albandar 2002b). Van der Velden konnte ebenfalls eine Beziehung zwischen dem Alter und der Zunahme an parodontalen Entzündungen herstellen. Es gibt jedoch keinen ausreichenden Beweis für eine physiologische apikale Migration des Epithelansatzes im Alter. Es scheint plausibler, dass die Anwesenheit von Plaque für die Destruktion verantwortlich ist (van der Velden 1984). Der Entzündungsablauf im Alter verläuft schneller, das Ausmaß der Zerstörung ist größer und die Wundheilung ist verlangsamt. Lindhe 
et al. untersuchten bei 62 Studienteilnehmern die Heilungsvorgänge nach chirurgischer Parodontaltherapie und stellten fest, dass das Alter keinen Einfluss auf die Ergebnisse hat. Es gäbe aber eine Tendenz, bei der jüngere Patienten kleinere Sondierungstiefen und insgesamt mehr Attachmentgewinn vorweisen können als ältere $\mathrm{Pa}$ tienten (Lindhe et al. 1985). Ergebnisse einer 10-Jahres Untersuchung von Ship et al. zeigen ähnliche Resultate. Mit dem Alter steigt der Attachmentverlust aber eher als Resultat von Rezessionen, als von pathologischen Prozessen in der Tiefe der Taschen (Ship \& Beck 1996, Taggart et al. 1990, Micheelis et al. 2008). Die Wechselbeziehung zwischen Alter und Attachmentverlust scheint eher das Resultat einer plaque-induzierten Entzündung bei „langer Einwirkdauer“ wiederzuspiegeln, als eine im Alter verminderte Resistenz (Plagmann 1989).

\subsection{Ethnische Unterschiede}

Eine genetische Prädisposition für die unterschiedliche Anfälligkeit für Parodontitis zwischen den menschlichen Rassen wurde schon oft diskutiert (Pihlström 2001). Eine Untersuchung beschäftigt sich mit älteren Sozialhilfeempfängern. Sie konnte zeigen, dass Afroamerikaner ein dreifach höheres Risiko für eine schwere Parodontitis hatten als „weiße“ Patienten der gleichen Altersgruppe. Zusätzlich schien Prevotella intermedia für die afroamerikanischen Patienten ein Risikofaktor zu sein (Beck et al. 1990). Umeda et al. schätzten, dass bei „African-American“ ein erhöhtes Risiko (Odds Ratio 2,95) für das Vorkommen von Porphyromonas gingivalis im Speichel vorliegt. Bei „Asian-American“ lag das erhöhte Risiko für Actinobacter actinomycetemcomitans in parodontalen Taschen bei OR 6,6 und für P. gingivalis in parodontalen Taschen, sowie im Speichel bei OR 5,7 bzw. 5,4. Bei untersuchten Patienten mit spanischer Abstammung lag das Risiko sogar bei OR 12,3 für A.a in parodontalen Taschen,für P.g. bei OR 6,1 in parodontalen Taschen und OR 8,7 im Speichel (Umeda et al. 1998). Bei näherer Betrachtung der Untersuchungen gibt es Hinweise, dass die Unterschiede eher auf sozioökonomischen Faktoren beruhen. Die vermuteten rassischen Unterschiede hängen eher mit Mangel- und Unterernährung, sozialem Status, speziellen Lebensformen und -gewohnheiten (z.B. Betelkauen), Stresssituationen (Krieg, Flucht) oder schlechter Mundhygiene, aber nicht mit rassischgenetisch bedingten Faktoren zusammen (Plagmann 1998). Studien, die Probanden mit gleichem sozioökonomischen Status untersuchten, fanden keine Unterschiede 
zwischen den Rassen heraus (Grossi et al. 1994). Eine gewisse genetische Variabilität ist ggf. in der Prävalenz für Polymorphismen des IL-1 $\alpha /$ IL-1 $\beta$ - Genotyps zu finden. Armitage konnte ein signifikant niedrigeres Vorkommen bei Chinesen $(2,3 \%)$ als bei Europäern (36\%) feststellen (Armitage et al. 2000).

\subsection{Geschlecht}

Das männliche Geschlecht weist in einigen Untersuchungen ein höheres Risiko für Parodontopathien auf als Frauen (Albandar 2002a, Albandar 2002b, Grossi et al. 1994, Grossi et al. 1995). Die deutsche Mundgesundheitsstudie (DMS IV 2006) zeigt, dass Männer häufiger an einer schweren Form der Parodontitis erkranken als Frauen. Auch sollen Männer generell eine schlechtere Mundhygiene aufweisen (Albandar 2002b).

\subsubsection{Soziale und Verhaltensfaktoren}

\subsection{Mundhygiene}

Der inzwischen klassische Modellversuch von Löe et al. zur experimentellen Gingivitis zeigte, welchen entscheidenden Stellenwert die Mundhygiene in der Prävention von Parodontopathien hat. Die Plaquemenge korreliert mit der Prävalenz parodontaler Erkrankungen (Löe et al. 1965). Gute Mundhygiene ist eine wichtige Voraussetzung für die Stabilität der parodontalen Gesundheit. Unterschiedliche Studien belegen, dass eine unzureichende Mundhygiene, unabhängig vom Alter, ein Risikofaktor für Parodontopathien darstellt (Albandar 2002b, Grossi et al. 1994, Grossi et al. 1995, DMS IV 2006). Eine Untersuchung von 565 Norwegern konnte zeigen, wie entzündete Gingivastellen, die über einen Untersuchungszeitraum von 26 Jahren immer auf Sondierung geblutet haben, 70\% mehr Attachmentverlust vorweisen als Bereiche, die dauerhaft entzündungsfrei waren (Schätzle et al. 2003).

\subsection{Ernährung}

Eine gesunde Ernährung ist wichtig für die allgemeine Gesundheit. Unausgewogene Ernährung und Bewegungsarmut sind die Hauptursachen von Morbidität und Mortalität weltweit. Eine nicht ausgewogene Ernährung ist für viele Erkrankungen, wie Adipositas, Hypertonie, Dyslipidämie, Diabetes Typ II, Herzkreislauferkrankungen, Osteoporose, Zahnkaries und einige Krebsarten verantwortlich. Eine negative Aus- 
wirkung von Zucker und gesüßten Getränken sind Karies und Zahnbetterkrankungen (Palacios et al. 2009). Ein höheres Risiko für parodontale Erkrankungen konnten Nishida et al. Rauchern im Zusammenhang mit einer erniedrigten Zufuhr von Vitamin C nachweisen. Es gibt einige weitere Untersuchungen, die positive Wechselbeziehungen zwischen Vitamin C- (Nishida M. et al. 2000a; Clark et al. 1990), Kalzium(Nishida M. et al. 2000b) und Vitamin- D- Supplementierung (Miley et al. 2009) und einer besseren parodontalen Gesundheit herstellen. Eine Studie zur Untersuchung von Patienten mit Osteoporose und Parodontitis konnte ebenfalls zeigen, inwieweit höhere Aufnahmemengen von Kalzium (min. 1000 mg/Tag) mit eingeschränkter Prävalenz für klinischen Attechmentverlust und geringerem Risiko für Zahnverlust verbunden sein können (Krall 2001).

\subsection{Rauchen}

Der Zigarettenrauch ist ein Gemisch aus über 4000 bekannten Substanzen. Neben Nikotin, Teerstoffen und Reizgasen sind auch Kohlenmonoxid, Blausäure und Arsen enthalten. Mindestens 50 dieser Substanzen sind nachweislich karzinogen (Benowitz 1996).

Einige klassische klinische Zeichen parodontaler Erkrankungen, wie erhöhte Taschentiefen, horizontale und vertikale Knochendefekte oder vermehrte Zahnbeweglichkeit, stimmen bei Rauchern sowie Nichtrauchern überein (Krall et al. 1997). Die klinischen Entzündungszeichen einer Gingivitis werden jedoch maskiert. Rauchen führt zu einer Hyperkeratose und Fibrose der Gingiva. Dabei ist gleichzeitig weniger Rötung und Schwellung feststellbar als bei einem Nichtraucher, der ebenfalls an einer Parodontitis erkrankt ist. Diese Wirkung ist auf die vasokonstriktorische Eigenschaft des Nikotins zurückzuführen (Salvi et al. 1997, Black et al. 2001). Unterschiedliche Studien zeigen, dass Raucher häufiger an Parodontitis leiden als Nichtraucher (Grossi et al. 1994, Albandar 2002b, DMS IV 2006). Am Beispiel der chronischen Parodontitis weisen Raucher, im Vergleich zu Nichtrauchern, folgende Befunde auf:

-höhere Sondiertiefen sowie eine größere Taschenanzahl (Bergstrom et al. 2000, Feldman et al. 1983),

- einen höheren Attachmentverlust und vermehrte gingivale Rezessionen (Grossi et al. 1994, Haffajee \& Socransky 2001, Linden \& Mullally 1994), - höhere Zahnverlustrate 
(Krall et al. 1997, Österberg \& Mellström 1986)

- geringere klinische Anzeichen einer Gingivitis, sowie eine geringere

Blutungsneigung auf Sondierung (Feldman et al. 1983, Bergstrom \& Preber 1986, Haffajee \& Socransky 2001, Dietrich et al. 2004)

und

- $\quad$ mehr Zähne mit Furkationsbefall (Kerdvongbundit \& Wikesjö 2000, Mullally \& Linden 1996).

Klinische Studien der vergangenen zehn Jahre haben gezeigt, dass die konservative (Labriola et al. 2005) wie auch die chirurgische Therapie ( Kaldahl et al. 1996,

Scabbia et al. 2001) bei Rauchern weniger erfolgreich ist. Raucher haben im Vergleich weniger Taschentiefen-Reduktion und die Wundheilung läuft verzögert ab (Ah et al. 1994, Grossi et al. 1997a, Haffajee et al. 1997). Durch die Behandlung der Parodontitis bei Rauchern und Nichtrauchern werden die Sondiertiefen reduziert. Der Raucher hat nach erfolgter Parodontaltherapie einen geringeren Attachmentgewinn im Vergleich zum Nichtraucher und ehemaligen Raucher (Grossi et al. 1997a, Jin et al. 2000). Stellen mit einer Sondierungstiefe von mehr als $7 \mathrm{~mm}$ zeigen nach chirurgischem Eingriff einen Attechmentgewinn von bis zu $1 \mathrm{~mm}$ weniger, als bei Nichtrauchern (Scabbia et al. 2001). Ebenfalls findet die Heilung bei Furkationsdefekten nach chirurgischen Eingriffen verzögert statt (Trombelli et al. 2003).

Eine Untersuchung zum Passivrauchen an 273 japanischen Arbeitern, die sich auf Daten aus parodontalen Sondierungstiefen, dem Attachmentniveau und einer Messung des Nikotinstoffwechselproduktes Cotinin im Speichel bezieht, konnte zeigen, dass selbst Passivraucher ein erhöhtes Risiko für das Entstehen einer chronischen Parodontitis haben können (Yamamoto et al. 2005; Nishida N. et al. 2006). 


\subsection{Stress}

In einigen Untersuchungen wird Stress als Risikofaktor diskutiert. Eine Studie zeigt, wie Patienten, die Stress aufgrund finanzieller Belastung entwickeln, signifikant mehr Attachmentverlust haben (Genco et al. 1999). Andere Studien treffen im Zusammenhang mit Stress ähnliche Aussagen (Rosania et al. 2009). Stressauslösende Faktoren wie z.B. Unzufriedenheit am Arbeitsplatz oder schwere Angstzustände können eindeutig mit Parodontitis assoziiert werden (Linden et al. 1996, Vettore et al. 2003).

\subsubsection{Systemische Faktoren}

\subsection{Alkohol}

Alkoholkonsum beeinträchtigt unser Immunsystem und erhöht die Wahrscheinlichkeit von Infektionen. Bei einer von Pitiphat durchgeführten Studie wurde der Alkoholkonsum als modifizierbarer und unabhängiger Risikofaktor für Parodontitis nachgewiesen. Verglichen mit „nicht-Trinkern“ lag das relative Risiko z.B. bei dem Konsum von 0,1-4,9 g Alkohol/Tag bei 1,24 (1,09-1,42) (Pitiphat et al. 2003).

\subsection{Diabetes mellitus}

Die Stoffwechselerkrankung Diabetes mellitus zählt heute neben dem Nikotinkonsum zu den wichtigsten Risikofaktoren für Parodontopathien. Der insulinabhängige Diabetes entwickelt sich oftmals vor dem 30. Lebensjahr. Diese Diabetesform beruht auf einer Autoimmunerkrankung bei der das körpereigene Immunsystem die insulinproduzierenden ß-Zellen des Pankreas zerstört. Der nicht-insulinabhängige Diabetes tritt in der Regel erst nach dem 30. Lebensjahr auf.

Diabetes alleine verursacht keine Gingivitis oder parodontale Taschen. Auch die mikrobielle Flora zwischen Diabetikern und gesunden Patienten unterscheidet sich nicht (Salvi et al. 1997). Taylor und Kollegen verglichen in einer Untersuchung gut eingestellte Diabetiker (Typ II) mit schlecht eingestellten Diabetikern im Hinblick auf den Attachmentverlust. Die Odds Ratios lagen bei gut eingestellten Diabetikern, im Vergleich zu gesunden / gut eingestellten Probanden, bei 2,2 und bei schlecht eingestellten Diabetikern, in Vergleich zu gut eingestellten, bei 5,3 (Taylor et al. 1998).

Der chronisch zu hohe Blutzuckerspiegel beeinflusst die Funktion der neutrophilen Granulozyten, Monozyten und Makrophagen. Immuninflammatorische Reaktionen wie die Produktion von proinflammatorischen Zytokinen (TNF-) von Makrophagen 
und Monozyten, zeigen eine erhöhte Immunantwort auf parodontale Erreger und erhöhen so die Destruktion des Parodonts (Mealey 2006). Fibroblasten die für den Kollagenstoffwechsel verantwortlich sind werden durch die zu hohe Glukosekonzentration beeinträchtigt. Darüber hinaus ist das Kollagen, durch erhöhte Mengen an Matrixmetalloproteasen anfälliger gegenüber rascherem Abbau was die schlechtere Wundheilung erklärt (Mealey 2006, Salvi et al. 1997). Bei Diabetikern, insbesondere Jenen mit unzureichender glykämischer Kontrolle, können größere Mengen an „advanced glycation end products“ (AGE's) im Gewebe bzw. im Parodont nachgewiesen werden (Schmidt et al. 1996, Katz et al. 2005). Die AGE's bewirken deutliche Veränderungen in der Funktion von Endothelzellen. Dies führt zu einer höheren Rigidität -und Dicke der Blutgefäße was sich auf eine gestörte Leukozytendiapedese, Sauerstoffdiffusion und Abräumung von Metaboliten auswirkt (Lalla et al. 2000). Des Weiteren besitzen Monozyten und Makrophagen Rezeptoren für AGE's was wiederum zu einer vermehrten Produktion von proinflammatorischen Zytokinen wie IL-1 $\beta$ und TNF- $\alpha$ führt (Schmidt et al. 1996). Diabetiker leiden zudem häufiger an eitrigen Parodontalabszessen, Zahnfleischentzündungen mit Ulzerationen und Mundwinkelrhagaden (Plagmann 1998).

Bakterielle -oder virale Infektionen, die eine systemische Entzündung hervorrufen, (z.B. Grippe) können eine Kontrolle des Glukosespiegels schwieriger machen (Yki-Järvinen et al 1989). Chronische Parodontalerkrankungen haben das Potenzial, eine Insulinresistenz hervorzurufen und die Kontrolle des Blutzuckers zu erschweren (Genco et al. 2005). Eine Untersuchung von Iwamoto et al. konnte zeigen, dass durch die Parodontaltherapie bei Typ-II-Diabetikern eine Senkung von TNF- Werten im Serum erreicht wurde. Diese Senkung wirkt sich positiv auf die HbA1c-Werte aus (Grossi et al. 1997b). So kann die Therapie der parodontalen Entzündung die Ausschüttung von proinflammatorischen Mediatoren im Serum verringern, welche eine bessere glykämische Kontrolle erlaubt (Iwamoto et al. 2001).

\subsection{Osteoporose}

Immer mehr Studien legen Beweise für die Wechselwirkung von Osteoporose und Parodontitis vor (Krall 2001, Wactawski-Wende 2001, Jeffcoat 2005). Krall konnte in Ihrer Untersuchung zeigen, dass höhere Aufnahmemengen von Calcium, Vitamin D und Östrogen mit eingeschränkter Prävalenz für klinischen Attachmentverlust und einem geringerem Risiko für Zahnverlust verbunden sind (Krall 2001). 


\subsection{HIV/ AIDS}

Die Prävalenz von oralen Läsionen bei HIV-infizierten Patienten liegt für die HIVassoziierte Gingivitis bei $10-15 \%$ und die HIV-assoziierte Parodontitis bei $5-10 \%$ (Murray 1994). Dabei hängt das Ausmaß der Destruktion von der Funktionsfähigkeit des Immunsystems ab. Man unterscheidet zwischen Patienten die sich mit HIV infiziert haben und jenen bei denen das Krankheitsbild AIDS bereits ausgebrochen ist. Bei HIV-Infizierten mit nur leichtem CD4+-Rückgang findet man kein vermehrtes Aufkommen von Parodontitis (Drinkard et al. 1991). Eine Untersuchung von 22 HIVseropositiven Patienten mit chronischer Parodontitis zeigt, dass die Erkrankung, wie bei nichtinfizierten Patienten, ebenfalls erfolgreich behandelt werden kann (Jordan et al. 2006). Orale Läsionen wie Candidiasis, Haarleukoplakie, NUG oder NUP können erste Zeichen einer HIV-Infektion oder deren Progression sein (Steinsvoll \& Herlofson 2006). Bei HIV-infizierten Patienten wurden weltweit Untersuchungen durchgeführt um festzustellen welche oralen Manifestationen auftreten können. Auffallend war die fast gleiche Verteilung bzw. Häufigkeit von oralen Läsionen. Am Häufigsten trat die orale Candidainfektion auf. Gefolgt von oraler Haarleukoplakie, Aphthen, Herpes simplex und dem Kaposi-Sarkom (Gillespie et al. 1993, Arendorf et al. 1998, Carpio et al. 2009). Regional bedingte Unterschiede konnten auf Cuba mit dem Abusus von Nikotin in Verbindung gebracht werden. Dort trat die Haarleukoplakie vor der oralen Candidiasis auf (Carpio et al. 2009).

\subsubsection{Genetische Faktoren}

Als klinisch relevanter genetischer Faktor gilt der Interleukin-1-Polymorphismus (Kornman et al. 1997).

\subsection{IL-1 Polymorphismus}

Das Interleukin-1 (IL-1) ist ein vielseitiger Mediator des Immunsystems. Es wird hauptsächlich von Makrophagen und Fibroblasten gebildet und besteht aus zwei in der Wirkungsweise ähnlichen Molekülen dem IL-1 $\alpha$ und dem IL-1 $\beta$. IL-1 aktiviert Tund B-Lymphzyten und induziert die Bildung von weiteren Zytokinen (TNF, Matrixmetalloproteasen, Prostaglangin $\mathrm{E}_{2}$ ). IL-1 beeinflusst den Knochenstoffwechsel indem es die Knochenneubildung hemmt sowie die Knochenresorption fördert. Somit verschiebt es das bestehende Gleichgewicht zwischen Knochenaufbau und -abbau zugunsten der destruktiven Vorgänge (Plagmann 1998). Je mehr Interleukin-1 produ- 
ziert wird desto schneller und tiefgreifender verläuft das Fortschreiten der Parodontitis. Wie stark die Interleukin-1- Produktion abläuft wird auf genetischer Ebene festgelegt. Forschungen im Bereich des menschlichen Genoms ergaben, dass verschiedene Polymorphismen im Bereich des IL-1 Clusters existieren welche für die Codierung des proinflammatorischen Zytokines Interleukin-1 ( $\alpha$ und $\beta$ ) verantwortlich sind. Als Polymorphismus wird ein Austausch von Basen an einer bestimmten Stelle in der DNA bezeichnet. Kornman et al. untersuchte die Wechselbeziehung verschiedener Polymorphismen innerhalb des IL-1 Gen-Clusters mit dem jeweiligen Schweregrad der Parodontitis. Diese Untersuchung ergab, dass bei der Anwesenheit eines bestimmten Genotyps (Allel 2 IL- $1 \alpha$ an Position -889 und IL-1 $\beta$ an Position +3953) eine Korrelation mit einem rascheren Voranschreiten der Parodontitis vorliegt

(Kornman et al. 1997, López et al. 2005a). Kornman konnte zeigen, wie Patienten mit adulter marginaler Parodontitis zu 36\% Genotyp positiv waren. Weiterhin konnte im Vergleich mit Patienten mit milderer oder mittelschwerer Parodontitis festgestellt werden, dass dieser Genotyp häufiger bei Patienten mit schwerer Parodontitis vorlag (Kornman et al. 1997). Eine andere Untersuchung beschäftigte sich mit dem IL-1 Cluster IL-1 $\alpha(+4845)$ und IL-1 $\beta$ (+3954). Bei dieser Untersuchung kam man ebenfalls zu dem Schluss, dass Genotyp positive Patienten ein erhöhtes Risiko besitzen an einer schweren Parodontitis zu erkranken als Genotyp negative (Odds Ratio 3,755,27) (McDevitt et al. 2000).

\subsubsection{Mikrobiologische Faktoren}

\subsection{Bakterien (siehe 2.1.4.2)}

\subsection{Viren}

Viren werden in einigen Untersuchungen als ein weiterer Risikofaktor für Parodontitis diskutiert (Philstrom 2001). Untersuchungen fanden eine hohe Prävalenz von Herpesviren (HSV), humanen Zytomegalieviren (HCMV) und Epstein-Barr-Viren (EBV) in parodontalen Taschen vor (Slots \& Contreras 2000, Contreras \& Slots 2000, Michaiowitcz et al. 2000, Ting et al. 2000, Contreras et al. 2000, Saygun et al. 2004, Bilichodmath et al. 2009). 


\subsubsection{Sozioökonomischer Status}

Der Einfluss sozialökonomischer Aspekte wird immer wieder diskutiert. Es fällt auf, dass Erwachsene mit niedrigem Bildungsstatus fast 2,5-mal so häufig an einer schweren Parodontitis erkranken als solche mit hohem Bildungsstatus (DMS IV 2006). In mehreren epidemiologischen Untersuchungen, insbesondere den USA und der dritten Welt wurde festgestellt, dass der prozentuale Anteil der Raucher innerhalb niedriger sozioökonomischer Schichten der Bevölkerung generell höher liegt als in privilegierten Schichten (Albandar et al. 2002a/b, DMS IV 2006). Österberg und Mellström untersuchten 1377 70-jährige Personen und kamen zu dem Ergebnis, dass der dentale Status unter anderem mit dem sozioökonomischen Status zusammenhänge (Österberg \& Mellström 1986). Dennoch gibt es Untersuchungen die beispielsweise keine Beziehung zwischen Einkommen (Palmquist \& Sjödin 1987) oder beruflicher Stellung (Rohner 1983) und dem gehäuften auftreten von Parodontitis feststellen. Es wird deutlich, dass sich der Einfluss sozioökonomischer Variablen auf die parodontale Destruktion über die Qualität der Mundhygiene definiert (Plagmann 1998).

\subsubsection{Lokale Faktoren}

Die lokalen Faktoren können alleine keine Parodontopathien auslösen. Sie begünstigen allerdings die Plaqueretention. Zahnanatomische Gegebenheiten, wie Schmelzperlen, Zahnnischen oder mesiale Wurzeleinziehungen können den Verlauf einer Parodontitis negativ beeinflussen.

Schätzle et al. (2001) konnten in Ihrer Untersuchung zeigen wie über einen Beobachtungszeitraum von 26 Jahren iatrogene Faktoren, wie Karies und sub-gingival gelegene Restaurationsränder die parodontale gesundheit kompromittierten. Schmelzperlen können die Gefahr für einen Furkationsbefall erhöhen. Der Schmelz verhindert die Anlagerung des parodontalen Stützgewebes und unterstützt so den Krankheitsverlauf. Ebenso können Wurzelanomalien Prädilektionsstellen für Plaqueanlagerungen sein und so den Krankheitsverlauf beeinflussen. Palatogingivale Gruben wurden beispielsweise in diesem Zusammenhang diskutiert (Withers et al. 1981). Aus Zahnfehlstellungen wie extreme Lingual- oder Labialkippungen der Zähne resultieren 
Gingivarezessionen (Gorman 1967) und verschachtelt stehende Zähne bereiten Schwierigkeiten bei der Pflege. Insuffiziente zahnärztliche Restaurationen und unbehandelte kariöse Läsionen bilden ebenfalls Retentionsstellen für Plaquebakterien (Orkin et al. 1987, Chen et al. 1987, Parsell et al. 1998). Die Mundatmung und ein unvollständiger Lippenschluss verhindern die Benetzung der Frontzähne mit Speichel und begünstigen so eine Gingivitis (Wagaiyu \& Ashley 1991). Der Speichel gehört zu den lokalen unspezifischen Abwehrfaktoren des Organismus gegen die Plaque. Ist der Speichelfluss eingeschränkt oder die Viskosität erhöht, z.B. durch Medikamente oder Radiatio, steigt das Risiko für Karies und Gingivitis (Plagmann 1998, Hellwig, Klimek, Attin 1999).

Die Anatomie der Weichgewebe, das okklusale Trauma, sowie bestehende pathologische Verhältnisse sind weitere lokale Faktoren die das Voranschreiten der Erkrankung negativ beeinflussen können (Hellwig et al.1999, Plagmann 1998).

\subsubsection{Klinisches Bild und Verlauf}

\subsubsection{Gingivitis - Die Intialläsion}

Die Initialläsion ist der pathohistologische Ausdruck erster akuter Entzündungsreaktionen der Gingiva. Sie entwickelt sich nach einer Plaqueneubildung innerhalb von zwei bis vier Tagen aus einer klinisch gesunden Gingiva. Dieser Zustand ist noch vollständig reversibel wenn die verursachende Plaque beseitigt wird (Löe 1965). Als Reaktion auf die Plaque kommt es zu einer Veränderung im Gefäßplexus mit Zunahme der Permeabilität und der Durchblutung. Eine entzündlich- ödematöse Schwellung entsteht und die Sulkusfluidfließrate steigt. Die Migration von immunkompetenten Zellen in den Gingivasulkus steigt (Page 1986, Hellwig et al. 1999).

\subsubsection{Gingivitis - Die Frühläsion}

Wenn die Plaque sich ungestört weiterentwickeln kann entsteht nach ca. 1 bis 2

Wochen die Initialläsion mit Verstärkung der klinischen Symptome. Es kommt zur Ansammlung von Abwehrzellen im Infiltrat des gingivalen Bindegewebes. Dieses Infiltrat besteht zu 70-90\% aus Lymphozyten und zu 7-16\% aus Makrophagen. Der Kollagenabbau beträgt ca. 60-70\%. Im koronalen Bereich kommt es, aus der normalerweise glatten Basalmembran, zur Ausbildung von Epithelzapfen in das Bindegewebe hinein (Page 1986, Hellwig et al. 1999). 


\subsubsection{Gingivitis - Die etablierte Läsion}

Nach ca. 6 Wochen unbeeinflusster Plaqueakkumulation geht die Entzündung in das Stadium der etablierten Läsion über. Die ursprünglich glatte Basalmembran des Saumepithels weist jetzt deutliche Epithelzapfenbildungen auf. Die gingivale Tasche ist mit Taschenepithel ausgekleidet, welches nicht selten Ulzerationen aufweist. Neutrophile Granulozyten bilden einen dichten Wall gegenüber den vorhandenen Mikroorganismen aus. Die typischen pathohistologischen Gesichtspunkte einer etablierten Gingivitis sind zum einen die persistierende akute Entzündung, sowie eine spezifische Population von Entzündungszellen im Infilrat, als auch Immunglobuline im Bereich des extravasalen Bindegewebes und Saumepithels und zum anderen ein zunehmender Anteil an Plasmazellen, ein weiterer Verlust von Kollagen, eine laterale Proliferation des Saumepithels. Es kommt zur Ausbildung einer gingivalen Tasche in der sich eine subgingivale Mikroflora etabliert (Page 1986, Plagmann 1998).

\subsubsection{Parodontitis - Die fortgeschrittene Läsion}

Wann und warum die etablierte Läsion in eine fortgeschrittene Läsion übergeht ist nicht bekannt. Der entscheidende Unterschied liegt in der Mitbeteiligung des Zahnhalteapparates an der Destruktion die nicht mehr reversibel ist. Klinisch gleicht das Bild dem der etablierten Läsion. Das zelluläre Infiltrat besteht überwiegend aus Plasmazellen und einem geringen Anteil an Lymphozyten. Die kollagenen Faserbündel werden fast vollständig zerstört. Es kommt zur Ausbildung einer echten Tasche die mit anhaltender Entzündung in Richtung apikal verschoben wird. Die Progression kann unterschiedlich schnell verlaufen. Meistens findet man kurze destruktive Phasen mit länger andauernden Remissionen vor (Müller 2001). 


\subsubsection{Systematik der Parodontitistherapie}

Die mechanische Entfernung der supra- und besonders der subgingivalen Plaque gehört zu den zentralen Behandlungsmaßnahmen im Rahmen der Parodontitistherapie.

Die systematische Parodontitistherapie gliedert sich in vier Abschnitte (Philstrom 2001):

1. Befunderhebung,

2. Initialtherapie,

3. Chirurgische Phase und

4. unterstützende Parodontitistherapie.

Im Folgenden wird genauer auf die Initialtherapie als auch auf die unterstützende Parodontitistherapie eingegangen.

\subsubsection{Initialtherapie/ Hygienephase}

Nach erfolgter Befundaufnahme beginnt der Abschnitt der Vorbehandlung. Sie startet mit der Aufklärung des Patienten über die Ätiologie der Erkrankung und deren Therapie. Es erfolgt eine Unterweisung in häuslicher Mundhygiene und eine professionelle Zahnreinigung zur Entfernung aller supragingivalen Beläge. Die Hygienephase soll den Patienten in die Lage versetzen eine adäquate Mundhygiene durchführen zu können. Der Behandler muss dafür Sorge tragen, dass der Patient die notwendige Mundhygiene durchführen kann indem er insuffiziente Füllungen/ Prothetik entfernt bzw. erneuert. Die Kontrolle, inwieweit der Patient mit den neuen Mundhygienemaßnahmen zurechtkommt, ist wichtig. Studien konnten zeigen, wie die aktive Mitarbeit des Patienten entscheidend zum Erfolg der Therapie beiträgt (Nyman und Lindhe 1977). Ist die Mitarbeit des Patienten gewährleistet wird mit der Bearbeitung der Wurzeloberfläche, dem sogenannten Scaling begonnen. Das Scaling bezeichnet dabei den Abtrag reiner Auflagerungen (Zahnstein, Konkremente, Plaque, Verfärbungen) von den Zahnoberflächen mit Hand- oder Ultraschallinstrumenten bei maximaler Schonung der Zahnhartsubstanz (v.a. des Wurzelzements) (O'Leary 1986). Unter Root planing versteht man den umfassenden, systematischen Abtrag entzündungsverursachender Auflagerungen, sowie Einlagerungen in die Zementoberfläche (O'Leary 1986). Dabei sollte nur die oberflächliche, kontaminierte Zementschicht entfernt werden. Das Scaling und Root planing kann sowohl ge- 
schlossen, als auch offen (mit chirurgischer Lappenbildung) erfolgen. Beim geschlossenen Arbeiten erfolgt die Wurzeloberflächenbearbeitung ohne Sicht.

Im Folgenden wird nur auf die nicht-chirurgische Parodontitis-Therapie eingegangen.

\subsubsection{Die mechanische Parodontitis-Therapie}

Die Durchführung der Parodontitis-Therapie erfolgt unter Einsatz verschiedener Instrumente: Handinstrumente, Schall- und Ultraschallscaler, rotierende sowie oszillierende Instrumente und Laser kommen zur Anwendung.

Im Nachfolgenden wird nur auf die Verwendung von Hand- und Ultraschallinstrumenten eingegangen.

\subsection{Handinstrumente}

Handinstrumente wie Scaler und Küretten werden aufgrund der besseren Taktilität für die Wurzeloberflächenbearbeitung eingesetzt und gehören heute zum „Goldstandard“ bei der Handinstrumentierung. Subgingival finden vor allem die Küretten ihre Anwendung. Sie bestehen aus einem Arbeitsteil, einem Schaft und einem Handgriff. Man unterscheidet Universalküretten von Spezialküretten. Bei dem Scaling und Root planing werden die für den jeweiligen Zahn geeigneten Küretten gemäß ihrer Geometrie in die parodontale Tasche eingeführt und mit ziehenden Bewegungen die Reinigung der Wurzeloberfläche durchgeführt. Die Kürette wird dabei mit dem Daumen, Zeige- und Mittelfinger in der modifizierten Schreibfederhaltung gefasst (Plagmann 1998).

\subsection{Ultraschallinstrumete}

Ultraschallgeräte arbeiten heute in Frequenzbereichen zwischen 18.000 - 50.000 Schwingungen pro Sekunde. Die hochfrequente elektrische Energie wird in mechanische Schwingungen umgewandelt. In der Regel werden zwei Typen von Ultraschallgeräten unterschieden, die magnetostriktiven und piezoelektrischen Ultraschallgeräte (Iff \& Marinello 1998).

- Magnetostriktives Prinzip

Das Prinzip beruht auf der Längenveränderung an ferromagnetischen Metallstäben im wechselnden Magnetfeld. Durch Anlegen eines elektrischen Stroms entsteht ein magnetisches Feld, das einen ferromagnetischen Stab oder ein Bündel Metall- 
Lamellen im Handstück in Schwingungen versetzt, welche direkt an die Arbeitsspitze weitergegeben werden. Diese bewegt sich mit einer Amplitude von 13 bis $72 \mu \mathrm{m}$ auf einer ellipsenähnlichen Bahn (Iff \& Marinello 1998, Petersilka \& Flemming 1999). Ein Beispiel für dieses Verfahren ist das Cavitron ${ }^{\text {TM }}$ JET (Dentsply ${ }^{\circledR}$ DeTrey, Konstanz).

\section{- Piezoelektrisches Prinzip}

Die Schwingungen der piezoelektrischen Ultraschallinstrumente werden durch das Anlegen einer hochfrequenten Wechselspannung an ein sich im Handstück befindlichen Kristall oder Keramikstab erzeugt. Die Kristalle sind bipolar, so dass bei Anlegen einer Wechselspannung es zur Kontraktion und Ausdehnung kommt. Dadurch können 25.000-50.000 lineare Schwingungen pro Sekunde erzeugt werden. Die Größe der Amplitude beträgt 12 bis $72 \mu \mathrm{m}$. Je nach Anlagerung der Ansätze an die Zahnoberfläche kommt es zum rein hämmernden oder rein schabenden Abtragsmuster. Der Piezon ${ }^{\circledR}$ Master 400 (EMS, München) ist ein Vertreter dieses Funktionsprinzips. Die Arbeitsspitzen (PS, PL1-5) sind einer Parodontalsonde in Länge und Form nachempfunden und sollen einen guten approximalen und subgingivalen $\mathrm{Zu}-$ gang bieten (Iff \& Marinello 1998, Petersilka \& Flemming 1999).

\section{- Vector®-System}

Das Vector®-Gerät (Dürr Dental, Bietigheim-Bissingen) nimmt aufgrund seiner oszillierenden Arbeitsweise eine Sonderstellung unter den Ultraschallgeräten ein. Die entstehenden linearen Schwingungen werden über einen Metallring in eine Bewegung längs des Instrumentenansatzes umgelenkt. Somit kommt es zu einer exakt linearen Oszillation, parallel zur Zahnoberfläche.

Wegen der nur sehr geringen Schwingung ist zur Wurzeloberflächenbearbeitung, als auch zur Plaqueentfernung, ein abrasives Medium erforderlich (Vector Fluid abrasiv, Vector Fluid Polish) (Iff \& Marinello 1998, Petersilka \& Flemming 1999).

\section{- Wirkungsweise der Ultraschallgeräte}

Die Wirkung der Ultraschallgeräte beruht auf einer mechanischen Schwingung im Raum. Bei Kontakt mit Konkrementen werden diese zerstört und entfernt. Die Schwingung des Instrumentenendes ist abhängig von der Frequenz und Amplitude, sowie dessen Form und Länge. Die meist linear kreisförmige Schwingung hat eine gleichmäßige Wirksamkeit nach allen Seiten hin und kann für schwierig zugängliche 
Stellen wie z.B. Furkationen genutzt werden (Iff \& Marinello 1998, Dragoo 1992, Petersilka \& Flemming 2005). Die Amplituden der Ultraschallgeräte werden mit 7 bis 28 um (Walmsley et al. 1984) beziehungsweise 30-60 $\mu \mathrm{m}$ (Chapple et al. 1995) oder mit 60 bis $100 \mu \mathrm{m}$ (Zitterbart 1987) abgegeben und sind von der Leistungseinstellung am Gerät abhängig. Die Beseitigung der Plaque/Biofilms erfolgt zusätzlich zur mechanischen Wirkung der Ultraschallwellen über den Kavitationseffekt. Die Kavitation beschreibt wie es über longitudinale Ultraschallwellen zur einer Pulsierung von Gasblasen kommt. Dabei werden große Energiemengen freigesetzt die zu Schockwellen und einer Temperaturerhöhung führen. Die freigesetzte Energie ist in der Lage Bakterien zu zerreißen (Walmsley et al. 1984). Zusätzlich treten akustische Mikroströmungen auf. Darunter versteht man das Entstehen von inneren und äußeren Wirbeln in Flüssigkeiten die durch Ultraschallfelder erzeugt werden. Diese besitzen einen erosiven Effekt, welcher Plaque wirkungsvoll entfernt, aber auch gesundes Gewebe zerstört (Iff \& Marinello. 1998).

Die Entstehung von Wärme, vor allem am Instrumentenansatz, macht den Einsatz einer Kühlung notwendig damit keine Schädigung umliegender Gewebe durch Temperaturerhöhung entsteht. In einer Studie wird berichtet, dass selbst bei Sondierungstiefen von $9 \mathrm{~mm}$ der Taschenfundus von der Kühlflüssigkeit erreicht wird (Nosal et al. 1991). Der Einsatz von antibakteriellen Lösungen wie beispielsweise Chlorhexidin $(\mathrm{CHX})$ als Kühlflüssigkeit kann einen unterstützenden Effekt auf die Therapie haben (Taggart et al. 1990). Eine Untersuchung von Raynolds und Kollegen bewertete die Wirkung einer 0,2\%-igen Chlorhexidinlösung und von Wasser als Kühlmittel bei einer Ultraschallbehandlung. In der mit $\mathrm{CHX}$ als Kühlflüssigkeit verwendeten Gruppe konnte vor allem bei mittleren Taschen (4-6 mm) nach 14 und 28 Tagen nach Therapie eine deutlich bessere Reduktion der Taschentiefe festgestellt werden, als in der Gruppe mit Wasser als Kühlflüssigkeit (Reynolds et al. 1992). In einer anderen Studie wurde kein Unterschied in der zusätzlichen Anwendung von CHX als Kühlflüssigkeit festgestellt (Guarnelli et al. 2008)

\section{- Wirkung auf die Zahnhartsubstanzen}

Zahlreiche wissenschaftliche Untersuchungen belegen, dass die Effizienz der Wurzeloberflächenreinigung nach Behandlung mit Ultraschallgeräten der von Handinstrumenten ebenbürtig (Badersten et al. 1981, Oosterwaal et al. 1987, Petersilka \& Flemming 2005, Guarnelli et al. 2008, loannou et al. 2009), teilweise überlegen ist 
(Dragoo 1992). Durch die grazilen Instrumentenansätze wird eine geringfügig bessere Erreichbarkeit des Taschenfundus (Dragoo 1992) und Furkationen (Petersilka \& Flemming 2005) erreicht. Bei der Parodontaltherapie mit Handinstrumenten wird viel Wurzelzement entfernt (Van Volkinburg et al. 1976, O'Leary 1986, Coldirin et al. 1990). Eine Untersuchung von Fukazawa \& Nishimura weist darauf hin, dass die vollständige Beseitigung von Zement die Zementogenese negativ beeinflusst. Es sollten genügend Zementoblasten übrigbleiben damit neues Wurzelzement gebildet werden kann (Fukazawa \& Nishimura 1994). Endotoxine sind Lipopolysaccharide von Zellwänden oder Zelldetritus von gramnegativen Bakterien. Sie penetrieren in die äußere Zementschicht und können die Wundheilung negativ beeinflussen. Sie sollten mit der oberflächlichen Zementschicht entfernt werden. Untersuchungen zur Wirksamkeit der Endotoxinentfernung konnten zeigen, dass die Lipopolysaccharide sehr effektiv mit Ultraschall entfernt werden konnten (Badersten et al. 1981, Smart et al. 1990).

- Wundheilung nach Ultraschalltherapie

Es konnten keine signifikanten Unterschiede bezüglich der Wundheilung nach Parodontitistherapie mit Ultraschall-, Schall-, oder Handinstrumenten gefunden werden (Badersten et al. 1981, Torfason et al. 1979, Biagini et al. 1988, Christgau et al. 2006).

\section{- Mikroflora}

Die Wurzeloberflächenreinigung mithilfe von Ultraschall führt auf Grund einer guten Spülwirkung und der physikalischen Wirkung der Ansätze, wie Kavitationseffekt und akustische Mikroströmung, zu einer starken Bakterienreduktion. Dabei reagieren gramnegative Bakterien und Spirochäten besonders empfindlich auf die Ultraschallvibrationen (Baehni et al. 1992).

Untersuchungen zeigen, dass das parodontale Debridement mit Ultraschall, sowie mit Handinstrumenten, zu gleichen Ergebnissen in Bezug auf die mikrobiologische Taschenflora führt (Oosterwaal et al. 1987, loannou et al. 2009). 
- Arbeitsweise

Das Handling mit Ultraschallgeräten unterscheidet sich von dem Reinigungsvorgang mit Handinstrumenten. Wegen der fehlenden Taktilität erfolgt die Anwendung nicht von koronal nach apical, da sonst intakte apikale Gewebe geschädigt werden können. Das Arbeitsende wird im ausgeschalteten Zustand zum Fundus der Tasche geführt und der Taschenboden auf einer Breite von zwei bis drei Millimetern sondiert. Parallel zur Zahnachse wird die Wurzeloberfläche mit „Serpentinenschleifen“ nach koronal gereinigt. Dabei wird der Bereich unmittelbar des approximalen Kontaktpunktes nicht ausreichend erreicht, weshalb der Ansatz horizontal ausgerichtet wird. Für die subgingivale Reinigung gibt es speziell gebogene Ansätze, die eine bessere Adaptation und subgingivalen Zugang ermöglichen. Um ein häufiges Wechseln der Aufsätze zu umgehen ist eine gewisse Anwendungssystematik von Vorteil (Petersilka \& Flemming 1999).

\section{- Aerosolentwicklung}

Das bei jeder Anwendung von Ultraschallgeräten entstehende Aerosol ist feiner als das Aerosol von Hand- und Winkelstücken. Die kleinen Wassertropfen enthalten Speichel, Blut, Pilze, und Mikroorganismen (Larato et al. 1967) die eine Gefahr für Patient und Behandler darstellen. Durch eine Chlorhexidinspülung des Patienten von 30-60 sec. vor der Behandlung kann die Gesamtkeimzahl stark reduziert werden (Eschmann-Speer et al. 1997).

\subsection{Weitere Verfahren zur Parodontitistherapie}

Weitere Möglichkeiten in der Parodontitistherapie bietet die Reinigung der Taschen mit einem Er:YAG Laser (Frentzen et al. 2005, Schwarz et al. 2008 ) sowie die antimikrobielle photodynamische Therapie (aPDT) (Hopp \& Biffar 2008, Eberhard 2008). Diese Verfahren werden nur der Vollständigkeit halber erwähnt und nicht näher beschrieben.

\subsection{Wundheilung nach der Parodontitistherapie}

Bei der parodontalen Wundheilung konkurrieren vier unterschiedliche Gewebekompartimente um die Wiederbesiedlung des entstandenen parodontalen Defektes und bestimmen auf diese Weise die Qualität des sich bildenden Attachments (Melcher 1985). Dabei handelt es sich um die Zellen des gingivalen Epithels, des Bindegewe- 
bes, des Alveolarknochens und des parodontalen Ligaments. An der Wurzeloberfläche bildet sich aufgrund der höheren Proliferationsgeschwindigkeit gegenüber den übrigen parodontalen Geweben ein langes Saumepithel, das durch Einsprossung von Tochterzellen des gingivalen Epithels aus dem Wundrand entsteht. Es bildet sich ein reparatives Gewebe, welches eine ähnliche Funktion wie das ursprüngliche Epithel besitzt. Das lange Saumepithel reicht bis fast an den Boden der ehemaligen Tasche heran. Die Anheftung erfolgt über Hemidesmosomen an die Zahnhartsubstanz. Im gingivalen Bindegewebe findet man parallel zur Zahnoberfläche verlaufende Kollagenfaserzüge. Durch diese Abdichtung entsteht ein Schutz des subepithelialen Bindegewebes vor bakteriellen- und physiko-chemischen Noxen. Der Alveolarknochen erneuert sich, abhängig von der Konfiguration der Tasche (Plagmann 1998, Schroeder 1997, Melcher 1985).

\subsubsection{Unterstützende Parodontitistherapie (UPT)}

Um die Entzündungsfreiheit nach einer Parodontitistherapie langfristig zu erhalten bedarf es der unterstützenden Parodontitistherapie („Recall“). Der Patient ist bereits vor Beginn der Therapie auf die regelmäßig stattfindenden Kontrolluntersuchungen und professionellen Zahnreinigungen aufmerksam zu machen. Das Intervall wird individuell nach Abschluss der korrektiven Phase festgelegt und richtet sich nach Compliance und Mundhygiene des Patienten. Sie findet in der Regel 2-4 mal/Jahr statt. Bei den Untersuchungen sollten die Mundhygienekontrolle, Remotivation und Plaque-/Zahnsteinentfernung durchgeführt werden. Mindestens einmal im Jahr sollte zusätzlich zur UPT eine umfassende Untersuchung mit Erhebung folgender Befunde stattfinden: Taschensondierung, die Kontrolle der Furkationsdefekte, Zahnbeweglichkeit, Okklusionskontrolle und Röntgenkontrolle ( alle 2-3 Jahre). Tritt ein Rezidiv auf, sollte die entsprechende Tasche mit Root Scaling und Root planing behandelt werden (Plagmann 1998).

Eine Untersuchung von 44 Patienten die nach einer Parodontitistherapie nicht an der UPT teilnehmen wollten ergab, dass bei diesen Patienten eine erhöhte RezidivNeigung vorlag und mehr Zähne verloren gingen, als bei den Patienten, die an der UPT teilnahmen (Becker et al. 1984). Axelsson und Kollegen untersuchten über 30 Jahre 550 Patienten. Diese befanden sich in regelmäßiger Behandlung (UPT). In diesem Zeitraum sind nur 21 Zähne aufgrund einer fortgeschrittenen Parodontitis oder Karies verloren gegangen. Zudem war ein geringer Attachmentgewinn von 0.3- 
0.5mm (mesial Flächen) und 0.1-0.2mm (lingual Flächen) zu verzeichnen (Axelsson et al. 2004). 


\section{Material und Methode}

\subsection{Administrative Vorbereitungen}

Aus der Patientenkartei einer allgemeinzahnärztlichen Praxis wurden alle Patienten, die in den vergangenen 10 Jahren eine Parodontaltherapie erhalten haben, rekrutiert. Von 1998 bis Beginn 2006 wurden bei etwa 270 Patienten Parodontaltherapien durchgeführt. Anhand der Unterlagen konnten 193 Patienten bestimmt werden. Davon waren 110 weibliche und 83 männliche Patienten, im Alter von 21 bis 83 Jahren welche anschließend für mindestens 3 Jahre an einem Nachsorgeprogramm teilnahmen. Die 193 ausgesuchten Probanden wurden angeschrieben (Anschreiben siehe Anlage S. 79-81). Davon waren 92 Probanden bereit an der Nachuntersuchung teilzunehmen. Das Einverständnis zur Durchführung der Studie wurde vom Praxisinhaber, der Ethikkommission (Antrags-Nr. 9/10/08) und der Medizinischen Fakultät der Universität Göttingen eingeholt.

\subsubsection{Untersuchungsort und -Zeitraum}

Die Untersuchungen fanden vom 01. Sep. 2008 bis zum 28. Feb. 2009 in einer privaten zahnärztlichen Praxis in Minden (Westfalen) statt.

\subsection{Auswahl der Probanden}

Das Patientenkollektiv bestand aus 92 Probanden und teilte sich in 54 Frauen und 38 Männer im Alter zwischen 21 und 83 Jahren. Bei allen Patienten umfasste die Parodontalbehandlung eine geschlossene Kürettage mit Ultraschall (Piezon Master $400 \circledR$, Fa. EMS, Schweiz). Die Behandlung teilte sich auf zwei, jeweils ca. einstündige Sitzungen an zwei aufeinander folgenden Tagen auf. Am ersten Behandlungstag wurden der 1. und 4. Quadrant am zweiten Tag der 2. sowie 3. Quadrant behandelt. Wenn ein Patient weniger Zähne besaß, konnte die Therapie auch komplett an einem Tag durchgeführt werden. Zur Anwendung kamen die Instrumentenaufsätze A, P, PS, PL1, PL2, PL3 der Fa. EMS (Schweiz). Die Kühlung erfolgte mit 0,2\% Chlorhexidindigluconatlösung (Fa. EMS, Schweiz). Die erste Kontrolle erfolgte 14 Tage nach der Behandlung und umfasste eine Mundhygienekontrolle (ApproximalRaum-Index (API), Sulkus-Blutungs-Index (SBI)). Die zweite Kontrolle fand 6

Wochen nach Behandlung statt und beinhaltete die Mundhygienekontrolle (API,SBI), sowie den „Bleading on Probing“ (BOP). Wenn positive BOP-Messungen auftraten, 
wurden diese Taschen nochmals mit dem Piezo Master $400 \AA$ (von PK) gereinigt. In dieser Sitzung wurde das UPT-Intervall der jeweiligen Patienten festgelegt und neue Termine für die unterstützende Parodontitistherapie vereinbart (Zeitlicher Ablauf siehe Abb.1). Die UPT-Sitzungen beinhalteten eine Kontrolle der Mundhygiene (API,SBI), Remotivation der Patienten, supragingivale Reinigung mit Handinstrumenten, Air Flow ${ }^{\circledR}$ (Fa. EMS, Schweiz) und eine Politur mit fluoridierter Polierpaste (Fa. Hawe Kerr). Abschließend wurde Elmex fluid $®$ oder lokal EC 40® (Fa. Certichen Produktion BV, Niederlande) auf die Zähne aufgetragen.

Professionelle

Zahnreinigung

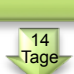

Erfolgskontrolle ggf.

Remotivation und Reinigung

\section{4}

Aufnehmen des

Parodontalstatus, ggf.

Remotivation und Reinigung

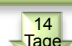

14
- Tage

1. Parodontalbehandlung

1. und 4. Quadrant

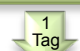

2. Parodontalbehandlung

2. und 3. Quadrant

14
- Tage

1. Kontrolle nach $P A$

(API, SBI)

28
- Tage
-

2. Kontrolle nach $P A$

(API, SBI, BOP)

$$
\text { UPT }
$$

Intervall 2-4 mal/ Jahr

Abb. Zeitlicher Ablauf der Parodontalbehandlung. 


\section{- Einschlusskriterien}

Kriterien/Voraussetzung für die Auswahl der Patienten:

- erfolgte Parodontalbehandlung im Zeitraum 1998 bis Ende 2005 im o.g.

Prüfzentrum

- Parodontalbehandlung stets durch gleichen Behandler (PK) durchgeführt

- mindestens 3-jährige aktive Nachsorge im Praxisrecall

- ein Parodontalstatus muss vor der Parodontalbehandlung erhoben worden sein (vorliegen)

- radiologische Unterlagen wie ein OPG oder Zahnfilme müssen aus der Zeit unmittelbar vor der Parodontalbehandlung vorhanden sein

- freiwillige Teilnahme für die Nachuntersuchung.

\section{- Ausschlußkriterien}

Probanden, bei denen einer der folgenden Punkte zutrifft:

- Probanden unter 18 Jahren

- anderweitig immunsupprimierte Patienten

- organtransplantierte Patienten

- Patienten, bei denen eine Endokarditisprophylaxe erforderlich ist

- Vorliegen von Hepatitis A, B, C, TBC, HIV

- Patienten mit Niereninsuffizienz

- Patienten mit Anfalls- oder Nervenleiden

- suchtkranke Patienten

- bekannte Unverträglichkeit/Überempfindlichkeit auf verwendete Materialien.

\subsection{Screening der Patientendaten}

Die Akten der ausgesuchten Patienten wurden nach folgenden Parametern durchsucht, um die Ausgangssituation zu erfassen:

1. Allgemeinanamnese

2. Dentaler Ausgangsbefund (DMF-T: fehlende, gefüllte und kariöse Zähne)

3. Radiologischer Befund (anhand vorliegender Panoramaschichtaufnahmen vor und Jahre nach der Behandlung, zur Ermittlung des Attachmentlevels)

4. Parodontaler Befund (Sondierungstiefen)

5. Recallfrequenz (anhand der Prophylaxekartei). 
Befunde der dritten Molaren wurden nicht berücksichtigt, außer sie standen an der Stelle des zweiten Molaren. Die radiologische Befundung des Attachmentverlustes erfolgte nach der direkten Millimetermethode für die radiologische Evaluation (Pepelassi et al. 2000), wobei der von Akesson im Jahre 1992 erhobene „Goldstandard“, welcher zur intraoperativen Befundung definiert wurde, auf Röntgenbilder übertragen wurde (Akesson et al. 1992). Pepelassi \& Diamanti-Kipioti sondierten dabei intraoperativ jeweils mesial und distal der zu untersuchenden Zähne. Die Differenz zwischen der Schmelz-Zement-Grenze (SZG) und dem alveolären Knochenkamm ergab den Knochenverlust (Pepelassi \& Diamanti-Kipioti 1997). Die gemessenen Millimeterwerte weisen auf den Grad der Knochendestruktion hin. Am Ausdruck der digitalen Röntgenbilder auf Fotopapier erfolgte die Messung direkt mit einem Millimeterraster jeweils mesial und distal eines Zahnes. Der Abstand zwischen der Schmelz-Zement-Grenze und dem Alveolarkamm wurde abgelesen. Die Diagnose erfolgt nach dem „Goldstandard“. Wenn die Darstellung der SZG im Röntgenbild nicht eindeutig zu ermitteln war, weil Prothetik, Füllungen oder Karies die Bestimmung erschwerten, wurde der Zervikalrand als Referenzpunkt angenommen (Pepelassi \& Diamanti-Kipioti 1997). Alle Auswertungen wurden von dem gleichen Untersucher (MJ) unter standardisierten Bedingungen durchgeführt. Alle erfassten Daten wurden in einem Erfassungsbogen festgehalten (siehe Anlage). Anhand der erhobenen Daten wurden die Patienten / Zähne in Risikogruppen unterteilt siehe 3.4 und 3.5 . 


\subsection{Einteilung der Patienten in Risikogruppen}

Anhand der vorliegenden Datenlage (Taschentiefen, fehlende Zähne, Attachmentlevel, Rauchgewohnheiten, Anamnese und Recallfrequenz) erfolgte die Einteilung der Patienten in Risikogruppen. Die Folgende Tabelle zeigt die Einteilung in Risikogruppen nach Lang \& Tonetti (2003), die Recallfrequenz wurde von uns als modifizierender Faktor in die Betrachtung mit einbezogen.

\begin{tabular}{|c|c|c|c|}
\hline Patientenrisiko & Niedriges Risiko (1) & Mittleres Risiko (2) & Hohes Risiko (3) \\
\hline Anzahl der TT > 5mm & $\leq 4 \mathrm{~mm}$ & $5-8 \mathrm{~mm}$ & $\geq 9 \mathrm{~mm}$ \\
\hline $\begin{array}{c}\text { Anzahl an fehlenden } \\
\text { Zähnen }\end{array}$ & $\leq 4$ Zähne & $5-9$ Zähne & $\geq 9$ Zähne \\
\hline $\begin{array}{c}\text { Knochenabbau in Rela- } \\
\text { tion zum Alter }\end{array}$ & $\leq 0,5$ & $>0,5-1,0$ & $>10$ \\
\hline Anzahl der Zigaretten & $<10 / \mathrm{Tag}$ & $10-19 / \mathrm{Tag}$ & $\geq 20 / \mathrm{Tag}$ \\
\hline Allgemeinerkrankungen & nein & $?$ & ja \\
\hline Recallfrequenz & $3 \times$ im Jahr & $1-2 \times$ im Jahr & keine \\
\hline
\end{tabular}

Tab.1 Modifiziert nach Lang \& Tonetti 2003

Ein „Niedriges Risiko“ liegt vor, wenn max. ein Wert im „Mittleren Risiko“ liegt.

Ein „Mittleres Risiko“ liegt vor, wenn 2 Werte im „Mittleren Risiko“ jedoch maximal ein Wert im „Hohen Risiko“.

Ein „Hohes Risiko“ liegt vor, sobald 2 Werte im „Hohen Risiko“ vorkommen.

\subsection{Prognoseeinteilung der Zähne}

Die vorliegende Datenlage erlaubte es Prognosen über die einzelnen Zähne treffen zu können.

\begin{tabular}{|c|c|c|c|}
\hline Prognose & Kategorie & Attachmentverlust & Definition \\
\hline sehr gut & 0 & $<25 \%$ & Attachmentverlust \\
\hline gut & 1 & $25 \%$ & $\begin{array}{c}\text { Attachmentverlust u./o. } \\
\text { Furkationsgrad I }\end{array}$ \\
\hline moderat & 2 & $25-50 \%$ & $\begin{array}{c}\text { Attachmentverlust u./o. } \\
\text { Furkationsgrad II, Mobilität } \leq \text { II }\end{array}$ \\
\hline fragwürdig & 3 & $50-75 \%$ & $\begin{array}{c}\text { Attachmentverlust u./o. nicht zugängli- } \\
\text { cher Furkationsgrad II/III, Mobilität II }\end{array}$ \\
\hline schlecht & 4 & $>75 \%$ & Attachmentverlust, Mobilität III \\
\hline
\end{tabular}

Tab.2 nach McGuire \& Nunn 1996 


\subsection{Zahnärztliche Nachuntersuchung}

Die zahnärztliche Nachuntersuchung umfasste die Erhebung der Anamnese, des zahnärztlichen Befundes, der fehlenden Zähne, des Attachmentlevels (PSA) und der Taschentiefen.

\subsubsection{Untersucher}

Eine Kalibrierung des Untersuchers fand im Vorfeld der Untersuchung an Probanden statt die nicht an der Untersuchung teilnehmen wollten. Die Kalibrierung wurde als erfolgreich angesehen, wenn eine Übereinstimmung mit den Befunden eines weiteren Untersuchers von min. $80 \%$ erreicht wurde. Der Untersucher wurde für alle in dieser Studie aufgenommenen Befunde entsprechend diesem Muster kalibriert.

\subsubsection{Anamnese}

Das Patientenkollektiv wurde anhand vorliegender Allgemeinerkrankungen in Gruppen unterteilt, um einen möglichen Einfluss auf den Verlauf der Parodontitis auszumachen. Alle untersuchten Patienten leiden an einer Form der chronischen Parodontitis.

Grp. 1: Diabetiker

Grp. 2: Koronare Herzkrankheiten, Hypertonie, Rheuma, Osteoporose

Grp. 3: Gesunde und Sonstige.

\subsubsection{Zahnärztlicher Befund}

- Zahnverlust (M-T)

Der Zahnerhalt dient als Maß für die Effektivität der Parodontitistherapie und wie lange parodontalgeschädigte Zähne erhalten werden konnten (Hirschfeld \& Wasserman 1978, König et al. 2002). Dazu wurden die Daten aus der „Erstbefundung“ (base) mit denen bei der Nachuntersuchung (end) erhobenen verglichen. Extrahierte Zähne deren Extraktionsgrund nicht die Parodontitis war, wurden gesondert berücksichtigt. Weisheitszähne wurden nicht miteinbezogen, außer sie nahmen die Position der zweiten Molaren ein. 
- Attachmentlevel in $\mathrm{mm}$

Die radiologische Knochenhöhe wurde mesial und distal aller Zähne, durch Messung des Abstandes zwischen der Schmelz-Zement-Grenze und der alveolären Knochenleiste festgestellt. Der Unterschied der parodontalen Knochenhöhe zwischen beiden Untersuchungen wurde für jede Messung der Zähne berechnet. Mittelwerte wurden zwischen den mesial- und distal-Flächen der Zähne gebildet. Aus den ermittelten Werten wurden Durchschnittswerte für die einzelnen Zahngruppen ermittelt.

- Sondierungstiefen (Taschentiefen TT) in mm

Die Messung der Taschentiefen erfolgte mit der Parodontalsonde (PCPUNC-15 HuFriedy). Dabei wurde die Sonde in einem Winkel von $10-15^{\circ}$ in die Tasche eingeführt und die Tiefe in Millimetern angegeben. Die Messungen wurden an zwei Messpunkten (mesial/distal) pro Zahn erhoben und in speziellen Erfassungsbögen notiert (siehe Anhang). Aus den ermittelten Werten wurden Durchschnittswerte für die einzelnen Zahngruppen ermittelt.

Einteilung der Zähne in Gruppen:

Grp. 1: Frontzähne OK/UK

Grp. 2: Prämolaren OK/UK

Grp. 3: OK-Molaren

Grp. 4: UK-Molaren

Innerhalb der Zahngruppen (pro Patient) wurden wiederum Mittelwerte gebildet. Sie erlauben es uns Aussagen über Veränderungen der TT über die Zeit zu treffen (pro Patient, pro Risikogruppe)

\subsection{Statistik}

Die statistische Bearbeitung der Rohdaten erfolgte in der Abteilung für medizinische Statistik und genetische Epidemiologie der Universität Göttingen

(Prof. Dr. Tim Friede). Die Auswertung der Daten erfolgte mit dem Statistikprogramm SAS® Version 9.1 (SAS Institute Inc., Cary, N.C., USA) und Statistica Version 9 (Fa. Stat Soft Inc., Oklahoma / USA). Die Darstellung der deskriptiven Statistik erfolgte mit Microsoft Excel 2008 (Office mac). Die Statistische Bewertung erlaubte die 
Auswertung von Kennwerten und Variablen, wie z.B. Median, Mittelwerte usw. Untersucht wurde das Patientengut zum Zeitpunkt „base“ und „end“. Die erhobenen Daten konnten auf statistische Signifikanz miteinander verglichen werden. Hierzu wurden nicht parametrische Tests vom ANOVA-Typ durchgeführt. Wir untersuchten jeweils eine gewählte Nullhypothese zu Fragestellungen auf ihre Bestätigung oder Ablehnung. Ergebnis eines jeden Tests war die Irrtumswahrscheinlichkeit „p“. Eine für einen Test ausgewählte Nullhypothese wurde abgelehnt, wenn $p<0.05$ ausfiel. Man bezeichnet dieses Testresultat dann als statistisch signifikant. Wenn $p>0.05$ betrug, war das Ergebnis nicht signifikant. 


\section{Ergebnisse}

\subsection{Ergebnisse Zahnverlust}

Zum Zeitpunkt „base“ besaßen die 92 untersuchten Patienten 2258 Zähne. Somit hatte jeder Patient durchschnittlich 24 Zähne. Zum Zeitpunkt der Nachuntersuchung lag die Anzahl der Zähne in situ bei 2204, d.h. 54 Zähne sind in diesem Betrachtungszeitraum durch Parodontitis verloren gegangen. Im Schnitt verlor jeder Patient 0,58 Zähne im gesamten Beobachtungszeitraum. Die Zahnverlustquote pro Patient und pro Jahr beträgt 0,09. Insgesamt sind während dieser Untersuchung 77 Zähne extrahiert worden. Gründe dafür waren Karies und chronisch apikale Parodontitis.

Zahnverlust

\begin{tabular}{|c|cccc|}
\hline Geschlecht & Männer & & Frauen & \\
Zeitpunkt & Base & End & Base & End \\
\cline { 2 - 5 } $\mathrm{n}$ & 38 & 38 & 54 & 54 \\
Alter $\varnothing$ & 49,26 & 55,26 & 48,18 & 54,39 \\
Zahnverlust & & 18 & & 36 \\
\hline
\end{tabular}

Tab. 1 Zahnverlust nach Geschlechtern unterteilt.

Tabelle 1 gibt einen Überblick über der Zahnverlust der Probanden. Über den Beobachtungszeitraum von durchschnittlich 6,66 Jahren (min. 3 bis max. 10) wurden 54 Zähne aus parodontalen Gründen extrahiert. Die Gruppe der männlichen Patienten verlor 18 und die der weiblichen Teilnehmer 36 Zähne. Das durchschnittliche Recallintervall betrug 1-2 Sitzungen/ Jahr.

Die Auswertung der nicht parametrischen Analyse ergab, dass das Alter einen signifikanten Einfluss auf den Zahnverlust hat $(p=0,01)$. Die übrigen Variablen, wie Rauchgewohnheiten $(p=0.61)$, Anamnese $(p=0,13)$, Jahre im Recall $(p=0,47)$, Recallfrequenz $(p=0,83)$ und das Geschlecht $(p=0,16)$ hatten keinen signifikanten Einfluss auf den Zahnverlust. Sie lagen über der vorher festgelegten Signifikanzgrenze von $p=0,05$. 


\subsubsection{Zahnverlust innerhalb der Zahngruppen}

Eine Einteilung der untersuchten Parodontien erfolgte in Zahngruppen 1-4.

Die Abbildung 1 zeigt die Anzahl der Zähne die innerhalb der Zahngruppen extrahiert wurden.

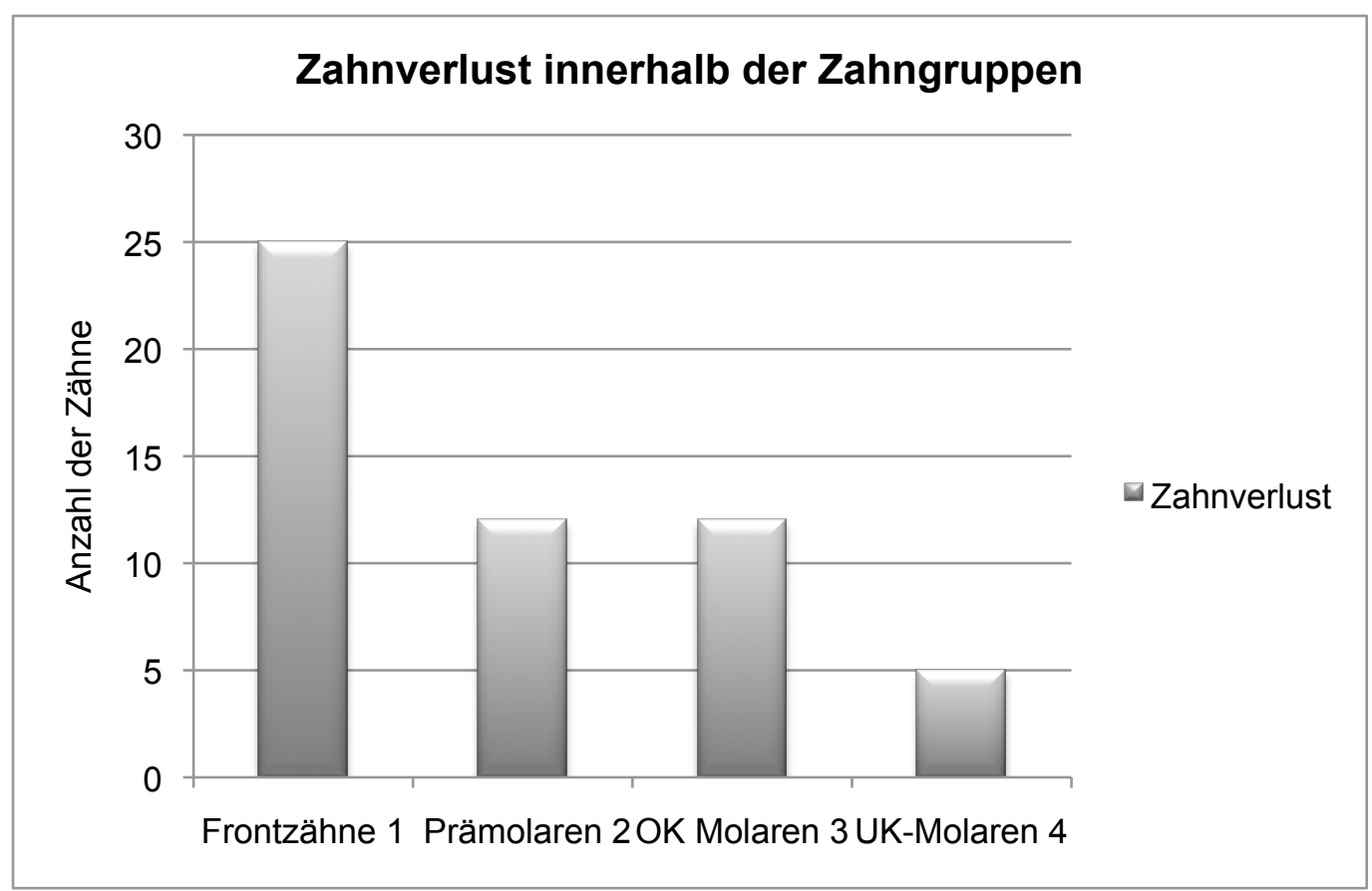

Abb. 1 Zeigt den Zahnverlust bei den Zahngruppen

Zahnverlust

\begin{tabular}{|l|cccc|}
\hline Zahngruppen & Frontzähne (1) & Prämolaren (2) & OK-Molaren (3) & UK-Molaren (4) \\
\cline { 2 - 5 } Summe & 1046 & 630 & 302 & 280 \\
Zahnverlust & $\mathbf{2 5}$ & $\mathbf{1 2}$ & $\mathbf{1 2}$ & $\mathbf{5}$ \\
Prozent & $2,39 \%$ & $1,90 \%$ & $3,97 \%$ & $1,78 \%$ \\
\hline
\end{tabular}

Tab. 2 Zeigt den Zahnverlust innerhalb der Zahngruppen.

Tabelle 2 verdeutlicht die Zahnverlustrate, unterteilt auf die Zahngruppen (1-4). In der Gruppe der Frontzähne konnten von 1046 gezählten Zähnen 25 (2,39\%) über den gesamten Beobachtungszeitraum nicht therapiert werden. In der Gruppe der Prämolaren sind es $12(1,90 \%)$ von 630, bei den Oberkiefermolaren sind es 12 (3,97\%) von 302 und bei den Unterkiefer Molaren konnten 5 (1,78\%) von 280 Zähnen nicht erhalten werden und mussten extrahiert werden. Die Gruppe der Oberkiefermolaren hatte die größte Zahnverlustrate. Die Gruppe der UK-Molaren dagegen die geringste. 


\subsection{Ergebnisse Sondierungstiefen}

Die folgende Abbildung 2 zeigt die Entwicklung der Sondierungstiefen des gesamten Patientenkollektives bei Erstuntersuchung (Base) und Nachuntersuchung (End). Es ist ein Rückgang der Sondierungstiefen von 1,13 mm zu erkennen.

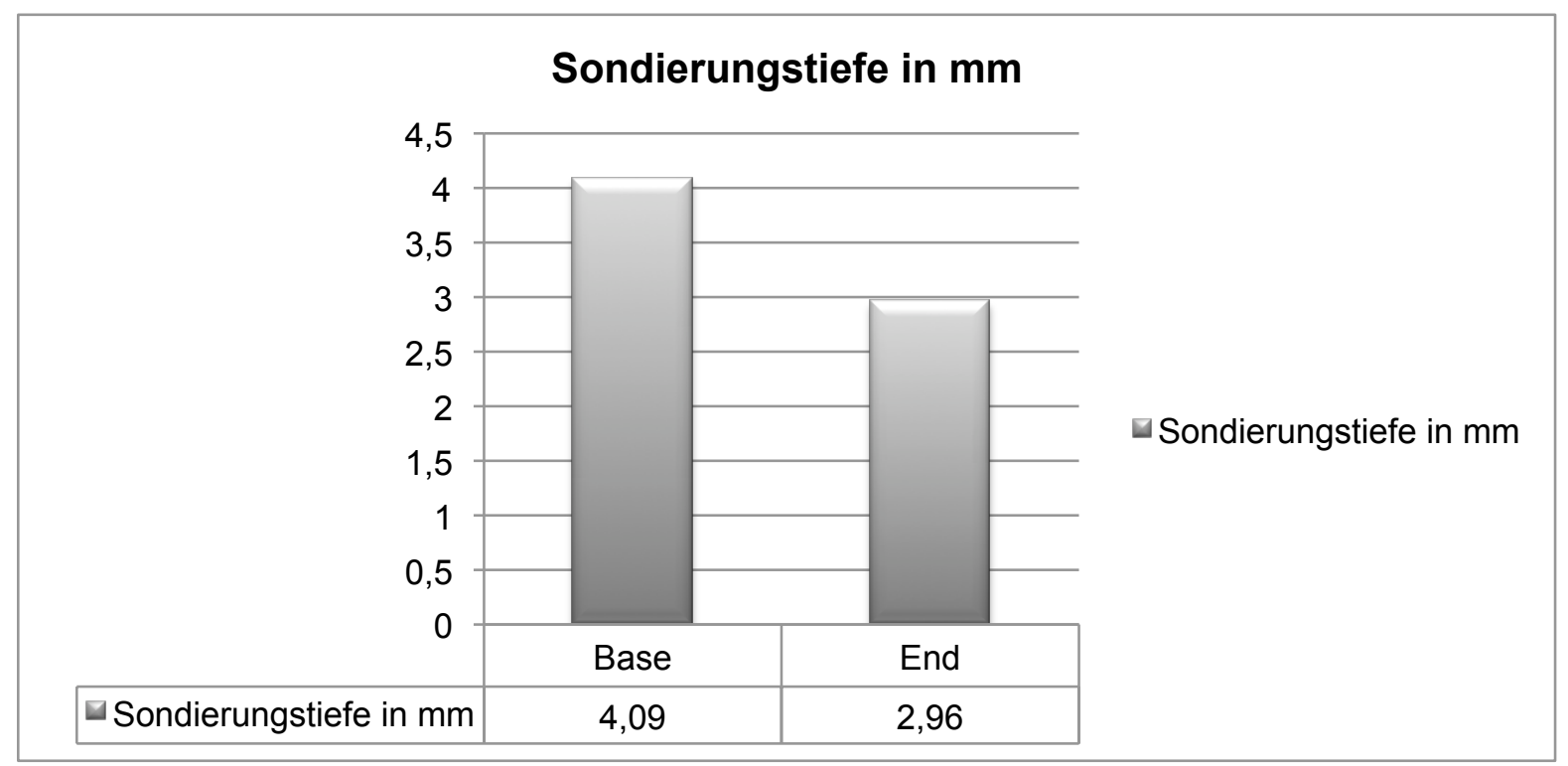

Abb. 2 Sondierungstiefen des gesamten Patientenkollektives

Die nachfolgende Grafik (Abb. 3) weist die Sondierungstiefen geschlechterspezifisch auf. Die Gruppe der Männer hat einen durchschnittlichen Rückgang von 1,18 mm und die der Frauen von 1,1 mm. Im Durchschnitt haben die Frauen geringere Sondierungstiefen als die Männer vorzuweisen.

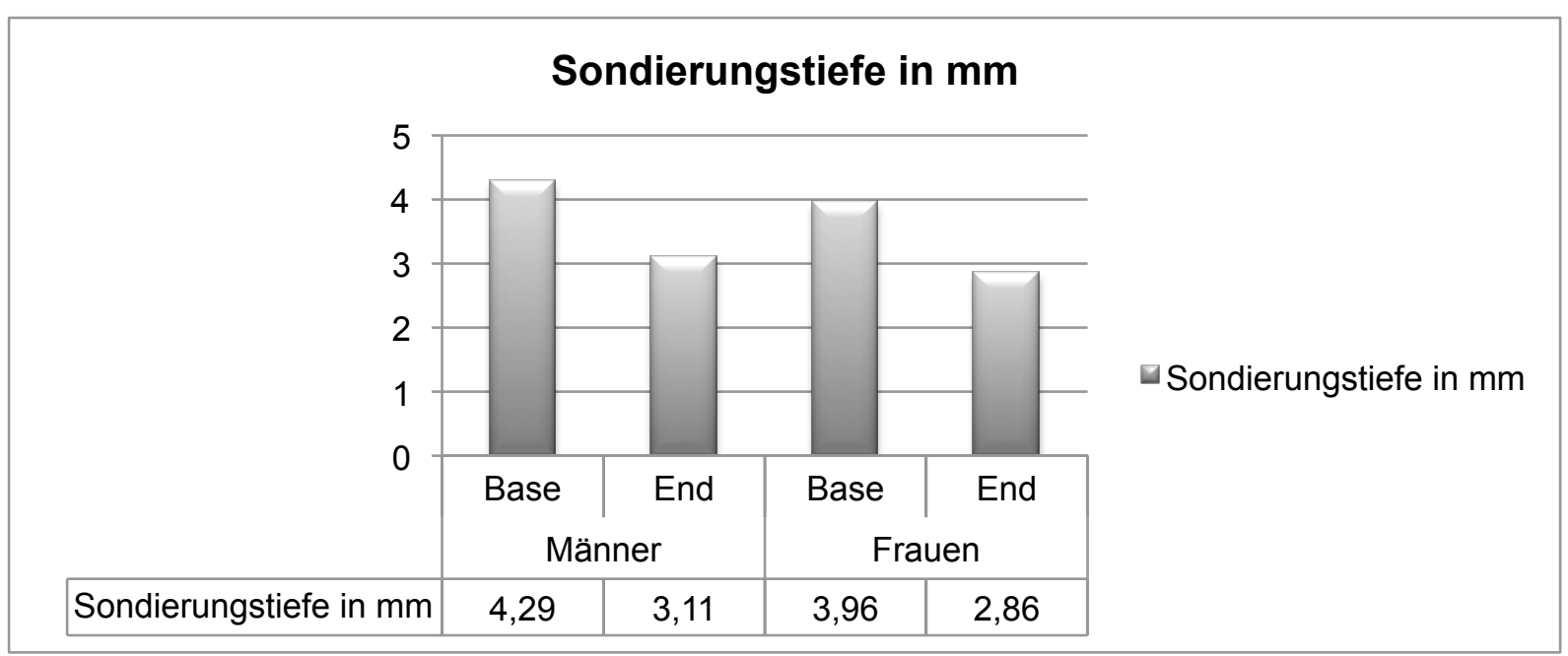

Abb. 3 Sondierungstiefen nach Geschlechtern getrennt. 
4.2.1 Sondierungstiefen innerhalb der Zahngruppen
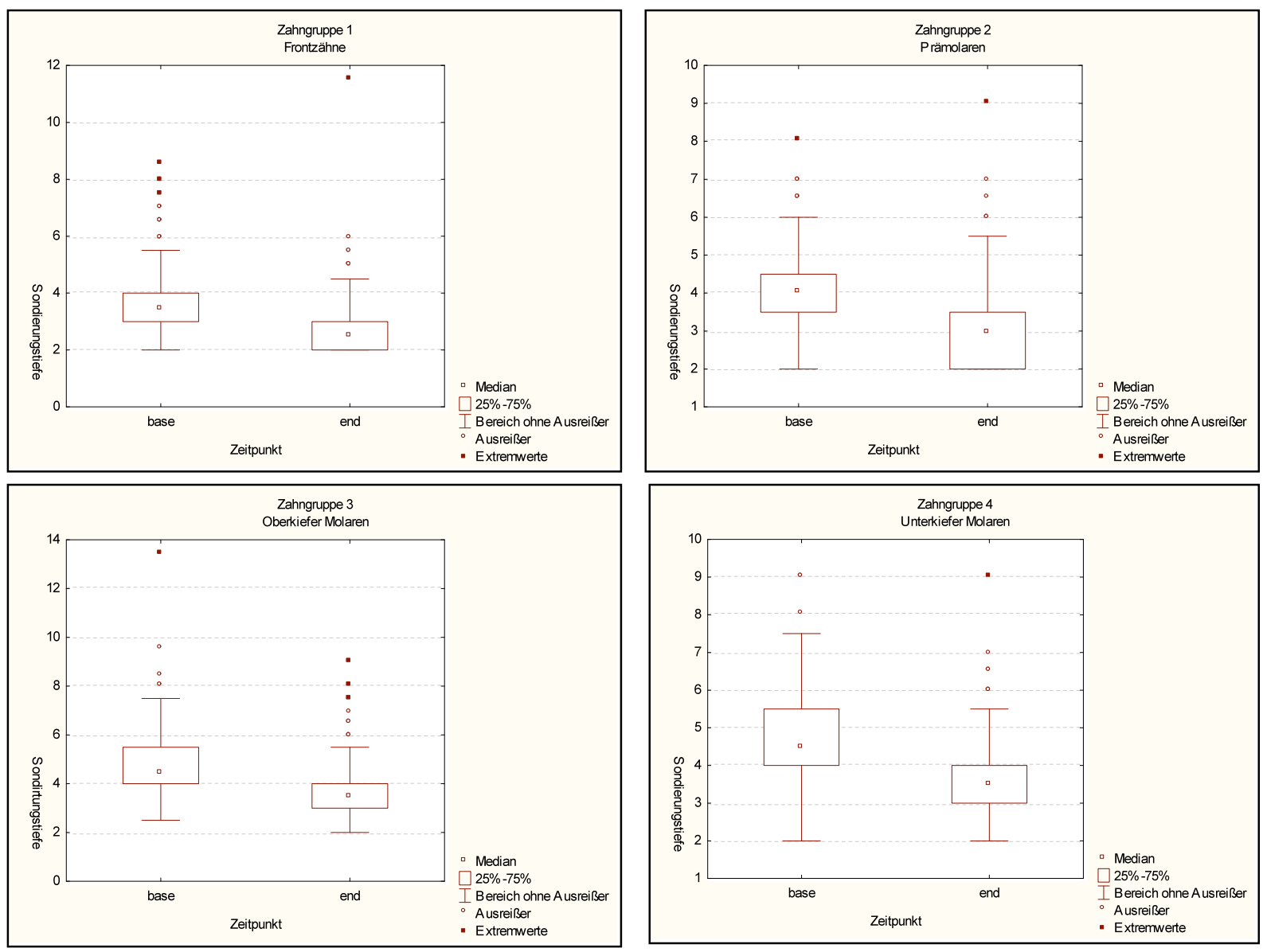

Abb. 4 Darstellungen der Sondierungstiefen bei Vor- und Nachuntersuchung der Zahngruppen 1-4.

Abbildung 4 zeigt die Sondierungstiefen der einzelnen Zahngruppen bei der Voruntersuchung und wie sie sich durch die Behandlung zum Positiven verschieben.

Sondierungstiefen verteilt auf die Zahngruppen

\begin{tabular}{|lccccc|}
\hline Base & $\mathbf{n}$ & Mittelwert & Median & min. & max. \\
\hline Zahnngruppe 1 & 1046 & $3,77 \pm 0,97$ & 3,5 & 2,0 & 8,5 \\
Zahngruppe 2 & 630 & $4,07 \pm 0,90$ & 4 & 2,0 & 8,0 \\
Zahngruppe 3 & 302 & $4,68 \pm 1,23$ & 4,5 & 2,5 & 13,5 \\
Zahngruppe 4 & 280 & $4,69 \pm 1,16$ & 4,5 & 2,0 & 9,0 \\
\hline End & $\mathbf{n}$ & Mittelwert & Median & min. & max. \\
\hline Zahngruppe 1 & 1021 & $2,60 \pm 0,78$ & 2,5 & 2,0 & 11,5 \\
Zahngruppe 2 & 618 & $2,93 \pm 0,90$ & 3,0 & 2,0 & 9,0 \\
Zahngruppe 3 & 290 & $3,66 \pm 1,25$ & 3,5 & 2,0 & 9,0 \\
Zahngruppe 4 & 275 & $3,66 \pm 1,06$ & 3,5 & 2,0 & 9,0 \\
\hline
\end{tabular}

Tab.3 Verteilung der Sondierungstiefen auf die Zahngruppen zum Zeitpunkt Base und End. 


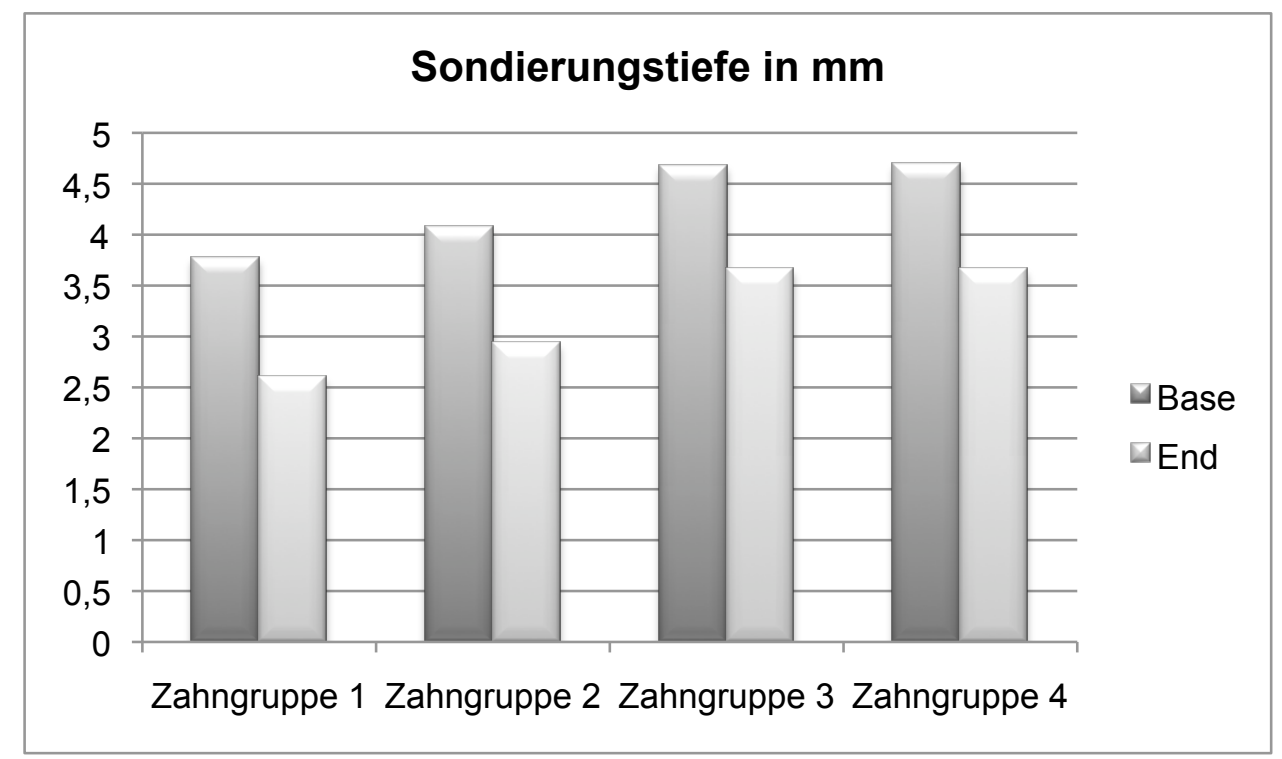

Abb. 5 Vergleich der Sondierungstiefen innerhalb der einzelnen Zahngruppen.

In Tabelle 3 und Abbildung 5 werden die Sondierungstiefen für jede Zahngruppe präsentiert. Im Durchschnitt gehen die Sondierungstiefen bei den Frontzähnen um 1,18mm, bei den Prämolaren um 1,14mm, den Oberkiefermolaren um 1,02mm und den Unterkiefermolaren um 1,03mm zurück.

Analyse der Kovariablen

\begin{tabular}{|c|c|c|c|c|}
\hline Kovariablen & $\begin{array}{c}\text { Zahngruppe } \\
\text { Frontzähne }\end{array}$ & $\begin{array}{l}\text { Zahngruppe } \\
\text { Prämolaren }\end{array}$ & $\begin{array}{l}\text { Zahngruppe } \\
\text { OK-Molaren }\end{array}$ & $\begin{array}{l}\text { Zahngruppe } \\
\text { UK-Molaren }\end{array}$ \\
\hline Rauchgewohnheiten & $p=0,004$ & $p=0,002$ & $p=0,090$ & $p=0,002$ \\
\hline Anamnese & $P=0,051$ & $p=0,673$ & $p=0,083$ & $p=0,409$ \\
\hline Alter & $p=0,180$ & $p=0,222$ & $p=0,0004$ & $p=0,478$ \\
\hline Jahre im Recall & $p=0,993$ & $P=0,127$ & $p=0,381$ & $p=0,460$ \\
\hline Recallfrequenz & $p=0,706$ & $p=0,419$ & $p=0,181$ & $p=0,836$ \\
\hline Geschlecht & $p=0,026$ & $p=0,154$ & $p=0,020$ & $p=0,109$ \\
\hline
\end{tabular}

Tab. 4 Zeigt die Kovariablen für die nicht parametrische Analyse und deren $p$-Werte für die einzelnen Zahngruppen (Signifikanzgrenze $p=0,05$ ).

In Tab. 4 werden die Kovariablen mit ihren p-Werten für die einzelnen Zahngruppen, bezogen auf die Sondierungstiefe aufgeführt. In der Zahn-Grp. 1 haben die Rauchgewohnheiten $(p=0,004)$, die Anamnese $(p=0,051)$ und das Geschlecht des Patienten $(p=0,026)$ signifikanten Einfluss auf die Sondierungstiefe.

In der Zahn-Grp. 2 weisen die Rauchgewohnheiten $(p=0,002)$ einen signifikanten Einfluss auf die Taschentiefe auf. In der Zahn-Grp. 3 besitzen sowohl das Alter 
$(p=0,0004)$ als auch das Geschlecht des Patienten $(p=0,020)$ einen signifikanten Einfluss auf die Sondierungstiefe. In der Zahn-Grp. 4 nehmen die Rauchgewohnheiten $(p=0,002)$ signifikanten Einfluss auf die Sondierungstiefe. Die übrigen Kovariablen haben keinen signifikanten Einfluss auf die Sondierungstiefe. Sie lagen über der vorher festgelegten Signifikanzgrenze von $p<0,05$.

\subsection{Ergebnisse Attachmentlevel}

Die Abbildung 6 veranschaulicht die Höhe des Attachmentlevels zum Zeitpunkt der Erst- und Nachuntersuchung. Er liegt bei der Erstuntersuchung bei $3,35 \mathrm{~mm}$ und kann durch die Behandlung auf 3,29 mm steigen.

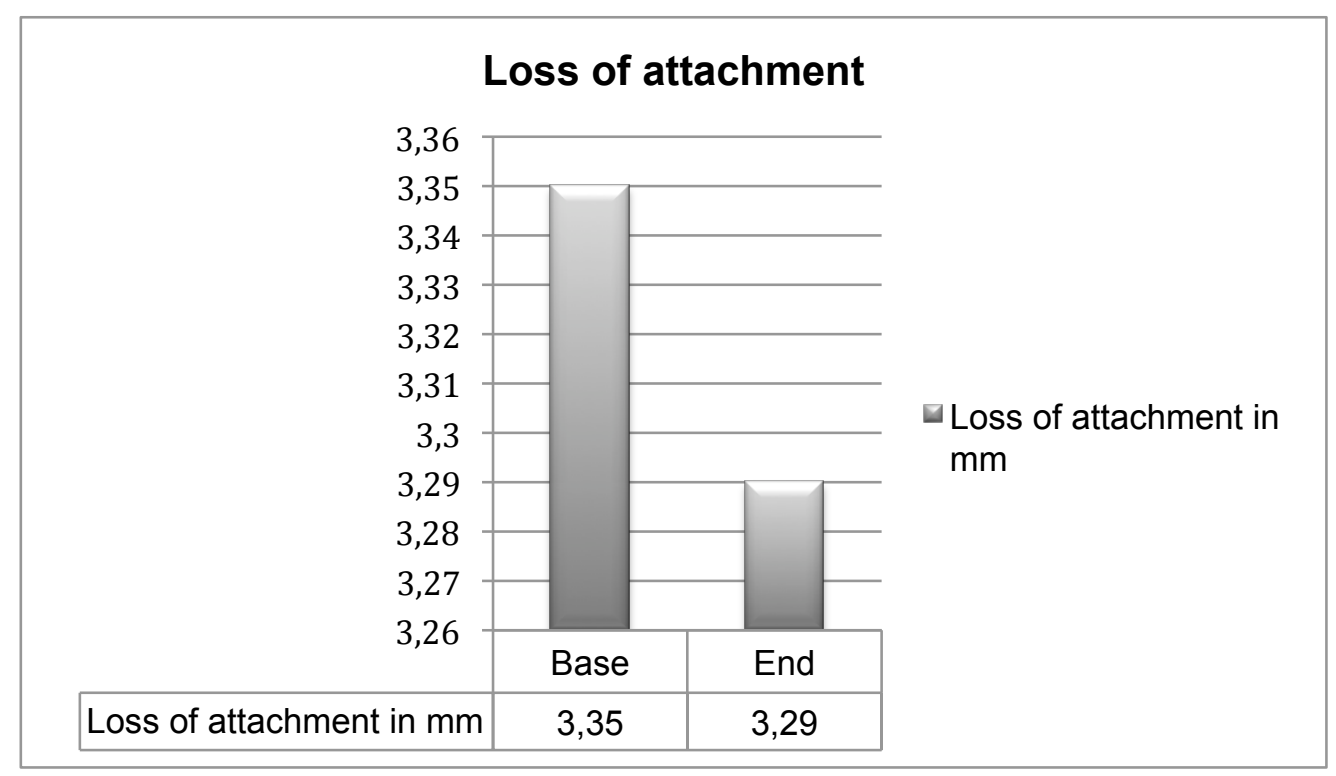

Abb. 6 Attachmentlevel des gesamten Patientenkollektives.

Die folgende Grafik 7 zeigt die Entwicklung der Werte für den Attachementlevel, zum Zeitpunkt der Erst- und Nachuntersuchung gesondert für Männer und Frauen.

Die Männer weisen einen Attachmentgewinn von 0,11 mm und die Gruppe der Frauen einen Gewinn von 0,03 mm auf.

Der Rückgang ist bei der Männergruppe etwas höher als bei den Frauen. 


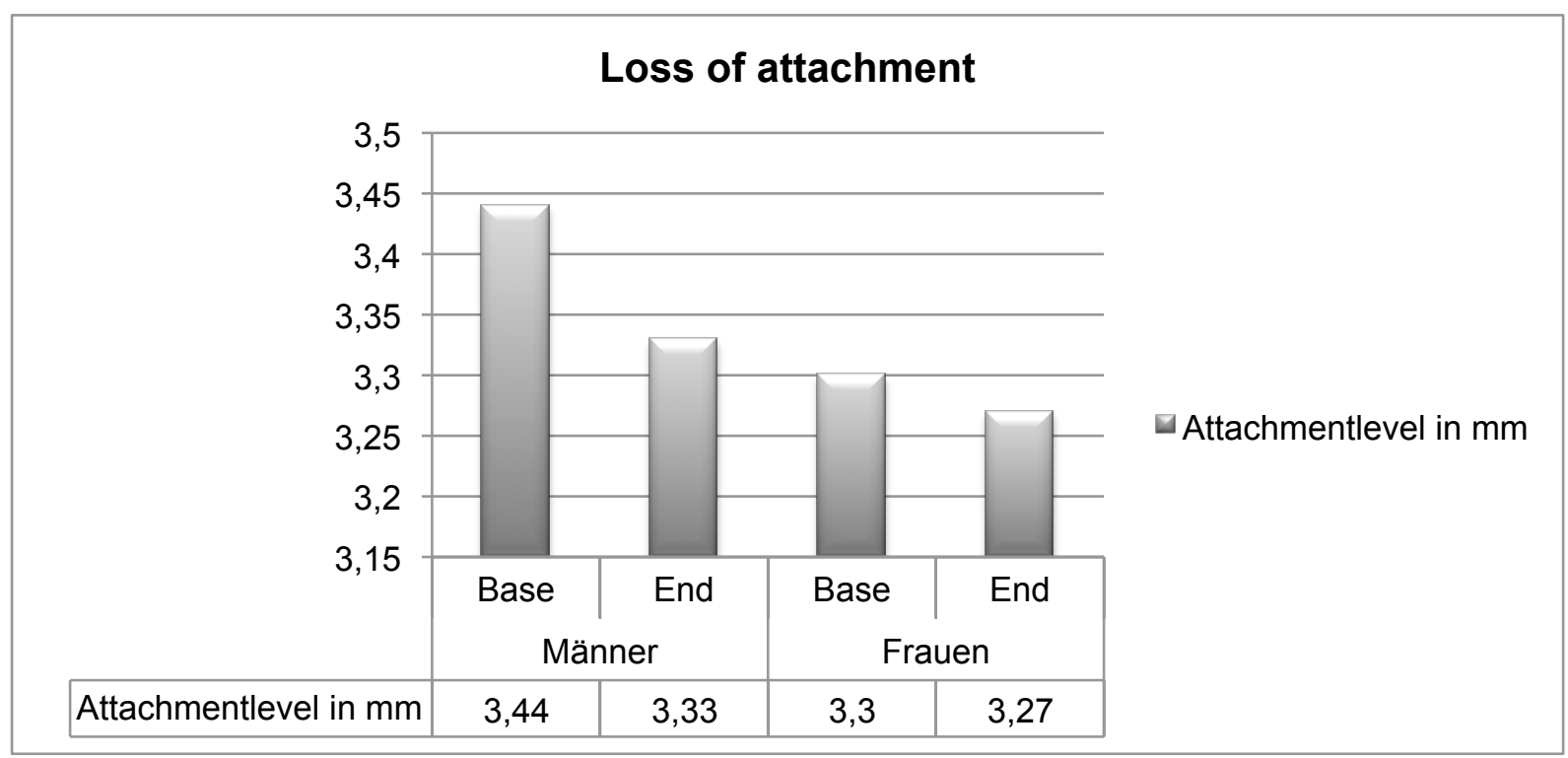

Abb. 7 Attachmentlevel nach Geschlechtern getrennt.

\subsubsection{Attachmentlevel innerhalb der Zahngruppen}

\begin{tabular}{|lccccc|}
\hline Base & $\mathbf{n}$ & Mittelwert & Median & min. & max. \\
\hline Zahngruppe 1 & 589 & $3,12 \pm 1,46$ & 3,0 & 1,0 & 11,0 \\
Zahngruppe 2 & 342 & $3,11 \pm 1,25$ & 3,0 & 1,0 & 9,0 \\
Zahngruppe 3 & 165 & $4,42 \pm 1,91$ & 4,0 & 2,0 & 12,0 \\
Zahngruppe 4 & 157 & $3,63 \pm 1,23$ & 3,5 & 0,5 & 9,0 \\
\hline End & $\mathbf{n}$ & Mittelwert & Median & min. & max. \\
\hline Zahngruppe 1 & 882 & $2,92 \pm 1,18$ & 3,0 & 1,0 & 12,0 \\
Zahngruppe 2 & 535 & $3,17 \pm 1,20$ & 3,0 & 1,0 & 11,0 \\
Zahngruppe 3 & 249 & $4,38 \pm 1,82$ & 4,0 & 2,0 & 15,0 \\
Zahngruppe 4 & 235 & $3,81 \pm 1,45$ & 3,5 & 0,5 & 12,0 \\
\hline
\end{tabular}

Tab.5 Attachmentlevel bei Zahngruppe 1-4 zum Zeitpunkt der Erst- und Nachuntersuchung. 


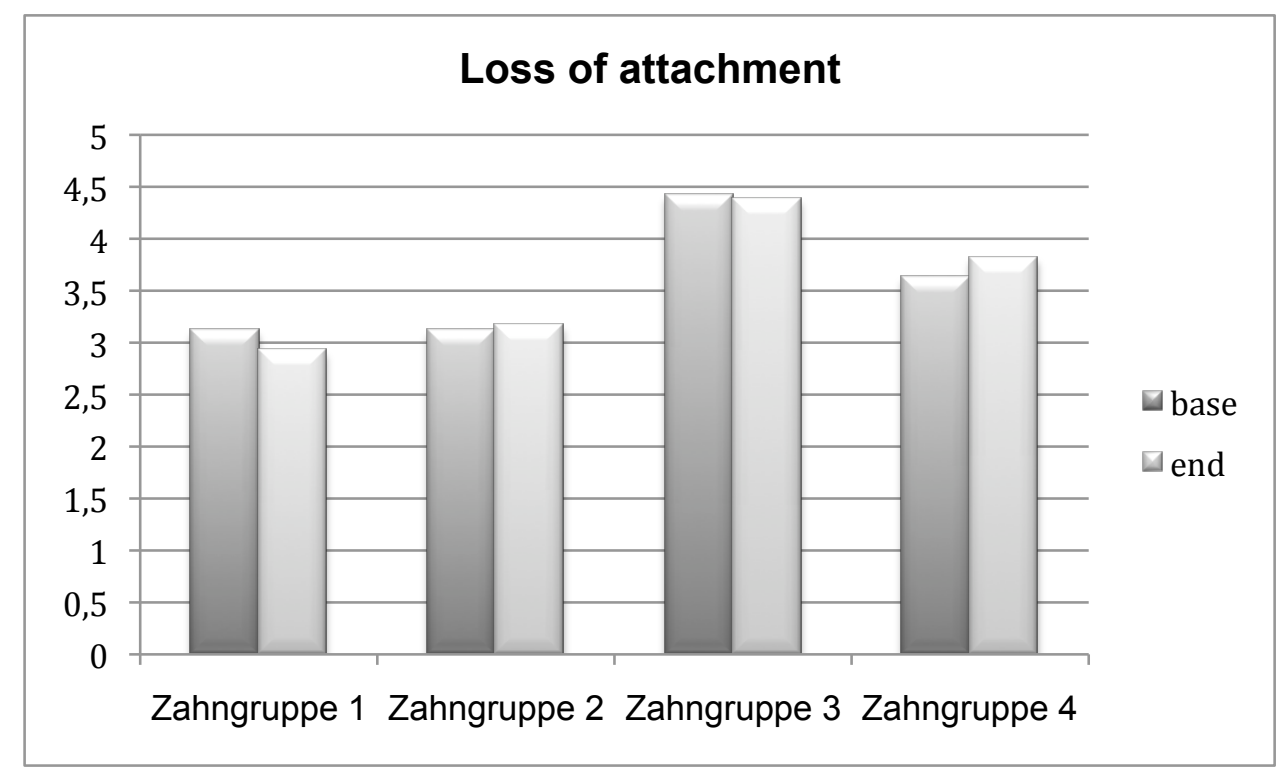

Abb. 8 Vergleich des Attachmentlevels innerhalb der einzelnen Zahngruppen.

Die Tabelle 5 und die Abbildung 8 präsentieren den Attachmentlevel für jede Zahngruppe. Im Durchschnitt steigt der Attachmentlevel bei der Frontzahngruppe um 0,19mm. Die OK-Molaren-Gruppe kann ebenfalls an 0,03mm gewinnen. Die Prämolaren- und UK-Molaren-Gruppe verlieren an Attachment im Durchschnitt $0,05 \mathrm{~mm}$ bzw. $0,20 \mathrm{~mm}$ bei den UK-Molaren.

\section{Analyse der Kovariablen}

\begin{tabular}{|l|llll|}
\hline \multicolumn{1}{|c}{ Kovarianten } & $\begin{array}{c}\text { Zahngruppe } \\
\text { Frontzähne }\end{array}$ & $\begin{array}{c}\text { Zahngruppe } \\
\text { Prämolaren }\end{array}$ & $\begin{array}{c}\text { Zahngruppe } \\
\text { Ok-Molaren }\end{array}$ & $\begin{array}{c}\text { Zahngruppe } \\
\text { Uk-Molaren }\end{array}$ \\
\hline Rauchgewohnheiten & $p=0,182$ & $p=0,392$ & $p=0,928$ & $p=0,239$ \\
Anamnese & $P=0,062$ & $\boldsymbol{p}=\mathbf{0 , 0 4 1}$ & $\boldsymbol{p}=\mathbf{0 , 0 2 8}$ & $p=0,133$ \\
Alter & $\boldsymbol{p}=\mathbf{0 , 0 0 0 4}$ & $\boldsymbol{p}=\mathbf{0 , 0 0 0 0 1}$ & $\boldsymbol{p}=\mathbf{0 , 0 0 0 0 2}$ & $\boldsymbol{p}=\mathbf{0 , 0 0 0 1}$ \\
Jahre im Recall & $p=0,866$ & $P=0,622$ & $p=0,521$ & $p=0,920$ \\
Recallfrequenz & $p=0,370$ & $p=0,249$ & $p=0,285$ & $p=0,230$ \\
Geschlecht & $p=1$ & $p=0,704$ & $p=0,546$ & $p=0,816$ \\
\hline
\end{tabular}

Tab. 6 Zeigt die Kovariablen für die nicht parametrische Analyse und deren $p$-Werte für die einzelnen Zahngruppen (Signifikanzgrenze $p=0,05$ ).

In Tab. 6 werden die Kovariablen mit ihren p-Werten für die einzelnen Zahngruppen, bezogen auf den Attachmentlevel dargestellt. In Zahn-Grp. 1 hat das Alter des Patienten $(p=0,0004)$ signifikanten Einfluss auf den Attachmentlevel.

In der Zahn-Grp. 2 weisen das Alter $(p=0,00001)$ und die Anamnese $(p=0,041)$ des Probanden einen signifikanten Einfluss auf den Attachmentlevel auf. In der ZahnGrp. 3 üben das Alter $(p=0,00002)$ und die Anamnese des Patienten $(p=0,028)$ 
einen signifikanten Einfluss auf den Attachmentlevel aus. In der Zahn-Grp. 4 nimmt das Alter $(p=0,0001)$ einen signifikanten Einfluss auf den Attachmentlevel.

Die übrigen Kovariablen haben keinen signifikanten Einfluss auf den Attachmentlevel. Sie liegen über der vorher festgelegten Signifikanzgrenze von $p<0,05$.

\subsection{Ergebnisse Patientenrisiko}

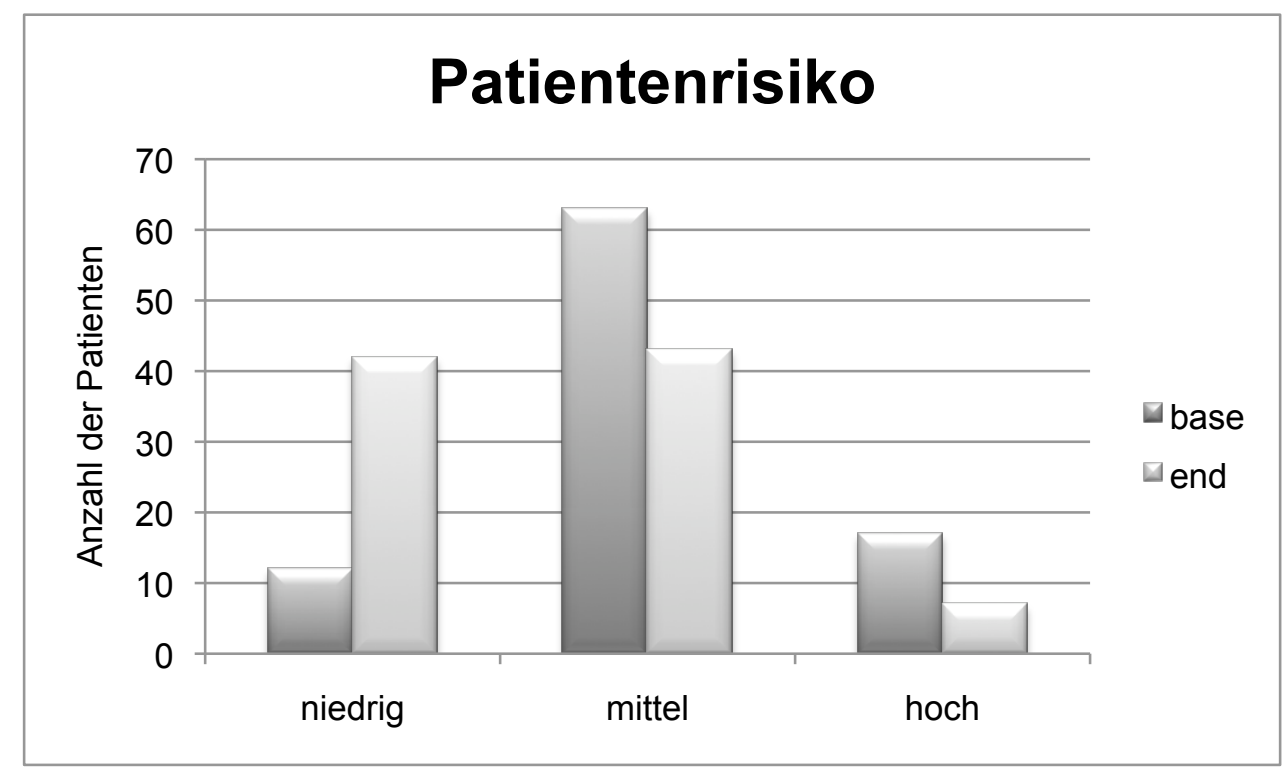

Abb. 9 Darstellung der Verteilung der Patienten auf die Risikogruppen bei Erst- und Nachuntersuchung.

Die Abbildung 9 zeigt wie das Patientenrisiko erneut an einer Parodontitis zu erkranken über die Beobachtungszeit abnimmt. In der „niedrig Risiko“ Gruppe sind zum Zeitpunkt „Base“ 12 (13,04\%) Patienten gezählt worden. Zum Zeitpunkt „End“ sind es bereits 42 (45,65\%) die eine niedrige Prognose bezüglich einer Neuerkrankung aufweisen. In der „mittel Risiko“- Gruppe sinken die Patientenzahlen von 63 (68,48\%) auf 43 (46,74\%) zum Zeitpunkt der Nachuntersuchung. Die Anzahl der „hoch Risiko“Patienten nimmt von $17(17,48 \%)$ auf 7 (7,61\%) ab. 


\subsection{Ergebnisse Zahnprognosen}

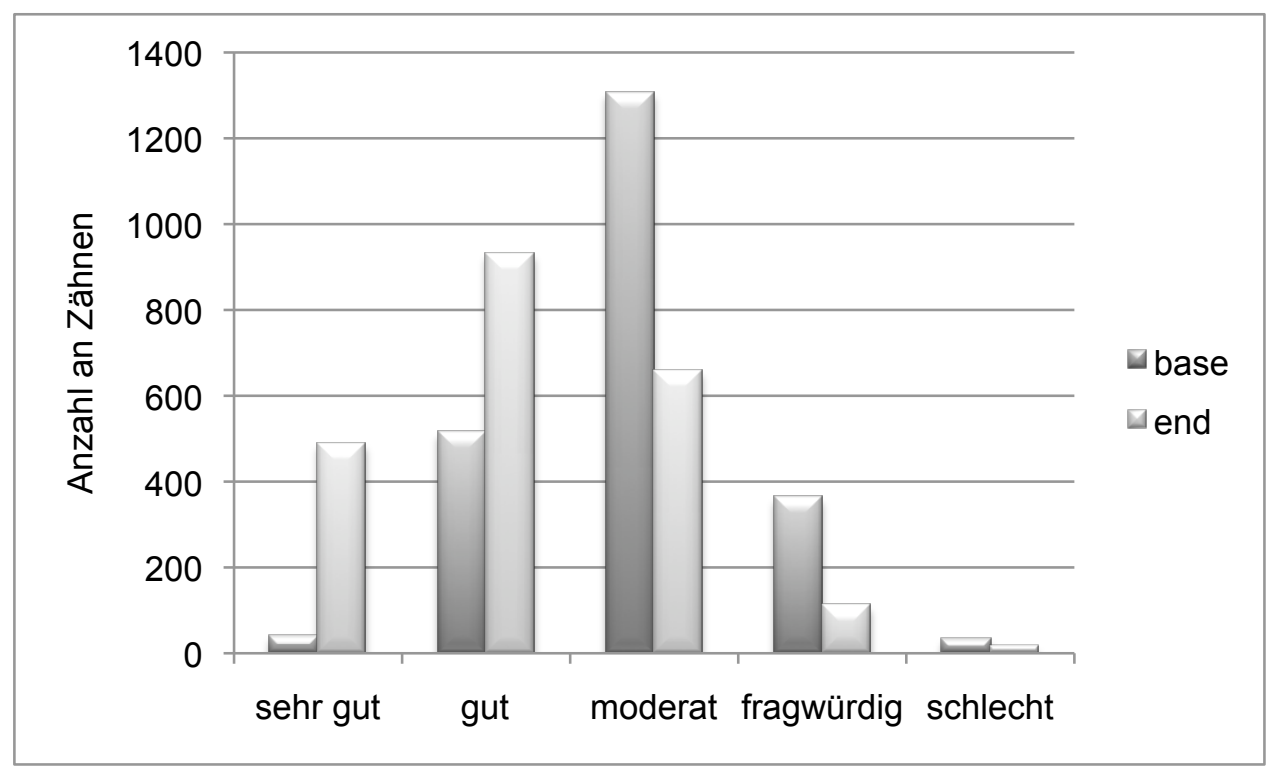

Abb. 10 Zeigt die Prognosen der Zähne bei Erst- und Nachuntersuchung

Abbildung 10 vergleicht die Veränderung der Prognosen der Zähne zum Zeitpunkt der Erstuntersuchung (base) und nach Behandlung und unterstützender Parodontitistherapie (end). Deutlich ist die Verschiebung zu den günstigeren Prognosen (für den Zahnerhalt) zu erkennen.

\section{Zahnprognosen}

\begin{tabular}{|rcccc|}
\hline $\begin{array}{r}\text { Base } \\
\text { Prognose }\end{array}$ & $\begin{array}{c}\text { Zahngruppe 1 } \\
\text { OK/UK-Front }\end{array}$ & $\begin{array}{c}\text { Zahngruppe 2 } \\
\text { OK/UK-Prämolaren }\end{array}$ & $\begin{array}{c}\text { Zahngruppe 3 } \\
\text { OK-Molaren }\end{array}$ & $\begin{array}{c}\text { Zahngruppe 4 } \\
\text { UK-Molaren }\end{array}$ \\
\hline sehr gut (0) & 35 & 4 & 0 & 1 \\
gut (1) & 360 & 112 & 20 & 23 \\
moderat (2) & 539 & 427 & 177 & 164 \\
fragwürdig (3) & 101 & 83 & 95 & 84 \\
schlecht (4) & 11 & 4 & 10 & 8 \\
\hline End & Zahngruppe 1 & Zahngruppe 2 & Zahngruppe 3 & Zahngruppe 4 \\
Prognose & OK/UK-Front & OK/UK-Prämolaren & OK-Molaren & UK-Molaren \\
\hline sehr gut (0) & 355 & 101 & 21 & 12 \\
gut (1) & 456 & 310 & 80 & 84 \\
moderat (2) & 190 & 187 & 144 & 137 \\
fragwürdig (3) & 18 & 18 & 36 & 39 \\
schlecht (4) & 2 & 2 & 9 & 3 \\
\hline
\end{tabular}

Tab. 7 Verteilung der Zähne innerhalb der Zahngruppen mit deren Ausgangs- und Endprognosen

Tabelle 7 veranschaulicht, wie die Prognosen der Zähne eindeutig günstiger im Hinblick auf den Zahnerhalt werden. Beispielsweise sind in Zahngruppe 1539 Zähne mit 
der Prognose „moderat“ bei der Erstuntersuchung bewertet worden. Nach der Therapiephase/UPT sind es nur noch 190 Zähne in der Frontzahngruppe mit der Prognose „moderat“. Dieser positive Effekt ist ebenfalls an den übrigen Prognosen abzulesen, siehe Tabelle 8.

\section{Zahnprognosen}

\begin{tabular}{|l|cccc|}
\hline \multirow{2}{*}{ Prognose } & $\begin{array}{c}\text { Zahngruppe 1 } \\
\text { Frontzähne }\end{array}$ & $\begin{array}{c}\text { Zahngruppe 2 } \\
\text { Prämolaren }\end{array}$ & $\begin{array}{c}\text { Zahngruppe 3 } \\
\text { OK- Molaren }\end{array}$ & $\begin{array}{c}\text { Zahngruppe 4 } \\
\text { UK- Molaren }\end{array}$ \\
\cline { 2 - 5 } verschlechtert & $7,05 \%$ & $7,44 \%$ & $12,24 \%$ & $12.91 \%$ \\
unverändert & $26,93 \%$ & $28,48 \%$ & $36,36 \%$ & $35,42 \%$ \\
verbessert & $66,01 \%$ & $64,08 \%$ & $51,40 \%$ & $51,66 \%$ \\
\hline
\end{tabular}

Tab. 8 Zeigt die Veränderung der Zahnprognosen in Prozent.

Betrachtet man alle untersuchten Zähne so verschlechtern sich insgesamt $8,59 \%$ in ihrer Prognose. 29,64\% der Parodontien bleiben in ihrer Prognose unverändert und $61,79 \%$ können durch die Behandlung und das UPT verbessert werden.

Die Tabelle 8 stellt die Veränderungen innerhalb der einzelnen Zahngruppen dar. Bei den Frontzähnen können 66,01\% der Zähne in ihrer Prognose verbessert werden. In der Gruppe der Prämolaren sind es 64,08\% und bei den OK-Molaren und UKMolaren sind es immerhin noch $51,40 \%$ bzw. 51,66\% deren Prognose noch verbessert werden kann.

\section{Analyse der Kovariablen}

\begin{tabular}{|c|c|c|c|c|}
\hline Kovariablen & $\begin{array}{l}\text { Zahngruppe } \\
\text { Frontzähne }\end{array}$ & $\begin{array}{c}\text { Zahngruppe } \\
\text { Prämolaren }\end{array}$ & $\begin{array}{l}\text { Zahngruppe } \\
\text { OK-Molaren }\end{array}$ & $\begin{array}{l}\text { Zahngruppe } \\
\text { UK-Molaren }\end{array}$ \\
\hline Rauchgewohnheiten & $p=0,028$ & $p=0,015$ & $p=0,054$ & $p=0,028$ \\
\hline Anamnese & $P=0,024$ & $p=0,288$ & $p=0,123$ & $p=0,214$ \\
\hline Alter & $p=0,065$ & $p=0,354$ & $p=0,0005$ & $p=0,727$ \\
\hline Jahre im Recall & $p=0,933$ & $P=0,118$ & $p=0,246$ & $p=0,052$ \\
\hline Recallfrequenz & $p=0,083$ & $p=0,518$ & $p=0,661$ & $p=0,814$ \\
\hline Geschlecht & $p=0,028$ & $p=0,540$ & $p=0,012$ & $p=0,185$ \\
\hline
\end{tabular}

Tab. 9 Zeigt die Kovariablen für die nicht parametrische Analyse und deren $p$-Werte für die einzelnen Zahngruppen (Signifikanzgrenze $p=0,05$ ).

Die Tab. 9 zeigt, welche Kovariablen auf das Risikoprofil in den einzelnen Zahngruppen Einfluss nehmen. In der Frontzahngruppe haben die Rauchgewohnheiten ( $p=$ $0,028)$, die Anamnese $(p=0,024)$ und das Geschlecht des Patienten $(p=0,028)$ signi- 
fikanten Einfluss auf das Risikoprofil. In der Prämolarengruppe weisen die Rauchgewohnheiten $(p=0,015)$ einen signifikanten Einfluss auf das Risikoprofil auf. Die Gruppe der OK-Molaren wird durch die Rauchgewohnheiten $(p=0,054)$, das Alter $(p=0,0005)$ und das Geschlecht des Patienten $(p=0,012)$ signifikant im Risikoprofil beeinflusst. In der Gruppe der UK-Molaren sind es die Rauchgewohnheiten $(p=0,028)$ und die Jahre, die der Patient in UPT ist $(p=0,052)$ die signifikanten Einfluss auf das Risikoprofil nehmen. Die restlichen Kovariablen hatten keinen signifikanten Einfluss auf das Risikoprofil, sondern lagen über der vorher festgelegten Signifikanzgrenze von $p<0,05$.

\subsection{Anamnese}

Tab. 10 Verteilung der Patienten auf die Anamnesegruppen.

\begin{tabular}{|c|cc|}
\hline Anamnese & Base & End \\
\hline Gruppe 1 & 1 & 1 \\
Gruppe 2 & 16 & 29 \\
Gruppe 3 & 75 & 62 \\
\hline
\end{tabular}

Tabelle 10 zeigt die Verteilung der Patienten auf die Anamnesegruppen 1-3 zum Zeitpunkt der Erst- und Nachuntersuchung.

\subsubsection{Sondierungstiefen innerhalb der Anamnesegruppen}

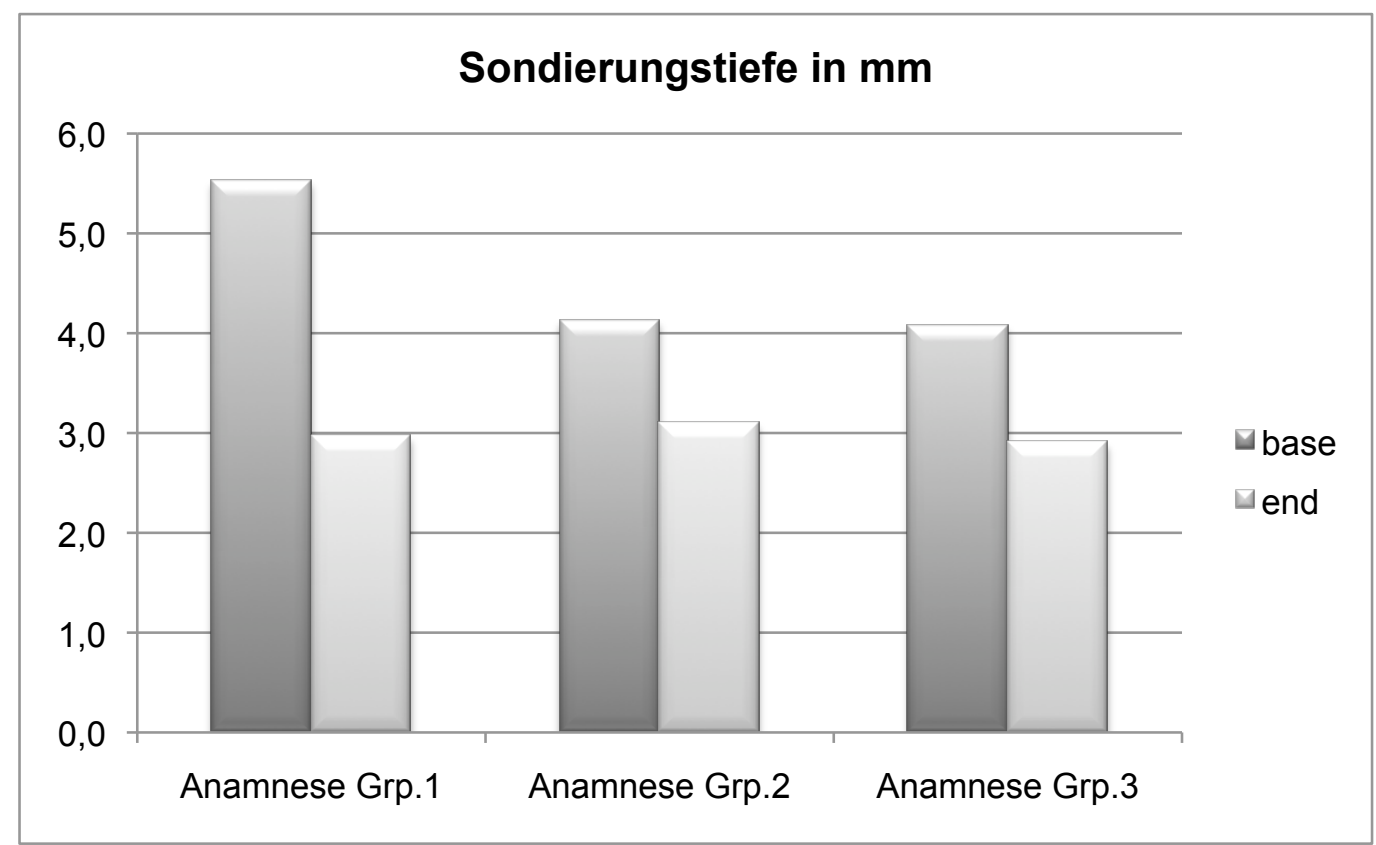

Abb. 11 Zeigt die Sondierungstiefen innerhalb der Anamnesegruppen 1-3. 
Sondiertiefen innerhalb der Anamnesegruppen

\begin{tabular}{|cccccc|}
\hline $\begin{array}{c}\text { Base } \\
\text { Anamnese }\end{array}$ & $\mathbf{n}$ & Mittelwert & Median & min. & max. \\
\hline Grp.1 & 17 & $5,52 \pm 1,39$ & 5,5 & 4 & 8 \\
Grp.2 & 391 & $4,13 \pm 0,99$ & 4 & 2,5 & 8,5 \\
Grp.3 & 1850 & $4,07 \pm 1,09$ & 4 & 2 & 13,5 \\
\hline End & $\mathbf{n}$ & Mittelwert & Median & min. & max. \\
Anamnese & 16 & $2,96 \pm 0,99$ & 2,5 & 2 & 5 \\
\hline Grp.1 & 673 & $3,10 \pm 1,16$ & 3 & 2 & 11,5 \\
Grp.2 & 1515 & $2,90 \pm 0,95$ & 3 & 2 & 9 \\
Grp.3 & & & & & \\
\hline
\end{tabular}

Tab. 11 Sondierungstiefe innerhalb der Anamnesegruppen 1-3 bei Erst- und Nachuntersuchung.

Die Abb. 11 und Tab. 11 sollen die Sondierungstiefen der Zähne in den AnamneseGruppen verdeutlichen. Die Sondierungstiefen nehmen in der Grp. 1 um 2,56mm, in Grp. 2 um 1,03mm und in Grp. 3 um 1,17mm ab.

4.6.2 Attachmentlevel innerhalb der Ananmesegruppe

\begin{tabular}{|lccccc|}
\hline $\begin{array}{l}\text { Base } \\
\text { Anamnese }\end{array}$ & $\mathbf{n}$ & Mittelwert & Median & min. & max. \\
\hline Grp.1 & 18 & $5,63 \pm 2,62$ & 5,50 & 2,00 & 11,00 \\
Grp.2 & 207 & $4,23 \pm 1,76$ & 4,00 & 1,00 & 11,00 \\
Grp.3 & 1028 & $3,14 \pm 1,33$ & 3,00 & 0,50 & 12,00 \\
\hline End & $\mathbf{n}$ & Mittelwert & Median & min. & max. \\
Anamnese & - & - & - & - & - \\
\hline Grp.1 & 600 & $3,47 \pm 1,67$ & 3,00 & 1,00 & 15,00 \\
Grp.2 & 1301 & $3,21 \pm 1,27$ & 3,00 & 0,50 & 12,00 \\
\hline
\end{tabular}

Tab. 12 Darstellung der Durchschnittlichen Attachmentlevels in den Anamnesegruppen.

Die Tabelle 12 zeigt den Attachmentlevel in den einzelnen Anamnesegruppen. In Gruppe 1 fehlt die Panoramaaufnahme des einzigen Patienten in dieser Gruppe, weil im Rahmen dieser Untersuchung keine zusätzlichen Röntgenaufnahmen angefertigt wurden wenn sie nicht für den weiteren Behandlungsverlauf notwendig waren. 


\subsection{Raucher und ihre Rauchgewohnheiten}

\begin{tabular}{|c|c|c|c|c|}
\hline Rauchgewohnheiten & Base & & End & \\
\hline & Frauen & Männer & Frauen & Männer \\
\hline Nichtraucher (0) & 48 & 31 & 41 & 23 \\
\hline Ehemals Raucher (1) & 0 & 0 & 2 & 4 \\
\hline Raucher (2) & 6 & 7 & 11 & 11 \\
\hline
\end{tabular}

Tab. 13 Aufteilung der Patienten nach Ihren Rauchgewohnheiten.

Tabelle 13 zeigt die Aufteilung der Patienten anhand Ihrer Raucheranamnese.

\subsubsection{Zahnverlust beim Raucher (2), ehemaligen Raucher (1) und Nichtraucher (0)}

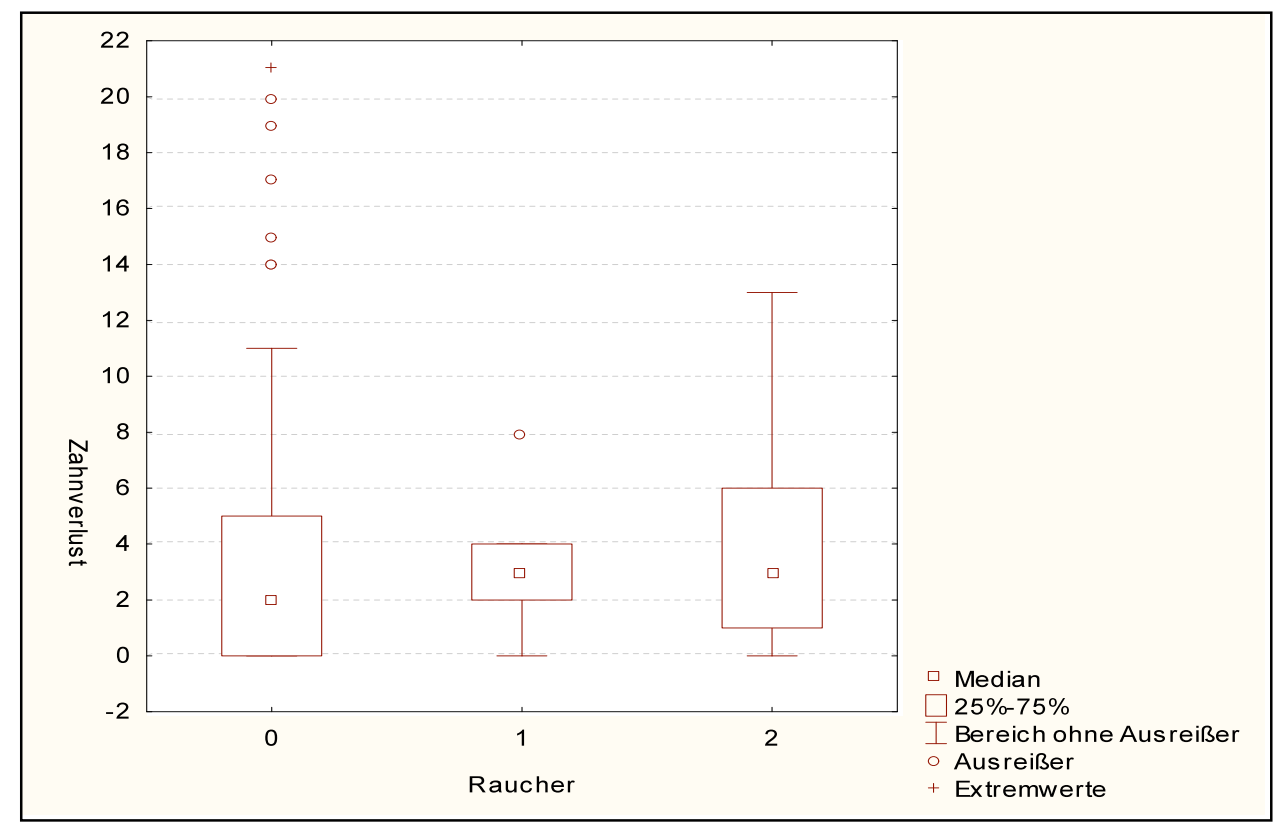

Abb. 12 Darstellung der Zahnverlustrate bei Nichtrauchern (0), ehem. Rauchern (1) und Rauchern (3).

\section{Zahnverlust}

\begin{tabular}{|cccccc|}
\hline Base & $\mathbf{n}$ & Mittelwert & Median & Min. & Max. \\
\hline Nichtraucher (0) & 79 & $3,40 \pm 4,25$ & 2 & 0 & 21 \\
ehemaliger R. (1) & 0 & - & - & - & - \\
Raucher (2) & 13 & $3,38 \pm 3,66$ & 3 & 0 & 12 \\
\hline End & $\mathbf{n}$ & Mittelwert & Median & Min. & Max. \\
\hline Nichtraucher (0) & 64 & $4,10 \pm 5,15$ & 2 & 0 & 21 \\
ehemaliger R. (1) & 6 & $3,33 \pm 2,65$ & 3 & 0 & 8 \\
Raucher (2) & 22 & $4,09 \pm 3,92$ & 3,5 & 0 & 13 \\
\hline
\end{tabular}

Tab. 14 Darstellung der Zahnverlustraten bei Rauchern im Vergleich zu Nichtrauchern und ehem. Rauchern. 
Die Abbildung 12, sowie die Tabelle 14 verdeutlichen die Zahnverlustrate, bezogen auf das Rauchverhalten der Patienten zu den Untersuchungszeiten. Die zum Zeitpunkt „base“ aufgeführten Durchschnittswerte beziehen sich auf die bis dahin schon fehlenden Zähne.

4.7.2 Sondiertiefen beim Nichtraucher, ehemaligen Raucher und Raucher

\begin{tabular}{|cccccc|}
\hline Base & $\mathbf{n}$ & Mittelwert & Median & Min. & Max. \\
\hline Nicht Raucher (0) & 1929 & $4,04 \pm 1,08$ & 4,00 & 2,00 & 13,50 \\
ehem. Raucher (1) & - & - & - & - & - \\
Raucher (2) & 329 & $4,43 \pm 1,05$ & 4,00 & 2,50 & 8,00 \\
\hline End & $\mathbf{n}$ & Mittelwert & Median & Min. & Max. \\
\hline Nicht Raucher (0) & 1530 & $2,85 \pm 0,99$ & 2,50 & 2,00 & 11,50 \\
ehem. Raucher (1) & 149 & $3,38 \pm 1,08$ & 3,00 & 2,00 & 9,00 \\
Raucher (2) & 526 & $3,18 \pm 1,02$ & 3,00 & 2,00 & 7,00 \\
\hline
\end{tabular}

Tab 15. Zeigt die Taschentiefen verteilt nach der Raucheranamnese.

4.7.3 Attachmentlevel beim Nichtraucher, ehemaligen Raucher und Raucher

\begin{tabular}{|rccccc|}
\hline Base & $\mathbf{n}$ & Mittelwert & Median & Min. & Max. \\
\hline Nicht Raucher (0) & 1078 & $3,3 \pm 1,51$ & 3,00 & 0,50 & 12,00 \\
ehem. Raucher (1) & - & - & - & - & - \\
Raucher (2) & 175 & $3,65 \pm 1,54$ & 3,00 & 2,00 & 11,00 \\
\hline End & $\mathbf{n}$ & Mittelwert & Median & Min. & Max. \\
\hline Nicht Raucher (0) & 1267 & $3,21 \pm 1,44$ & 3,00 & 0,50 & 15,00 \\
ehem. Raucher (1) & 149 & $3,35 \pm 1,45$ & 3,00 & 2,00 & 11,00 \\
Raucher (2) & 485 & $3,48 \pm 1,31$ & 3,00 & 1,00 & 12,00 \\
\hline
\end{tabular}

Tab 16. Zeigt den Attachmentlevel verteilt nach der Raucheranamnese.

Tabellen 15 und 16 zeigen den Wandel der Sondietiefe bzw. des Attachmentlevels für der Nichtraucher, ehemals Raucher und Raucher über die Nachsorgezeit von durchschnittlich 6,66 Jahren. Auffällig ist die Zunahme an Rauchern von Initial 13 auf 22 Patienten, siehe dazu auch Tabelle 13. 
4.7.4 Sondierungstiefen im Vergleich mit den Rauchgewohnheiten

\begin{tabular}{|c|c|c|c|c|c|}
\hline Base & $\mathrm{n}$ & Mittelwert & Median & $\min$. & max. \\
\hline nichtraucher & 1929 & $4,04 \pm 1,08$ & 4,00 & 2,00 & 13,50 \\
\hline$<10$ St. / Tag & 25 & $3,58 \pm 0,51$ & 3,50 & 3,00 & 5,00 \\
\hline 10-20 St. / Tag & 151 & $4,31 \pm 1,11$ & 4,00 & 2,50 & 8,00 \\
\hline >20 St. / Tag & 153 & $4,62 \pm 0,90$ & 4,50 & 3,00 & 7,00 \\
\hline End & $n$ & Mittelwert & Median & $\min$. & max. \\
\hline nichtraucher & 1533 & $2,86 \pm 0,99$ & 2,50 & 2,00 & 11,50 \\
\hline$<10$ St. / Tag & 206 & $3,00 \pm 0,96$ & 3,00 & 2,00 & 6,50 \\
\hline 10-20 St. / Tag & 328 & $3,26 \pm 1,05$ & 3,00 & 2,00 & 9,00 \\
\hline$>20$ St. / Tag & 138 & $3,36 \pm 1,14$ & 3,00 & 2,00 & 7,00 \\
\hline
\end{tabular}

Tab. 17 Zeigt die Sondierungstiefen im Verhältnis zu den Rauchgewohnheiten der Patienten.

Die Tabelle 17 zeigt die Veränderung der Sondierungstiefen bei den Nichtrauchern und Rauchern. Die Rauchergruppe ist nach ihren Rauchgewohnheiten aufgeteilt. Die Taschentiefen sinken in der Nichtrauchergruppe um 1,18mm. In der Rauchergruppe weisen die Patienten mit nur $<10$ Zigaretten/ Tag die geringste Abnahme von 0,58mm, die Patienten mit einem Zigarettenkonsum vom 10-20 St./ Tag eine Taschentiefenreduktion von 1,05mm. Die Patienten mit einem Konsumverhalten von $>20$ St./ Tag zeigen den höchsten Effekt an Taschenreduktion von 1,26mm im Vergleich zur Erstuntersuchung.

4.7.5 Attachmentlevel im Vergleich mit den Rauchgewohnheiten

\begin{tabular}{|r|ccccc|}
\hline \multicolumn{1}{|c}{ Base } & $\mathbf{n}$ & Mittelwert & Median & min. & max. \\
\hline nichtraucher & 1078 & $3,30 \pm 1,51$ & 3,00 & 0,50 & 12,00 \\
<10 St. / Tag & 25 & $2,24 \pm 0,43$ & 2,00 & 2,00 & 3,00 \\
10-20 St. / Tag & 99 & $3,88 \pm 1,62$ & 3,00 & 2,00 & 11,00 \\
>20 St. / Tag & 51 & $3,88 \pm 1,38$ & 3,50 & 2,00 & 10,00 \\
\hline End & $\mathbf{n}$ & Mittelwert & Median & min. & max. \\
\hline nichtraucher & 1270 & $3,22 \pm 1,44$ & 3,00 & 0,50 & 15,00 \\
<10 St. / Tag & 190 & $3,14 \pm 0,97$ & 3,00 & 1,00 & 7,00 \\
10-20 St. / Tag & 301 & $3,46 \pm 1,38$ & 3,00 & 1,00 & 12,00 \\
>20 St. / Tag & 140 & $3,85 \pm 1,56$ & 3,50 & 2,00 & 12,00 \\
\hline
\end{tabular}

Tab. 18 Zeigt den Attachmentlevel im Verhältnis zu den Rauchgewohnheiten der Patienten.

Die Tabelle 18 zeigt den Wandel des Attachmentlevels bei den Nichtrauchern und Rauchern. Die Rauchergruppe ist zusätzlich nach ihren Rauchgewohnheiten unterteilt. Der Attachmentlevel steigt in der Nichtrauchergruppe um 0,08mm. In der Rau- 
chergruppe zeigen die Patienten mit nur $<10$ Zigaretten/ Tag eine Verschlechterung von 0,9mm. Die Patienten mit einem Zigarettenkonsum vom 10-20 St./ Tag können einen Gewinn von 0,42 mm verzeichnen. Die Patienten mit einem Konsumverhalten von >20 St./ Tag zeigen den geringsten Fortschritt von 0,03 mm, im Vergleich zur Erstuntersuchung. 


\section{Diskussion}

Ziel der Untersuchung war es, den Behandlungserfolg von parodontal behandelten Patienten nach geschlossener Kürettage mit Ultraschall (Piezon Master 400®, Fa. EMS, Schweiz) und mehrjähriger unterstützenden Parodontitistherapie

( $\varnothing$ 6,66 Jahne) in einer zahnärztlichen Praxis, hinsichtlich langfristigem Zahnerhalt zu untersuchen. Daneben sollten Veränderungen der Taschentiefe und des Attachmentlevels verglichen werden.

\section{$\underline{5.1 \text { Bewertung des Studiendesigns }}$}

Die Hauptschwierigkeit zum Vergleich der Untersuchungen mit parodontal erkrankten Patienten liegt in den unterschiedlich großen Untersuchungsgruppen, in der Anzahl der Behandler, in der Wahl der Therapie, im Betrachtungszeitraum und in der unterschiedlichen Betrachtungsweise der Ergebnisse. Eine gewisse Fehlerquote ist aufgrund des Studiendesigns, trotz vorhergehender Kalibrierung des Untersuchers (MJ) nicht auszuschließen. Fehler bei der Messung können beim Ablesen der Sondiertiefe, bei der Schmerzprovokation durch die Sondierung, durch die Variabilität des Drucks, die Angulation der Sonde, den Entzündungsgrad des Gewebes sowie von abnormalen Wurzel- und Kronenformen abhängig sein (Janssen et al. 1988b). Bei der Sondierung von Taschentiefen ermittelten Janssen et al. (1988a), zwischen den Sondierungen unterschiedlicher Behandler eine Standardabweichung von 0,7 mm. Eine weitere Studie, ebenfalls von Janssen und Kollegen zeigte wie der Faktor Taschentiefe einen höheren Stellenwert bei der Exaktheit der Messungen der Sondiertiefe hatte, als der Faktor Blutungstendenz und so die Genauigkeit beeinflusste (Janssen et al. 1988b).

Wie in zahlreichen klinischen Studien bereits hinreichend gezeigt werden konnte hat eine regelmäßige Teilnahme an der UPT, nach erfolgter parodontaler Behandlung einen positiven Einfluss auf den Verlauf der Erkrankung (Hirschfeld \& Wasserman 1978, Mc Fall 1982, Goldman et al. 1986, Wood et al. 1989, Mc Leod et al. 1997, König et al. 2002, Checchi et al. 2002, Axelsson et al. 2004, Eickholz et al. 2008). Welchen negativen Effekt es nach sich zieht wenn sie nicht stattfindet, zeigten Becker et al. (1984). Daher wurde aus ethischen Gründen auf eine nochmalige Darstellung dieses Sachverhaltes verzichtet und nur Patienten, die regelmäßig an der 
Nachsorge teilnahmen in diese Untersuchung mit einbezogen.

Das Patientenkollektiv wurde anhand der erhobenen Anamnese in drei Gruppen geteilt. Die erste Gruppe soll die Erkrankungen beinhalten, die laut Studien den größten Einfluss auf den Verlauf der Parodontitis besitzen, wie der Diabetes Mellitus (Grossi et al. 1994, Grossi et al. 1995, Taylor et al. 1998). In Gruppe 2 wurden alle Patienten die an koronaren Herzkrankheiten, Hypertonie, Rheuma, Osteoporose leiden, zusammengefasst. Sie bildeten die Gruppe deren Erkrankungen einen geringeren Einfluss auf die Parodontitis besitzt (Wactawski-Wende 2001, Mercado et al. 2001, Lösche et al. 2004). Die Gruppe 3 umfasst alle Patienten, die entweder gesund sind oder an Krankheiten leiden, die keinen nachgewiesenen Einfluss auf die Parodontitis haben.

\subsection{Bewertung der Studienergebnisse}

\subsubsection{Zur Geschlechterverteilung}

Das Patientenkollektiv setzte sich zu 58,7\% (54) aus weiblichen und zu 41,3 \% (38) aus männlichen Patienten zusammen. Damit entspricht die Geschlechterverteilung in dieser Untersuchung der von vielen zitierten Studien (Mc Fall 1982, Goldman et al. 1986, Wood et al. 1989, Grossi et al. 1994, Grossi et al. 1995, Faggion et al. 2007).

Den Beobachtungen widersprechen allerdings die Ergebnisse, dass Männer häufiger an Parodontopathien erkranken als Frauen und die Erkrankung progredienter verläuft, was die vorliegende Studie ebenfalls belegt (Albandar 2002a, Albandar 2002b, Grossi et al. 1994, Grossi et al. 1995, DMS IV 2006).

\subsubsection{Zum Alter der Studienteilnehmer}

Das durchschnittliche Alter der Patienten lag bei 55 Jahren und liegt demnach über dem Altersbereich der zitierten Untersuchungen (Hirschfeld \& Wasserman 1978, Mc Fall 1982, Wood et al. 1989, Mc Leod et al. 1997, Checchi et al. 2002, Eickholz et al. 2008). Zahlreiche Studien belegen, wie die Anzahl an Erkrankungen mit dem Patientenalter steigt (Grossi et al. 1994 , Grossi et al. 1995). Die deutsche Mundgesundheitsstudie aus dem Jahre 2006 zeigt auf, wie bei den Erwachsenen 52,7\% der 35bis 45 -jährigen an einer mittelschweren Parodontitis erkrankt sind und $20,5 \%$ an 
einer schweren Ausprägung des Krankheitsbildes leiden. Die Seniorengruppe (65-74 Jahre) ist am Häufigsten (ca. 88\%) von der Erkrankung betroffen. Hier leiden 48,0\% unter einer mittelschweren und 39,8\% unter einer schweren Form (DMS IV 2006).

\subsubsection{Bewertung des Zahnverlustes}

Der Zahnverlust ist die wahre Kenngröße einer Parodontitistherapie an welcher der eigentliche Erfolg zu messen ist (Hirschfeld \& Wasserman 1978, König et al. 2002). In dieser Untersuchung wurden bei 92 Patienten, in einem durchschnittlichem Beobachtungszeitraum von 6,66 Jahren (min. 3 bis max. 10), 54 Zähne aus parodontalen Gründen extrahiert. Durchschnittlich hat jeder Patient 0,58 Zähne verloren. Das entspricht einer jährlichen Zahnverlustquote von 0,09 pro Patient. Diese Ergebnisse entsprechen in etwa älteren Untersuchungen, wie der von Hirschfeld \& Wassermann (1978). Die Studie umfasste 600 Patienten die über einen Zeitraum von 22 Jahren aktiv an der UPT teilnahmen. Die Zahnverlustrate belief sich auf 0,08 Zähne/ pro Patient und pro Jahr in UPT. Trotz höherer Patientenzahlen sind die Ergebnisse in etwa mit der hier vorliegenden Studie vergleichbar.

Mc Fall konnte 1982 in einer ähnlichen Untersuchung zeigen, wie 100 Patienten die über 19 Jahre regelmäßig an der UPT teilnahmen 259 Zähne aus parodontalen Gründen verloren. Über den gesamten Behandlungszeitraum gingen 299 Zähne verIoren. Pro Patient belief sich der Zahnverlust auf 0,14 Zähne/ Jahr. Allerdings beobachteten beide oben zitierten Untersuchungen ihr Patientenkollektiv über einen längeren Zeitraum, als die hier gegenwärtige Untersuchung.

Übersicht über retrospektive Langzeituntersuchungen zum Zahnverlust

\begin{tabular}{|c|c|c|c|c|c|c|c|c|}
\hline & Hirschfeld \& & Mc Fall & Goldman et al. & Wood et al. & Mc Leod et al. & Checchi et al. & Eickholz et al. & aktuelle \\
\hline & Wasserman 1978 & 1982 & 1986 & 1989 & 1997 & 2002 & 2008 & Studie 2010 \\
\hline $\mathrm{n}$ & 600 & 100 & 211 & 63 & 114 & 92 & 100 & 92 \\
\hline Alter $\varnothing$ & $42(12-73)$ & $43,8(8-71)$ & $41,8(18-67)$ & $45(24-67)$ & $53(26-79)$ & $45(28-65)$ & $46,6(15-67)$ & $55(21-77)$ \\
\hline Jahre in UPT $\varnothing$ & 22 & 19 & 22,2 & 13,6 & 12,5 & 6,7 & 10 & 6,7 \\
\hline Anzahl der Zähne & 15666 & 2627 & 5761 & 1607 & 2899 & 2180 & 2301 & 2258 \\
\hline Zahnverlust insgesamt & 1312 & 299 & 771 & 115 & 220 & 50 & 210 & 77 \\
\hline Zahnverlust nur PA & 1110 & 259 & - & 88 & 152 & 44 & - & 54 \\
\hline Zahnver. pro Jahr/Patient & 0,08 & 0,14 & 0,16 & 0,1 & 0,11 & 0,07 & 0,21 & 0,09 \\
\hline Zahnverlust pro Patient & 1,8 & 2,6 & 3,6 & 1,4 & 1,9 & 0,48 & 2,1 & 0,58 \\
\hline
\end{tabular}

Tab. 1 Langzeituntersuchungen im Überblick

In einer Untersuchung von Goldman und Kollegen (1986) prüften die Autoren den Effekt der Parodontaltherapie und des langjährigen Recall's ( $\varnothing$ 22,2 Jahre) auf den 
Zahnverlust bei 211 Patienten. Sie hatten im Vergleich mit anderen und unserer Untersuchung die höchsten Zahnverlustquoten von 3,6 Zähnen/Patient, aber auch mit die längste Beobachtungszeit. Die Zahnverlustquote bei Goldman et al. (1986) umfasste auch Zähne die nicht aus parodontalen Gründen verloren gingen. In allen oben zitierten Studien waren die OK-Molaren die Zähne mit der höchsten Verlustquote und die UK-Molaren mit der Geringsten, was sich mit den Ergebnissen unserer Studie deckt (OK-Molaren 3,97\%, UK-Molaren 1,78\%) (Hirschfeld \& Wasserman 1978, Mc Fall 1982, Goldman et al. 1986, Mc Leod et al. 1997, Gilbert et al. 1999, König et al. 2002). Die Autoren führen das auf die Tatsache zurück, dass die UKMolaren die längsten und dicksten Wurzeln zur Verankerung im Kiefer besitzen (Goldman et al. 1986) und die OK-Molaren durch die Wurzelanatomie, die schwierigere Plaqueentfernung, okklusalen Stress und iatrogene Probleme, die höchste Mortalitätsrate besitzen (Mc Fall 1982, Wood et al. 1989, Mc Leod et al. 1997).

Checchi und Kollegen (2002) stellten in Ihrer Studie fest, dass während der Beobachtungszeit von durchschnittlich 6,7 Jahren, nach parodontalchirurgischer Intervention, 44 Zähne aus parodontalen Gründen extrahiert wurden. Das entspricht einem Zahnverlust von 0,48 Zähnen pro Patient oder einer jährlichen Verlustrate von 0,07 Zähnen pro Patient. Die Beobachtungszeit sowie die Ergebnisse dieser Untersuchung decken sich mit unseren Beobachtungen. Außerdem machten die Autoren die Beobachtung, dass das Risiko für Zahnverlust um den Faktor 5,6 höher war bei Patienten die die UPT nur unregelmäßig wahrnahmen (Checchi et al. 2002).

Eickholz et al. (2008) untersuchten ebenfalls den Zahnverlust bei 100 Patienten nach aktiver parodontitis Therapie und 10 Jahren Recall. Die Patienten verloren 211 Zähne während dieser Zeit, d.h. 0,21 Zähne pro Patient jährlich. Sie erklären die höheren Werte mit der Tatsache, dass die vom Spezialisten behandelten Patienten oft zur Weiterbehandlung zu ihrem Hauszahnarzt zurückkehrten und auch die UPT nicht mehr in den Händen der Spezialisten liegt. Wenn Kontrollen stattfinden bleiben die Ursachen für den Zahnverlust oft im Verborgenen (Eickholz et al. 2008). Somit fallen Zähne im Rahmen eines prothetischen Gesamtkonzeptes neuem Zahnersatz (auch Implantaten) zum Opfer, obwohl aus parodontologischer Sicht der Zahn nicht entfernt werden müsste. Nicht zuletzt fließen die Wünsche und Bedürfnisse des Pati- 
enten und die Fähigkeiten und Erfahrung des Zahnarztes in die Therapieplanung mit ein und können das Ergebnis „Zahnverlust" positiv, wie auch negativ beeinflussen (Zaher et al. 2005, Bahrami et al. 2008).

Fazit: Der Vergleich mit der Literatur erlaubt die Schlussfolgerung, dass unsere Ergebnisse, bezogen auf den Zahnverlust mit den Resultaten anderer, exemplarisch ausgewählter Untersuchungen übereinstimmen. Durch die Ultraschalltherapie sowie die regelmäßige Nachsorge kann die Konstante „Zahnverlust“ positiv beeinflusst werden.

\subsubsection{Bewertung der Sondierungstiefen}

Die Sondierungstiefe ist eine Größe die nicht zwangsläufig als Beleg für den Erfolg der Therapie gesehen werden darf, weil mögliche falsch positive oder falsch negative Ergebnisse diese Größe beeinflussen können. Dennoch gehört die klinische Sondierung als fundamentaler Bestandteil zur parodontalen Untersuchung, weil man bei einer schlechter werdenden Erkrankung mehr Entzündungen und tiefere Taschen findet (König et al. 2002). Der Vergleich vieler Studien wird durch die gewählte Einteilung bzw. die Betrachtungsweise der Ergebnisse erschwert. Oftmals werden die Kategorien, in diesem Fall für die Sondierungstiefe, nach dem Erstbefund vorgenommen (< 4mm, 4-6 mm und > $6 \mathrm{~mm}$ ). Dabei werden aber wichtige Gesichtspunkte wie z.B. die Zahnmorphologie außer Acht gelassen. Ein Frontzahn mit einem rund bis ovalen Wurzelquerschnitt ist erfolgreicher zu therapieren als ein Oberkiefer Molar, obwohl beide vielleicht nur $4 \mathrm{~mm}$ Sondiertiefe aufweisen. Daher wurden die Zähne in dieser Untersuchung nach Zahngruppen sortiert und dann verglichen.

Die Behandlung der parodontalen Taschen mit Ultraschall bewirkte eine deutliche Taschentiefenreduktion. Die Taschentiefen betragen nach durchschnittlicher UPT von 6,66 Jahren an den Frontzähnen 2,60 mm, an den Prämolaren 2,94 mm und jeweils an den OK- und UK- Molaren 3,66 mm. Im Vergleich zur Erstuntersuchung verringerten sich die Sondierungstiefen um 1,18 mm bis 1,02 mm. Eine Untersuchung aus dem Jahre 2006 vergleicht die Taschentiefenreduktion von Handinstrumenten und Ultraschall in einer Splith-mouth-Studie. Die Autoren kamen zu dem Ergebnis, dass in der Gruppe mit moderater Parodontitis $1 \mathrm{~mm}$ an Reduktion erreicht werden konnte und bei der Gruppe mit fortgeschrittener Erkrankung $2 \mathrm{~mm} / 1,8 \mathrm{~mm}$. Die Kontrollen fanden 4 Wochen und 6 Monate nach Therapie statt. Es waren keine 
signifikanten Unterschiede zwischen den mit Handinstrumenten und Ultraschall therapierten Quadranten festzustellen (Christgau et al. 2006). Guarnelli et al. (2008) testeten den unterstützenden Einfluss von $\mathrm{CHX}$ als Adjuvans zum Ultraschalldebridement. Sie stellten eine Abnahme der Taschentiefen von 5,75 mm auf 4,62 mm nach 12 Wochen in der Kontrollgruppe und von 5,5 $\mathrm{mm}$ auf 4,25 mm in der Testgruppe fest. Dies sind ähnliche Resultate wie in unserer Untersuchung. Eine weitere Untersuchung zur Effektivität von Ultraschall in der Parodontaltherapie berichtet von einer durchschnittlichen Reduzierung der Sondierungstiefen von 0,45 mm sechs Monate nach aktiver Therapie. Die Abnahme in den Taschentiefen war in der Kategorie $\leq 4 \mathrm{~mm}$ (Initiale Taschentiefe) mit 0,11 $\mathrm{mm}$ am Geringsten und mit 2,28 $\mathrm{mm}$ in der Kategorie > $6 \mathrm{~mm}$ am Höchsten. Die Gruppe 4-6 mm hatte einen Erfolg von 1,28 mm zu verzeichnen (loannou et al. 2009). König et al. (2002) hatten nach chirurgischer Therapie und 8 Jahren Nachsorge, im Vergleich mit der vorliegenden Studie, bessere Ergebnisse im Bezug auf die Taschentiefenreduktion erzielen können. Sie konnten in der Kategorie < $4 \mathrm{~mm} 0 \mathrm{~mm}$, in Kategorie 4-6 mm 1,6 mm und in der Kategorie > $6 \mathrm{~mm}$ bis zu 4,3 $\mathrm{mm}$ Taschentiefenreduktion nach 8 Jahren UPT erreichen. Die Autoren stellten fest das zu Beginn der UPT die Sondiertiefen noch besser waren, als nach 8 Jahren UPT. In der Kategorie < $4 \mathrm{~mm}$ waren es 2,4 mm, in der Kategorie 4-6 mm 2,9 mm und in der Kategorie > $6 \mathrm{~mm} \mathrm{3,4} \mathrm{mm} \mathrm{die} \mathrm{erreicht} \mathrm{werden}$ konnten. Einen ähnlichen Effekt konnten Serino et al. (2001) ein Jahr nach nichtchirurgischer Therapie beobachten. Die Werte fielen für die Sondiertiefen von Anfangs 4,2 mm auf 3,1 mm zurück. Betrachten wir die gleichen parodontalen Taschen nach 12 Jahren UPT sehen wir eine Taschentiefenreduktion von jetzt nur 0,5 mm, von vorerst 4,2 $\mathrm{mm}$ auf 3,7 $\mathrm{mm}$ Sondiertiefe. Die Untersuchungen von Christgau et al. (2006), Guarnelli et al. (2008) und loannou et al. (2009) fassen einen verhältnismäßig kurzen Beobachtungszeitraum zusammen. Es bleibt abzuwarten in wie weit die Resultate durch die Nachsorge konstant bleiben können. König et al. 2002 und Serino et al. (2001) zeigen in ihren Studien wie die Ergebnisse im laufe der Zeit noch variieren können. Des Weiteren ist die Tatsache, dass die Reduktion der Sondierungstiefe, nach mechanischer Behandlung, eine Kombination aus Attachmentgewinn und der Zunahme an Zahnfleischrückgang ist, nicht außer Acht zulassen (Proye et al. 1982, Taggart et al. 1990, Ship et al. 1996). 


\section{$\underline{\text { 5.5.5 Bewertung des Attachmentlevels }}$}

Die Veränderungen des Attachmentlevels als voraussagbare Größe für die Parodontitistherapie ist in zahlreichen Untersuchungen belegt (Haffajee \& Socransky 1986, Reddy et al. 2000, Rosling et al. 2001).

Aus diesem Grund wurde der Attachmentlevel anhand von Panoramaaufnahmen die zum Zeitpunkt der Erstuntersuchung erstellt wurden mit denen vom Augenblick der Nachuntersuchung verglichen. Der Wert stieg in dieser Untersuchung von durchschnittlich 3,35 mm auf 3,29 mm. Betrachtet man die Ergebnisse geschlechtspezifisch, so konnte der Wert für die weiblichen Studienteilnehmer von 3,30 mm auf 3,27 $\mathrm{mm}$ steigen. Bei den Männern stieg er von anfangs 3,44 mm auf 3,33 mm nach der Beobachtungszeit an. Unsere Resultate zeigen, dass durch die systematische Parodontitistherapie und die regelmäßige Nachsorge es möglich war das Attachmentniveau über die gesamte Beobachtungszeit konstant beizubehalten.

In einer Untersuchung von Taggart et al. (1990) hatten Patienten die mit Ultraschall behandelt wurden 10 Wochen nach Behandlung durchschnittlich 0,5 mm Attachmentgewinn. Sculean et al. untersuchten bei 19 Patienten unter anderem den Erfolg einer Ultraschallkürettage auf den Attachmentlevel. Ihre Bilanz zeigte einen Attachmentgewinn, bei einwurzeligen Zähnen von 0,5-0,6 mm und bei mehrwurzeligen Zähnen eine Attachmentzunahme von 0,6-0,7 mm, nach sechs Monaten Beobachtungszeit (Sculean et al. 2004). Die zitierten Quellen haben einen, im Gegensatz zu der vorliegenden Studie, deutlichen Attachmentgewinn beobachten können allerdings nach verhältnismäßig kurzer Beobachtungszeit.

Axelsson und Kollegen zeigten in ihrer Untersuchung von 550 Patienten die sich in einem Zeitraum von 30 Jahren in der Nachsorge befanden, dass nach nicht chirurgischer Therapie ein Gewinn an Attachment von 0,3 bis 0,5 mm möglich war.

Zwischenzeitlich verzeichneten die Autoren an einigen Stellen keinen Gewinn. Sogar Attachmentverlust wurde beschrieben. Die Resultate variierten zwischen 0 und 0,4 mm Gewinn nach 30 Jahren Nachsorge (Axelsson et al. 2004). Diese Studie beschreibt einen ähnlichen Ausgang beim Attachmentlevel wie es Serino et al. (2001) und König et al. (2002) bei den Sondiertiefen beobachteten. Sie stellten fest dass nach relativ kurzer Beobachtungszeit die Werte, in diesem Fall für den Gewinn an Attachment, kurzfristig ansteigen jedoch Langzeituntersuchungen wie die von Axelsson et al. diese Erfolge nach unten korrigieren. Betrachten wir den Attachmentlevel innerhalb der Zahngruppen stellen wir den gleichen Effekt fest wie Reddy und Kolle- 
gen in ihrer Untersuchung. Sie zeigten, dass die Gruppe der OK-Molaren den größten Attachmentverlust aufwies, was sich mit unseren Beobachtungen deckt (Reddy et al. 2000). Die Messungen für die Bestimmung des Attachmentlevels erfolgten anhand von Panoramaschichtaufnahmen (PSA) nach der direkten Millimetermethode (Pepelassi et al. 2000). Die Bestimmung des Attachmentlevels an Röntgenbildern dient oft als Ersatz für die Messung während chirurgischer Maßnahmen (Zybutz et al. 2000). Zahlreiche Untersuchungen befassten sich mit der Sensitivität von Röntgenaufnahmen in Bezug auf den parodontalen Knochenabbau (Hämmerle et al. 1990, Akesson et al. 1992, Pepelassi \& Diamanti-Kipioti 1997, Pepelassi et al. 2000, Zybutz et al. 2000). Die Autoren kamen zu dem Schluss, dass die periapicalen Röntgenbilder 4,7 mal erfolgreicher in der Auffindung von ossären Defekten waren als PSA (Pepelassi \& Diamanti-Kipioti 1997, Pepelassi et al. 2000). Zudem war die Form der Kiefer (OK oder UK), die Zahngruppe (Morphologie), die mesial / distal Fläche als mögliche Fehlerquellen bei der PSA-Technik aufgefallen. Der Hauptgrund jedoch war das Überlappen der mesial / distal Flächen (2,3 mal höher als bei periapicalen Röntgenbildern) der das Auffinden der SZG erschwerte und die Messung negativ beeinflusste (Pepelassi \& Diamanti-Kipioti 1997). Hämmerle et al. stellten fest, dass bei stark fortgeschrittener Parodontitis die Aussage von Röntgenbilden überschätzt wurde (Hämmerle et al. 1990). Zudem ist die Auswertung der Röntgenbilder stark behandlerabhängig. Akesson et al. ließen ihre Röntgenbilder von 5 Gutachtern analysieren und stellten deutliche Unterschiede in den Ergebnissen fest. Ihre Forderung lautete, dass Röntgenbilder von mehr als 2 Gutachtern bewertet werden sollten (Akesson et al. 1992), welche in dieser Untersuchung jedoch nicht erfüllt wird. Obwohl die radiologische Bewertung des Alveolarlevels, aufgrund der 2-dimensionalen Abbildung eines drei-dimensionalen Ausmaßes der ossären Defekte, nie die tatsächliche Situation erfassen wird (Hämmerle et al. 1990), ist dennoch die Panoramaaufnahme ein gutes, schnelles und einfaches Instrument der Diagnostik um Knochendefekte darzustellen. Diese können in ausgewählten Bereichen für eine detailliertere Diagnostik durch die Anwendung von Zahnfilmen erweitert werden (Akesson et al. 1992). In dieser Untersuchung wurde für die Recherche auf das Praxisarchiv zurückgegriffen und die vorhandenen Panoramaaufnahmen verwendet. Im Rahmen dieser Untersuchung wurden keine zusätzlichen Aufnahmen angefertigt, wenn sie nicht für die weitergehende Behandlung benötigt wurden. 
5.2.6 Bewertung der Einflussnahme der Allgemeinerkrankungen auf die Parodontitis Von den 92 Studienteilnehmern konnte ein Patient (0.92\%) der Anamnesegrp. 1 zugeordnet werden und litt an Diabetes mellitus Typ II. Laut der Gesundheitsberichterstattung des Bundes (www.gbe-bund.de) leiden 10\% (ca. 8 Millionen) der Bevölkerung in der Bundesrepublik Deutschland an dieser Erkrankung. Zahlreiche Untersuchungen belegen die Wechselwirkungen zwischen der Parodontitis und dem Diabetes mellitus, sei es die schlechtere Wundheilung oder die auffällig stärker verlaufende Entzündungsreaktion. Schlecht eingestellte Diabetiker weisen ein um dreifach erhöhtes Risiko auf an einer Parodontitis zu erkranken (Grossi et al. 1994, Grossi et al. 1995, Taylor et al. 1998, Plagmann 1998, Mealey 2006). Aufgrund der Größe der Anamnesegrp.1 ist die Aussage der Ergebnisse eher begrenzt, weil diese nicht repräsentativ sind. Der Anamnesegrp. 2 wurden bei der Erstuntersuchung 16 und in der Nachuntersuchung 29 Patienten zugeteilt. Sie litten an koronaren Herzkrankheiten (KHK), Hypertonie, Rheuma oder Osteoporose. Diesen Erkrankungen wird laut weitreichender Untersuchungen ebenfalls eine Einflussnahme auf die Parodontitis zugesprochen. So spielt die Bakteriämie von parodontopathogenen Keimen bei der Entstehung von atherosklerotischen Plaques eine Rolle (Lösche et al. 2004, Chun et al. 2005). In einer Untersuchung von Mercando et al. (2001) gibt es einen nachweisbaren Einfluss der Parodontitis und der rheumatoiden Arthritis (Mercando et al. 2001). Jeffcoat zeigte in einer Literaturübersicht aus 15 Studien, die sich mit den Wechselbeziehungen zwischen Parodontitis und Osteoporose befassten, wie 13 davon über alveolaren Knochenverlust berichteten (Jeffcoat 2005). Die Sondierungstiefe in der Anamnese-Grp. 2 sinkt von anfangs 4,13 mm auf 3,10 $\mathrm{mm}$ nach UPT. Der Attachmentlevel steigt in dieser Gruppe von Initial 4,23 mm auf 3,47 mm. Bei einem Vergleich mit der Anamnese-Grp. 3 wird ein geringer Unterschied deutlich. Ob dieser von dem Einfluss der rheumatoiden Arthritis, den KHK, Hypertonie oder der Osteoporose herrührt ist fraglich und sollte in weiter reichenden Untersuchungen eindeutiger herausgearbeitet werden.

Die größte Anamnesegruppe bilden die Patienten mit Erkrankungen die keinen nachweisbaren Einfluss auf die Parodontitis nehmen oder gesund sind. Die Gruppengröße sinkt von Initial 75 Patienten auf 62. Die Sondierungstiefen sinken ebenfalls von durchschnittlich 4,07 $\mathrm{mm}$ auf 2,90 $\mathrm{mm}$. Das Attachmentniveau nimmt in dieser Gruppe von 3,14 mm auf 3,21 mm zu. 
Fazit : Ein Einfluss, der o. g. Allgemeinerkrankungen auf die Ergebnisse ist nicht erkennbar. Auch ein direkter Vergleich der Anamnesegruppen untereinander ist nicht möglich, auf Grund der stark variierenden Gruppengröße.

\subsubsection{Bewertung der Zahnprognose/ des Patientenrisikos}

Die Behandlungsplanung steht am Beginn jeder Therapie und ist wohl einer der wichtigsten Schritte in der Behandlung. Der Behandler entscheidet welche Zähne therapiert werden können und welche nicht. Dafür benötigt er evidenzbasierte Kriterien die ihm die Entscheidung erleichtern. Fehleinschätzungen von Zahnprognosen führen zu unnötigen Kosten (Faggion et al. 2007). Hirschfeld \& Wasserman (1978) zeigten in Ihrer Untersuchung, dass nur 16,6\% der Unterkiefer-Molaren mit Furkationsbefall in der „Well - maintained“- Gruppe ( $n=499$ Patienten) extrahiert wurden. Mit dem Wissen um dieses Ergebnis können diese Zähne als Stützpfeiler für die Prothetik herangezogen werden.

Zu Beginn unserer Auswertung wurden den Zähnen Prognosen von sehr gut bis schlecht, in Anlehnung an die Studie von Mc Guire und Nunn (1996), zugeordnet (siehe 3.5 S. 39). Unter der Fragestellung, wie sich die Therapie und die 6,66 jährige Nachsorge auf die Zahnprognosen auswirkt verzeichneten wir in der Gruppe der Frontzähne eine 66 \% Verbesserung der Zahnprognosen. In der Prämolaren-Gruppe verbesserten sich bei 64 \% der Zähne die Prognosen, die Zähne in der Gruppe der OK-Molaren erreichten eine Besserung von 51,4 \%. In der Gruppe der UK-Molaren registrierten wir bei 51,6 \% der Zähne eine günstigere Prognose als zu Beginn der Untersuchung. Betrachtet man alle untersuchten Zähne, so verschlechtern sich insgesamt 8,59\% in ihrer Prognose. 29,64\% der Parodontien bleiben in ihrer Prognose unverändert und 61,79\% können durch die Behandlung und das UPT verbessert werden.

Mc Guire \& Nunn (1996) und Hirschfeld \& Wasserman (1978) betrachteten in ihren Untersuchungen, zu den Risikofaktoren für Zahnverlust, nur zahnbezogene Befunde. Patientenbezogene Faktoren wie das Alter, das Geschlecht, Allgemeinerkrankungen und das Rauchverhalten spielen jedoch ebenfalls eine wichtige Rolle für den Zahnverlust (Albandar 2002 a/b). Aus diesem Grund fassten wir zahn- und patientenbezogene Befunde in dem Risikomodell nach Lang \& Tonetti (2003) zusammen und konnten eine ähnlich positive Tendenz bei der Entwicklung des Patientenrisikos beobachten. Das Risikomodell nach Lang \& Tonetti wurde von uns um den Faktor 
„Recallfrequenz“ erweitert, weil einige Untersuchungen belegen wie durch regelmäßige UPT langfristig Erfolge erzielt werden (Lindhe \& Nyman 1984, Axelsson 2004) und diese ausbleiben wenn sie nicht stattfindet (Becker et al. 1984). Die Gruppe der Studienteilnehmer, die zu Beginn der Untersuchung über ein hohes Risiko erneut an einer Parodontitis zu erkranken verfügten, konnte von $17(17,48 \%)$ auf $7(7,61 \%)$ Patienten schrumpfen. Die mittel Risiko-Gruppe konnte von Anfangs $63(68,48 \%)$ auf 49 (46,74\%) Mitglieder sinken. Die Gruppe mit dem geringsten Risiko hatte den größten Zuwachs zu verbuchen. Sie wuchs von Initial 12 (13,04\%) auf 42 Patienten $(45,65 \%)$ an. Leider ist nach intensiver Literaturrecherche keine Quelle bekannt in der die vielfach zitierten Untersuchungen von Mc Guire \& Nunn (1996) und Lang \& Tonetti (2003) zur Anwendung kommen. Die Studien die sich mit Zahnverlust befassen zielen darauf ab Risikofaktoren für den Zahnverlust aufzuzeigen (Hirschfeld \& Wasserman 1978, McFall 1982, Goldman et al. 1985, Wood et al. 1989, McLeod et al. 1997, Gilbert et al. 1999, König et al. 2002, Faggion et al. 2007, Bahrami et al. 2008, Eickholz et al. 2008, Pretzl et al. 2008). Keine bekannte Untersuchung verdeutlich wie sich die Zahnprognosen / das Patientenrisiko durch Behandlung der Parodontitis und regelmäßiger Nachsorge beeinflussen lassen.

\subsubsection{Bewertung des Rauchverhaltens auf den Krankheitsverlauf}

Die Untersuchung des Einflusses des Rauchverhaltens auf den Zahnerhalt ergab keinen Unterschied zwischen der Gruppe der Nichtraucher (NR) und der Raucher (R). Beide verloren im Durchschnitt 4,10 und 4,09 Zähne. Einzig die Gruppe der ehemaligen Raucher (ER) hatte einen Zahnverlust von 3,33 Zähnen vorzuweisen. Der NR weist eine Taschentiefenreduktion von 1,19 mm auf. Der R eine Abnahme an Sondiertiefe von 1,25 mm, im Vergleich mit anderen Studien ist der Unterschied jedoch marginal. Ähnliche Ergebnisse können wir auch bei der Betrachtung des Attachmentlevels beobachten. Bei dem NR kann der Attachmentlevel von 3,30 mm auf 3,21 mm steigen, ähnlich wie beim $\mathrm{R}$ ist der Gewinn an Attachment, von 3,65 mm auf 3,48 mm als eher gering zu bewerten. Die meisten Studien können deutliche Unterschiede im Erkrankungsverlauf zwischen Rauchern und Nichtrauchern herausarbeiten, was mit unseren Beobachtungen nicht im Einklang steht (Österberg \& Mellström 1986, Krall et al. 1997, Bergström et al. 2000, Scabbia et al. 2001, König et al 2002, Labriola et al. 2005 ). In einer Untersuchung aus dem Jahre 2001 zeigten Haffajee und Socransky, dass Rauchen einen signifikanten Einfluss auf den Zahn- 
verlust, die Taschentiefen und das Attachmentniveau besitzt. Sie untersuchten 289 Patienten. Die Raucher unter ihnen hatten einen durchschnittlichen Zahnverlust von 3,4 Zähnen. Die ehemaligen Raucher verloren 2,8 Zähne und dem Nichtraucher fehlten im Schnitt 2,1 Zähne. Die Taschentiefen lagen bei den Rauchern im Durchschnitt bei 3,47 $\mathrm{mm}$, die ehemals Raucher hatten 3,27 mm vorzuweisen und die Nichtraucher 3,15 mm. Der Attachmentverlust lag beim Raucher 0,7 mm höher, als der von Nichtrauchern. Unsere Ergebnisse liegen über den aus der Studie von Haffajee \& Socransky (2001).

Eine weitere Untersuchung welche die Wirkung des Tabakkonsums auf die Effektivität der Parodontalbehandlung untersuchte, stellte fest, dass Raucher im Vergleich mit Nichtrauchern signifikant weniger Taschentiefenreduktion und geringeren Attachmentgewinn aufwiesen. Raucher hatten durchschnittlich 0,5 mm weniger Attachmentgewinn und Taschentiefenreduktion im Vergleich zum Nichtraucher (Ah et al. 1994). Preber \& Bergström zeigten in Ihrer Untersuchung an 4959 Parodontien, nach nicht-chirurgischer Therapie, wie die Taschentiefen von vorerst durchschnittlich 4,5 $\mathrm{mm}$ auf 3,37 $\mathrm{mm}$ beim Raucher und von 4,45 $\mathrm{mm}$ auf 3,22 $\mathrm{mm}$ beim Nichtraucher reduziert wurden. Die Autoren fanden heraus, dass $80 \%$ der Raucher sowie 84\% der Nichtraucher eine Taschentiefenreduktion vorweisen konnten (Preber \& Bergström 1986).

Auffällig in unserer Untersuchung war die Zunahme der Raucher über die Beobachtungszeit, von Initial 13 auf 22 Patienten mit positiver Raucheranamnese. Über eine Erklärung dieser Tatsache kann nur spekuliert werden. Sie kann in der eventuellen Nachlässigkeit beim ersten Anamnesegespräch oder der für den Patienten nicht ganz durchschaubaren Weitläufigkeit der Erkrankung beim Erstbefund liegen. Die Unterstellung der Falschaussage ist zwar bekannt aber hier nicht berechtigt, weil sich die Patienten in einer regelmäßigen und jahrelangen Nachsorge befinden und ein Vertrauensverhältnis aufbauen.

\section{$\underline{\text { Fazit }}$}

Die Resultate entsprechen den Ergebnissen aus älteren, hier zitierten Untersuchungen und zeigen, wie erfolgreich die Ultraschall-Kürettage im Hinblick auf Zahnverlust, die Taschentiefenreduktion und den Attachmentlevel ist. Für den langfristigen Erhalt des Parodontiums spielt die Nachsorge bzw. die unterstützende Parodontitis- 
therapie (UPT) eine wichtige Rolle. Untersuchungen beweisen, dass kurzfristige Erfolge ohne Nachsorge nicht von Dauer sind (Becker et al. 1984, Serino et al. 2001, König et al. 2002). 


\section{Zusammenfassung}

In dieser Untersuchung sollte geklärt werden, wie erfolgreich die konservative Parodontaltherapie mit Ultraschall und die Nachsorge in einer privatzahnärztlichen Praxis durchgeführt werden kann. Die relevanten Patientendaten wurden dem Patienten archiv der Praxis entnommen und zusammen mit den Ergebnissen einer aktuellen Untersuchung verglichen. Untersucht werden sollten klinische Parameter wie, Zahnverlust, Sondierungstiefe und Attachmentlevel. Die Resultate lassen sich wie folgt zusammenfassen: An der Nachuntersuchung nahmen 92 Patienten (54 Frauen und 38 Männer) mit einem durchschnittlichen Alter von 55 Jahren teil. Untersucht und therapiert wurden 2258 Parodontien. Die Patienten wurden vor mindestens 3 bis 10 Jahren einer systematischen Parodontalbehandlung unterzogen und werden bis heute in regelmäßiger Nachsorge ( $\varnothing$ 6,66 Jahre) betreut. In dem Beobachtungszeitraum konnten 54 Zähne aufgrund von Parodontitis nicht therapiert werden und mussten extrahiert werden. Im Schnitt verlor jeder Patient 0,58 Zähne im gesamten Beobachtungszeitraum. Das entspricht einer jährlichen Zahnverlustquote von 0,09 pro Patient. Die Initiale Sondierungstiefe lag bei durchschnittlich 4,09 mm und konnte auf 2,96 mm durch die Therapie und Nachsorge reduziert werden. Die Auswertung des Attachmentlevels lag bei der Erstuntersuchung bei 3,35 mm und konnte über den Beobachtungszeitraum konstant auf 3,29 mm (Nachuntersuchung) gehalten werden. Die Auswertung der nach Allgemeinerkrankungen unterteilten Studiengruppen ergab keinen nachweisbaren Einfluss der Anamnese auf den Krankheitsverlauf.

Das Patientenrisiko erneut an einer Parodontitis zu erkranken konnte durch die Therapie und jahrelange Nachsorge deutlich gesenkt werden. In der „niedrig Risiko“ Gruppe sind zum Zeitpunkt „Base“ 12 (13,04\%) Patienten gezählt worden. Zum Zeitpunkt „End“ sind es bereits 42 Patienten (45,65\%) die eine niedrige Prognose bezüglich einer Neuerkrankung aufweisen. In der „mittel Risiko“- Gruppe sinken die Patientenzahlen von Anfangs 63 (68,48\%) auf 43 (46,74\%) zum Zeitpunkt der Nachuntersuchung. Die Anzahl der „hoch Risiko“- Patienten nimmt von 17 (17,48\%) auf 7 $(7,61 \%)$ ab. Einen ähnlichen Effekt erzielte die Therapie und Nachsorge auf die Zahnprognosen. So konnten in der Gruppe der Frontzähne 66 \% der Zähne ihre Prognose verbessern, $64 \%$ in der Gruppe der Prämolaren, $51 \%$ in der Gruppe der Oberkiefer Molaren und ebenfalls $51 \%$ der Unterkiefer-Molaren. Eine Risikoanalyse ergab, dass das Alter einen signifikanten Einfluss $(p=0,01)$ auf den Zahnverlust 
hatte. Die Ergebnisse dieser Untersuchung machen deutlich, wie erfolgreich eine systematische Parodontaltherapie und eine konsequente Nachsorge sein können. 


\section{Anhang}

\subsection{Patienten Erfassungsbogen}

1. Baseline Pat.-Nr.: Datum:

Anamnese:

Medikation:

Raucher:

Mundhygiene u. Recallverhalten

\begin{tabular}{|c|l|l|l|l|l|}
\hline Jahr & zst & IP/ TBP Plaque Index & Jahr & zst & IP/TBP Plaque Index \\
\hline 1998 & & & 2004 & & \\
\hline 1999 & & & 2005 & & \\
\hline 2000 & & & 2006 & & \\
\hline 2001 & & & 2007 & & \\
\hline 2002 & & & 2008 & & \\
\hline 2003 & & & & & \\
\hline
\end{tabular}

\section{Risikogruppe:}

\begin{tabular}{|c|c|c|c|c|c|c|c|c|c|c|c|c|c|c|c|}
\hline $\mathrm{AL}$ & & & & & & & & & & & & & & & $\mathrm{AL}$ \\
\hline TT & & & & & & & & & & & & & & & TT \\
\hline FB & & & & & & & & & & & & & & & FB \\
\hline B & & & & & & & & & & & & & & & B \\
\hline & 7 & 6 & 5 & 4 & 3 & 2 & 1 & 1 & 2 & 3 & 4 & 5 & 6 & 7 & \\
\hline B & & & & & & & & & & & & & & & B \\
\hline FB & & & & & & & & & & & & & & & FB \\
\hline TT & & & & & & & & & & & & & & & TT \\
\hline $\mathrm{AL}$ & & & & & & & & & & & & & & & $\mathrm{AL}$ \\
\hline
\end{tabular}




\section{Paro-Behandlung:}

Mikrobiologische Untersuchung:

Wann:

Keime:

\section{Nachuntersuchung}

Anamnese:

Medikation:

Raucher:
Antibiose:

Sonstiges:

Datum:

\begin{tabular}{|c|c|c|c|c|c|c|c|c|c|c|c|c|c|c|c|}
\hline Rez & & & & & & & & & & & & & & & Rez \\
\hline LG & & & & & & & & & & & & & & & LG \\
\hline $\mathrm{AL}$ & & & & & & & & & & & & & & & $A L$ \\
\hline TT & & & & & & & & & & & & & & & TT \\
\hline $\mathrm{FB}$ & & & & & & & & & & & & & & & FB \\
\hline B & & & & & & & & & & & & & & & B \\
\hline & 7 & 6 & 5 & 4 & 3 & 2 & 1 & 1 & 2 & 3 & 4 & 5 & 6 & 7 & \\
\hline & & & & & & & & & & & & & & & \\
\hline B & & & & & & & & & & & & & & & B \\
\hline $\mathrm{FB}$ & & & & & & & & & & & & & & & FB \\
\hline TT & & & & & & & & & & & & & & & TT \\
\hline $\mathrm{AL}$ & & & & & & & & & & & & & & & $\mathrm{AL}$ \\
\hline LG & & & & & & & & & & & & & & & LG \\
\hline Rez & & & & & & & & & & & & & & & Rez \\
\hline
\end{tabular}




\subsection{Bogen zur Auswertung von Röntgenbildern}

Patienten-Nr.:

OPG vom

\begin{tabular}{|c|c|c|c|c|c|c|c|c|c|c|c|c|c|c|c|}
\hline $\mathrm{mm}$ & & & & & & & & & & & & & & & $\mathrm{mm}$ \\
\hline 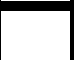 & 7 & 6 & 5 & 4 & 3 & 2 & 1 & 1 & 2 & 3 & 4 & 5 & 6 & 7 & \\
\hline $\mathrm{mm}$ & & & & & & & & & & & & & & & $\mathrm{mm}$ \\
\hline
\end{tabular}

OPG vom

\begin{tabular}{|c|c|c|c|c|c|c|c|c|c|c|c|c|c|c|c|}
\hline $\mathrm{mm}$ & & & & & & & & & & & & & & & $\mathrm{mm}$ \\
\hline . & 7 & 6 & 5 & 4 & 3 & 2 & 1 & 1 & 2 & 3 & 4 & 5 & 6 & 7 & \\
\hline $\mathrm{mm}$ & & & & & & & & & & & & & & & $\mathrm{mm}$ \\
\hline
\end{tabular}




\subsection{Anamnese}

Patienten-Nr:

Datum:

Rauchen Sie ?

Nein $\square \quad$ Ja $\square$, Anzahl __ I Tag

Allergien ?

Nein $\square \quad$ Ja $\square$,

Diabetes ?

Nein $\square \quad$ Ja $\square$

Herzerkrankungen ?

Nein $\square \quad$ Ja $\square$,

Organtransplantation ?

Nein $\square \quad$ Ja $\square$

Immunsuppression?

Nein $\square \quad$ Ja $\square$

Rheuma ?

Nein $\square \quad$ Ja $\square$

Osteoporose?

Nein $\square \quad$ Ja $\square$

Nerven - oder Anfallsleiden ?

Nein $\square \quad$ Ja $\square$

Infektionskrankheiten ?

( HIV, Hepatitis, Geschlechtskrankheiten )

Nein $\square \quad$ Ja $\square$

Nierenerkrankungen ?

Nein $\square \quad$ Ja $\square$

Schwangerschaft?

Nein $\square \quad$ Ja $\square$

Sonstige Erkrankungen ?

Nein $\square \quad$ Ja $\square$

Wenn „Ja“ welche:

Medikamente: 


\subsection{Patientenaufklärung}

Prof. Dr. med. dent. Rainer F. Mausberg

Georg-August-Universität Göttingen, Zentrum Zahn-, Mund- und Kieferheilkunde; Abteilung Zahnerhaltung und Präventive Zahnheilkunde und Parodontologie; Robert-Koch-Str. 40, 37075 Göttingen; Tel.: 0551/3922877

\section{Patientenaufklärung}

\section{„Eine Nachuntersuchung von parodontal Behandelten / Recallpatienten in einer privatzahnärztlichen Praxis "}

Sehr geehrte Patientin, sehr geehrter Patient!

Gesundheit beginnt im Mund! Keine andere Erkrankung im Mund hat so weitreichende Auswirkungen auf den Organismus wie die Parodontitis, häufig „Parodontose“ genannt.

Damit sich eine Parodontitis entwickelt, sind Bakterien aus dem Zahnbelag (Plaque) erforderlich. Die Parodontitis ist eine Erkrankung der zahnumgebenden Strukturen, dazu gehört das Zahnfleisch, der Kieferknochen und die Wurzelhaut mit dem Wurzelzement, das für die Aufhängung des Zahnes im Knochenfach verantwortlich ist. Die Plaque, oder auch Biofilm, kann nur mechanisch entfernt werden. Dies geschieht im Rahmen einer gewissenhaften häuslichen Mundhygiene und professionellen Zahnreinigung. Wird der Biofilm nicht konsequent entfernt bildet sich schon nach wenigen Tagen eine Gingivitis (Zahnfleischentzündung). Bei richtiger Behandlung ist diese vollständig reversibel und es resultiert kein weiteres Voranschreiten der Erkrankung. Verbleibt dieser bakterielle Reiz entwickelt sich eine Parodontitis. Patienten bemerken oft das die Zähe „länger“ werden, kälteempfindlich, Zähne „wackeln“, Zahnwanderungen sind auch nicht selten, schlechter Geschmack und Geruch entstehen. Über Zahnschmerzen berichtet aber keiner dieser Patienten. Wir wissen, dass eine frühe Erkennung Zahnverlust vorbeugt und somit Lebensqualität sichert. Gesunde Zähne bis ins hohe Alter! Im Rahmen dieser wissenschaftlichen Untersuchung sollen Patienten nachuntersucht werden, die in den vergangenen 2-8 Jahren hinsichtlich einer Parodontitis behandelt worden sind. Untersucht werde soll, wie erfolgreich die Therapie langfristig war, d.h. wie viele Zahne erhalten werden konnten und wie sich die Zahnfleischtaschen über den langen Zeitraum verändert haben. Im Rahmen dieser Untersuchung erhalten sie Informationen über Ihren oralen Gesundheitszustand, Ihren Persönlichen Behandlungserfolg und werden zukünftig noch intensiver in das Nachsorge Programm integriert.

Risiken und Nebenwirkungen bei der Durchführung der Untersuchung sind nicht zu erwarten, da keine Medikamente oder operative Eingriffe notwendig sind. Ihre Patientendaten werden anonymisiert behandelt und nur zu Untersuchungszwecken verwendet. Die Nachuntersuchung dauert etwa 20 min. und ist nicht mit zusätzlichen Kosten verbunden.

Wir bitten um die freiwillige Teilnahme an der Studie. Sie können jederzeit die Teilnahme widerrufen, ohne Angabe von Gründen und ohne Nachteile erwarten zu müssen.

Ich wurde persönlich über diese Studie aufgeklärt und habe den Aufklärungsbogen erhalten. 


\subsection{Anschreiben an die Patienten}

Herr Michael Jablonski

02. Okt. 2008

Musterstraße 22

35756 Musterstadt

Sehr geehrter Herr Patient

Ihre Zahnarztpraxis Dr. Peter Kröncke nimmt an einer wissenschaftlichen Untersuchung der Zahnklinik der Georg-August-Universität Göttingen teil. Dabei werden Patienten nachuntersucht, die über einen langen Zeitraum in unserer Praxis prophylaktisch (professionelle Zahnreinigung) betreut wurden und bei denen eine Parodontalbehandlung (Zahnfleischbehandlung) durchgeführt worden ist. Die dabei erhobenen Daten werden gesammelt und im Hinblick auf die erfolgreiche Behandlung von Parodonthopathien ausgewertet.

Die Teilnahme ist freiwillig und macht eine einmalige Nachuntersuchung der durchgeführten Parodontalbehandlung notwendig. Die Untersuchung beinhaltet eine „normale“ zahnärztliche Untersuchung und das Erheben eines Parodontalstatus (Taschentiefenmessung); also ein ganz gewöhnlicher Kontrolltermin bei ihrem Zahnarzt. Die Nachuntersuchung ist für Sie mit keinerlei Kosten und Unannehmlichkeiten verbunden. Sollten sie dieses Jahr schon einmal beim Zahnarzt zur Kontrolluntersuchung gewesen sein, bitten wir sie, diese im Rahmen unserer wissenschaftlichen Untersuchung zu wiederholen.

Die Untersuchungstermine werden von Oktober 2008 bis Februar 2009 während der bekannten Sprechzeiten durchführt. Bitte geben Sie der Sprechstundenhilfe einen Hinweis am Telefon, wenn Sie einen Termin ausmachen möchten.

Wir würden uns sehr freuen, wenn Sie uns bei unserem Vorhaben unterstützen würden.

Als Anlage finden sie die Patientenaufklärung, bitte bringen sie diese unterschrieben zu ihrem persönlichen Termin mit.

Mit besten Grüßen 


\subsection{Einwilligung zur Untersuchung}

Prof. Dr. med. dent. Rainer F. Mausberg

Georg-August-Universität Göttingen, Zentrum Zahn-, Mund- und Kieferheilkunde; Abteilung Zahnerhaltung; Präventive Zahnheilkunde und Parodontologie; Robert-Koch-Str. 40, 37075 Göttingen; Tel.: 0551/3922877

\section{Einwilligungserklärung in die Teilnahme an der}

\section{„Eine Nachuntersuchung von parodontal Behandelten / Recallpatienten} in einer privatzahnärztlichen Praxis“"

Ich, wurde von meinem Arzt vollständig über Wesen, Bedeutung und

Tragweite der klinischen Untersuchung mit dem Titel:

„Eine Nachuntersuchung von parodontal Behandelten / Recallpatienten in einer privatzahnärztlichen Praxis “

aufgeklärt.

Mir ist bekannt, dass bei dieser Untersuchung personenbezogene Daten, insbesondere der medizinische Befund über mich erhoben, gespeichert und ausgewertet werden sollen. Die Verwendung der Angaben über meine Gesundheit erfolgt nach gesetzlichen Bestimmungen und setzt vor der Teilnahme an der Klinischen Prüfung die folgende freiwillig abgegebene Einwilligungserklärung voraus.

Ich habe den Aufklärungstext gelesen und verstanden. Ich hatte die Möglichkeit, Fragen zu stellen, und habe die Antworten verstanden und akzeptiere diese. Mein Arzt hat mich über die mit der Teilnahme an der Studie verbundenen Risiken und den möglichen Nutzen informiert.

Ich hatte ausreichend Zeit, mich zur Teilnahe an dieser Untersuchung zu entscheiden und weiß, dass die Teilnahme freiwillig ist.

Mir ist bekannt, dass ich jederzeit und ohne Angaben von Gründen diese Zustimmung widerrufen kann, ohne dass sich dieser Entschluss nachteilig auswirkt.

Ich habe eine Kopie der Patienteninformation und dieser Einwilligungserklärung erhalten.

Ich erkläre hiermit meine freiwillige Teilnahme an dieser Studie. 


\section{Literaturverzeichnis:}

Aass, A, M., Rossow, I., Preus, H. R., Gjermo, P. (1994): Incidence of Early Periodontitis in a Group of Young Individuals During 8 Years: Association With Selected Potential Predictors. J Periodontol 65 (9), 814-819

Ah, M.K.B., Johnson, G.K., Kaldahl, W.B., Patil, K.D., Kalkwarf, K.L. (1994):

The effect of smoking on the response to periodontal therapy. J Clin Periodontol 21, 91-97

Akesson, L., Hakansson, J., Rohlin, M. (1992): Comparison of panoramic and Intraoral radiography and pocket probing fort he measurement of the marginal bone level. J Clin Periodontol 19, 326-332

Albandar, J. M. (2002a): Periodontal diseases in North America. Periodontol 2000 29, 31-69

Albandar, J. M. (2002b): Global risk factors and risk indicators for periodontal diseases. Periodontol 2000 29, 177-206

Albandar, J. M., Rams, T.E. (2002): Global epidemiology of periodontal diseases: an overview. Periodontol 2000 29, 7-10

Albandar, J. M., Brown, L.J., \& Löe, H. (1997): Putative Periodontal Pathogens in Subgingival Plaque of Young Adults With and Without Early-Onset Periodontitis. J Periodontol 68, 973-981

Albandar, J. M., DeNardin, A. M., Adesanya, M. R., Diehl, S. R., Winn, D. M. (2001): Associations between serum antibody jevels to periodontal pathogens and early-onset periodontitis. J Periodontol 72 (11), 1463-1469

Arendorf, TM., Bredekamp, B., Cloete, C.A., Sauer, G. (1998): Oral manifestations of HIV infection in 600 South African patients. J Oral Pathol Med 27, 176-179 
Armitage, G.C. (1999): Development of a classification system for periodontal disea se and conditions. Ann Periodontol 4, 1-6

Armitage, G.C., Wu, Y., Wang, H.Y., Sorrell, J., di Giovine, F.S., \& Duff, G.W. (2000): Low prevalence of a periodontitis-associated interleukin-1 composite genotype in individuals of Chinese heritage. J Periodontol 71, 164-171

Armitage, G.C. (1999): Development of a classification system for periodontal disea se and conditions. Ann Periodontol 4, 1-6

Axelsson, P., Nyström, B., Lindhe, J. (2004): The long-therm effect of plaque control program on tooth mortality, caries and periodontal disease in adults. Results after 30 years of maintance. J Clin Periodontol 31, 749-757

Badersten, A., Nilvéus, R., Engelberg, J. (1981): Effect of nonsurgical periodontal therapy I. Moderately advanced periodontitis.

J Clin Periodontol 8, 57-72

Baehni, P., Thilo, B., Chapuis, B., Pernet, D. (1992): Effects of ultrasonic and sonic scalers on dental plaque microflora in vitro and in vivo.

J Clin Periodontol 19, 455-459

Bahrami, G., Vaeth, M., Kirkevang, L-L., Wenzel, A., Isidor, F. (2008):

Risk factors for tooth loss in an adult population: a rediographic study. J Clin Periodontol 35, 1059-1065

Beck, J.D., Koch, G.G., Rozier, R.G., \& Tudor, G.E. (1990): Prevalence and Risk Indicators for Periodontal Attachment Loss in a Population of Older Communitydwelling Blacks and Whites. J Periodontol 61, 521-528

Becker, W., Becker, B.E., Berg, L.E. (1984): Periodontal treatment without maintenance. A retrospective study in 44 patients.

J Periodontol 55, 505-509 
Benowitz, N.L. (1996): Pharmacology of nicotine: addiction and therapeutics. Annu Rev Pharmacol Toxicol 36, 597-613

Bergstrom, J., Preber, H. (1986): The influence of cigarette smoking on the development of experimental gingivitis. J Periodontal Res 21, 668-676

Bergstrom, J., Eliasson, S. Dock, J. (2000): A 10-Year Prospective Study of Tobacco Smoking and Periodontal Health. J Periodontol 71, 1338-1347

Biagini, G., Checchi, L., Miccoli, M.C., Vasi, V., Castaldini, C. (1988): Root Curettage and Gingival Repair in Periodontitis. J Periodontol 59, 124-129

Bilichodmath, S., Mangaiekar, S. B., Sharma, D. C., Prabhakar, A. K., Reddy, S. B., Kalburgi, N. B., Patil, S. R., Bhat, K. (2009): Herpesviruses in chronic and aggressive periodontitis patients in an Indian population.

J Oral Sci 51 (1), 79-86

Black, C.E.,Huang, N., Neligan, P.C., Levine, R.H., Lipa, J.E., Lintlop, S., Forrest, C.R., Pang, C.Y. (2001): Effect of nicotine on vasoconstrictor and Vasodialtator responses in human skin vasculature.

Am J Physiol Regulatory Integrative Comp Physiol 281, R1097-R1104

Brunner, M., Salvi, G.E., Lang, N.P. (2002): Aggressive Parodontitis. Parodontologie 13/4, 321-343

Carpio, E., López, V., Fardales, V., Benítez, I. (2009): Oral manifestations of HIV infection in adult patients from the province of Sancti Spiritus, Cuba. J Oral Pathol Med 38, 126-131

Chapple, I.L., Walmsley, A.D., Saxby, M.S., Moscrop, H. (1995): Effect of instrument power setting during ultrasonic scaling upon treatment outcome. J Periodontol 66, 756-760 
Checchi, L., Montevecchi, M., Gatto, M.R.A., Trombelli, L., (2002):

Retrospective study of tooth loss in 92 treated periosontal patients J Clin Periodontol 29, 651-656

Chen, J-T. J., Burch, J.G., Beck, F.M., Horton, J.E. (1987): Periodontal attechment Loss associated with proximal tooth restorations.

J Prosthet Dent 57, 416-420

Christersson, L. A., Zambon, J. J., Genco, R. J. (1991): Dental bacterial plaques. Nature and role in periodontal disease. J Clin Periodontol 18 (6), 441-446

Christgau, M., Männer, T., Beuer, S., Hiller, K.-A., Schmalz, G. (2006): Periodontal healing after non-surgical therapie with a modified sonic scaler: a controlled clinical trial. J Clin Periodontol 33, 749-758

Chun, Y-H.P., Chun, K.-R.J., Olguin, D'-A., Wang, H.-L. (2005):

Biological foundation for periodontitis as a potential risk factor for atherosclerosis. J Periodontal Res 40, 87-95

Clark D.E., Navia J.M., Manson-Hing L.R., Duncan H.E. (1990): Evaluation of Alveolar Bone in Relation to Nutritional Status During Pregnancy. J Dent Res 69, 890-895

Coldirin, N.B., Yukna, R.A., Weir, J., Caudill, R.F. (1990): A Quantitative Study of Cementum Removal With Hand Curettes. J Periodontol 61, 293-299

Contreras, A., Slots, J. (2000): Herpesviruses in Human periodontal disease. J Periodontal Res 35 (1), 3-16

Contreras, A., Nowzari, H., Slots, J. (2000): Herpesviruses in periodontal pocket and Gingival tissue specimens. Oral Microbiol Immunol 15 (1), 15-18 
Dietrich, T., Bernimoulin J.P., Glynn, R.J. (2004): The Effect of Cigarette Smoking on Gingival Bleading. J Periodontol 75, 16-22

DiRienzo, J. M., Slots, J., Sixou, M., Sol, M. A., Harmon, R., McKay, T. L. (1994):

Specific genetic variants of Actinobacillus actonomycetemcomitans correlate with disease and health in a regional population of families with localized juvenile periodontitis. Infect Immun 62 (8), 3058-3065

DMS IV (Vierte Deutsche Mundgesundheitsstudie); Institut der Deutschen Zahnärzte Berlin, Köln 2006

Dörfer, C.E., Becher, H., Ziegler, C.M., Kaiser, C., Lutz, R., Jörß, D., Lichy, C., Buggle, F., Bültmann, S., Preusch, M., Grau, A.J. (2004): The association of gingivitis and periodontitis with ischemic stroke.

J Clin Periodontol 31, 396-401

Dragoo, M.,R. (1992): A clinical evaluation of hand and ultrasonic instruments on subgingival debridement. 1. With unmodified and modified ultrasonic inserts. Int J Periodontics Restorative Dent 12, 310-323

Drinkard, C.R., Decher, L., Little, J.W., Rhame, F.S., Balfour, H.H., Jr., Rhodus, N.L., Merry, J.W., Walker, P.O., Miller, C.E., Volberding, P.A., \& Melnick, S.L. (1991): Periodontal status of individuals in early stages of humanimmunodeficiency virus infection. Community Dent Oral Epidemiol 19, 281-285

Eberhard, T. (2008) Die antimikrobielle Photodynamische Therapie (aPDT):

Ergebnisse einer 2-Jahresuntersuchung. Zahnmedizin / Parodontologie 02/2008, 46-51

Eickholz, P., Kaltschmitt, J., Berbig, J., Reitmeir, P., Pretzl, B. (2008):

Tooth loss after active periodontal therapy. 1: patient-related factors for risk, prognosis, and quality of outcome.

J Clin Periodontol 35, 165-174 
Eschmann-Speer, C., Lange, D.E., Müller, R.F. (1997): Reduktion des Keimgehaltes behandlungsbedingter zahnärztlicher Aerosole.

Dtsch Zahnärztl Z 52, 436-438

Faggion, C.M. Jr., Petersilka, G., Lange, D.E., Gerss, J., Flemmig, T.F. (2007):

Prognostic model for tooth survival in patients treated for periodontitis.

J Clin Periodontol 34, 226-231

Feldman, R.S., Bravacos, J.S., Rose, C.L. (1983): Association Between Smoking Different Tobacco Produkts and Periodontal Disease Indexes.

J Periodontol 54, 481-487

Frentzen, M., Sculean, A., Visser, H. (2005): Laser in der Parodontologie Wissenschaftliche Stellungnahme der DGZMK und DGP Dtsch Zahnärztl Z 60 (6), www.dgzmk.de

Fukazawa, E., Nishimura, K. (1994): Superficial Cemental Curettage: Its Efficacy in Promoting Improved Cellular Attachment on Human Root Surface Previously Damaged by Periodontitis. J Periodontol 65, 168-176

Genco, R.J., Ho, A.W., Grossi, RG., Dunford, R.G., Tedesco, L.A. (1999):

Relationship of Stress, Distress and Inadequate Coping Behaviors to Periodontal Disease. J Periodontol 70, 711-723

Genco, R.J., Grossi, S.G., Ho, A., Nishimura, F., Murayama, Y. (2005): A Proposed Model Linking Inflammation to Obesity, Diabetes, and Periodontal Infections. J Periodontol 76, 2075-2084

Gilbert, G.H., Miller, M.K., Duncan, R.P., Ringelberg, M.L., Dolan, T.A., Foerster, U. (1999): Tooth-specific and person-level predictors of 24-month tooth loss among older adults. Community Dent Oral Epidemiol 27, 372-385

Gillespie, G. Marino, R. (1993): oral manifestations of HIV infection: a Panamerica perspective. J Oral Pathol Med 22, 2-7 
Goldman, M.J., Ross, I.F., Goteiner, D. (1986): Effect of Peiodontal Therapy on Patients Maintained for 15 Years or Longer. A Retrospective Study J Periodontol 57, 347-353

Gorman, W.J. (1967): Prevalence and etiology of gingival recession. J Periodontol 38, 316-322

Grossi, S.G., Zambon, J., Ho, A.W., Koch, G., Dunford, R.G., Machtei, E.E., Norderyd, O.M., \& Genco, R.J. (1994): Assessment of risk for periodontal disease. I. Risk indicators for attachment loss.

J Periodontol 65, 260-267

Grossi, S.G., Genco, R.J., Machtei, E.E., Ho, A.W., Koch, G., Dunford, R., Zambon, J., \& Hausmann, E. (1995): Assessment of risk for periodontal disease. II. Risk indicators for alveolar bone loss. J Periodontol 66, 23-29

Grossi, S.G., Zambon, J., Machtei, E.E., Schifferle, R., Andreana, S., Genco, R.J., Cummins, D., Harrap, G. (1997a): Effects of smoking and smoking cessation on healing after mechanical periodontal therapy. J Am Dent Assoc 128, 599-607

Grossi, S.G., Skrepcinski, F.B., DeCaro, T., Robertson, D.C., Ho, Alex, A.W., Dunford, R.G., Genco, R.J. (1997b): Treatment of Periodontal Disease in Diabetics Reduced Glycated Hemoglobin. J Periodontol 68, 713-719

Guarnelli, M.E., Franceschetti, G., Manfrini, R., Trombelli, L. (2008): Adjunctive effect of chlorhexidine in ultrasonic instrumentation of aggressive periodontitis patients: a pilot study. J Clin Periodontol 35, 333-341

Haffajee, A.D., Socransky, S.S. (1986): Attachment level changes in destructive periodontal diseases. J Clin Periodontol 13, 461-472 
Haffajee, A.D., Socransky, S.S. (2001): Relationship of cigarette smoking to attachment level profiles. J Clin Periodontol 28, 283-295

Haffajee, A.D., Cugini, M.A., Dibart, S., Smith, C., Kent, R.L. Jr., Socransky, S.S. (1997): The effect of SRP on the clinical and microbiological parameters of periodontal disease. J Clin Periodontol 24, 324-334

Hämmerle, C.H.F., Ingold, H-P., Lang, N.P. (1990): Evaluation of clinical and radiographic scoring methods before and after initial periodontal therapy. J Clin Periodontol 17, 255-263

Haubek, D., Poulsen, K., Westergaard, J., Dahlén, G., Kilian, M. (1996): Highly toxic clone of Actinobacillus acitomycetemcomitans in geographically widespread cases of juvenile periodontitis in adolescents of African origin.

J Clin Microbiol 34 (6), 1576-1578

Hellwig, E., Klimek, J., Attin, Th.: Einführung in die Zahnerhaltung. 2. Auflage Urban \& Fischer Verlag München 1999, 299-321

Hirschfeld, L., Wasserman, B. (1978): A longlterm survey of tooth loss in 600 treated patients. J Periodontol 49, 225-237

Hopp, M., Biffar, R. (2008) Die antimikrobielle Photodynamische Therapie (aPDT): nach dem HEBO-Verfahren. Zahnmedizin / Parodontologie 07/2008, 72-77

Iff, M., Marinello, C.P. (1998): Ultraschlgeräte, Anwendung in der Parodontologie. Eine Literaturübersicht. Acta Med Dent Helv 3, 149-160

Ioannou, I., Dimitriadis, N., Papadimitriou, K., Sakellari, D, Vouros, I, Konstantinidis, A. (2009): Hand instrumentation versus ultrasonic debriment $n$ the treatment of chronic periodontitis: a randomized clinical and microbiological trial.

J Clin Periodontol 36, 132-141 
Iwamoto, Y., Nishimura, F., Nakagawa, M., Sugimoto, H., Shikata, K., Makino, H., Fukuda, T. Tsuji, T., Iwamoto, M., Murayama, Y. (2001): The Tffect of Antimicrobial Periodontal Treatment on Circulating Tumor Necrosis Factor-Alpha and Glycated Hemoglobin Level in Patients With Type 2 Diabetes. J Periodontol 72, 774-778

Janssen P.T.M., Drayer, A., Faber, J.A.J., van Palenstein Halderman, W.H. (1988a): Accuracy of repeated single versus averages of repeated duplicates of probing depth measurements. J Clin Periodontol 15, 569-574

Janssen P.T.M. Faber, J.A.J., van Palenstein Halderman, W.H. (1988b):

Effect of probing depth and bleeding tendency on the reproducibility of probing depth measurements. J Clin Periodontol 15, 565-568

Jeffcoat, M., (2005): The Association Between Osteoporosis and Oral Bone Loss. J Periodontol 76, 2125-2132

Jin, L., Wong, K.Y., Leung, W.K., Corbet, E.F. (2000): Comparison of treatment Response pattern following scaling and root planing in smokers and nonsmokers with untreated adult periodontitis.

J Clin Dent 11, 35-41

Jordan, R.A., Gängler, P., Jöhren, H.P. (2006): Clinical treatment outcomes of Periodontal therapie in HIV-seropositive patients undergoing highly active antiretroviral therapie. Eur J Med Res 30, 232-235

Kaldahl, W.B., Johnson, G.K., Patil, K.D., Kalkwarf, K.L. (1996): Levels of Cigarette Consumption and Response to Periodontal Therapy.

J Periodontol 67, 675-681 
Katz, J., Bhattacharyya, I., Farkhondeh-Kish, F., Perez, F.M., Caudle, R.M., Heft, M.W. (2005): Expression of the receptor of advanced glycation end products ingingival tissues of type 2 diabetes patients with chronic periodontal disease: a study utilizing immunohistochemistry and RT-PCR.

J Clin Periodontol 32, 40-44

Kerdvongbundit, V., Wikesjö, U.M.E. (2000): Effect of Smoking on Periodontal Health in Molar Teeth. J Periodontol 71, 433-437

Kornman, K.S., Crane, A., Wang, H.Y., di Giovine, F.S., Newman, M.G., Pirk, F.W., Wilson, T.G., Jr., Higginbottom, F.L., \& Duff, G.W. (1997): The interleukin-1 genotype as a severity factor in adult periodontal disease.

J Clin Periodontol 24, 72-77

König, J., Plagmann, H-C., Rühling, A., Kocher, T. (2002): Tooth loss and pocket probing depths in compliant periodontally treated patients: a retrospective analysis. J Clin Periodontol 29, 1092-1100

Krall E.A., (2001): The Periodontal-Systemic Connection: Implications for Treatment of Patients with Osteoporosis and Periodontal Disease.

Ann Periodontol 6, 209-213

Krall, E.A., Dawson-Hughes, B., Garvey, A.J., Garcia, R.I. (1997): Smoking, smoking cessation, and tooth loss. J Dent Res 76, 1653-1659

Labriola, A., Needleman, I., Moles, D.R. (2005): Systematic review of the effect of smoking on nonsurgical periodontal therapy. Periodontol $200037,124-137$

Lalla, E., Lamster, I.B., Feit, M., Huang, L., Spessot, A., Qu, W., Kislinger, T., Lu, Jan., Stern, D.M., Schmidt, A.M. (2000): Blockade of RAGE suppresses periodontitis-associated bone loss in Diabetic mice.

J Clin Invest 105, 117-1124 
Lang, N.P. \& Tonetti, M.S. (2003): Periodontal risk assessment (PRA) for patients in supportive periodontal therapy (STP). Oral Health Prev Dent. 1, 7-16

Larato, D.C., Ruskin, P.F., Martin, A. (1967): Effect of an ultrasonic scaler on becteri al counts in air. $J$ Periodontol 38, 550-554

Linden, G.J., Mullally, B.H. (1994): Cigarette Smoking and Periodontal Destruction in Young Adults. J Periodontol 65, 718-723

Linden, G.L., Mullally, B.H., Freeman, R. (1996): Stress and the progression of Periodontal disease. J Clin Periodontol 23, 675-680

Lindhe, J., Nyman, S. (1984): Long-term maintenance of patients treated for Advanced periodontal disease. J Clin Periodontol 10, 504-514

Lindhe, J., Socransky, S., Nyman, S., Westfelt, E., \& Haffajee, A. (1985): Effect of age on healing following periodontal therapy.

J Clin Periodontol 12, 774-787

Loomer,P.M. (2004): Microbiological diagnostic testing in the treatment of periodontal diseases. Periodontol 2000 34, 49-56

Löe, H, Theilade, E., Jensen, B. (1965): Experimental Gingivitis in Man. J Periodontol 36, 177-187

Lösche, W. (2004): Marginale Parodontitis und Herz-Kreislauf-Erkrankungen. Quintessenz 55, 393-402

López, N.J., Jara L., Velenzuela C.Y. (2005a): Association of Interleukin-1 Polymorphisms With Periodontal Disease. J Periodontol 76 (2), 234-243

López, N.J., Da Silva, I., Ipinza, J., Gutiérrez, J. (2005b): periodontal Therapy Reduces the Rate of preterm Low Birth Weight in Women With PregnancyAssociated Gingivitis. J Periodontol 76, 2144-2153 
Manau, C., Echeverria, A., Agueda, A., Guerrero, A., Echeverria J.J. (2008):

Periodontal disease definition may determine the association between periodontitis and pregnancy outcomes.

J Clin Periodontol 35, 385-397

Mariotti, A. (1999): Dental Plaque-Induced Gingival Diseases.

Ann Periodontol 4, 7-17

Marsh, P.D (2004): Dental Plaque as a Microbial Biofilm.

Caries Res 38, 204-211

Mc Devit M.J., Wang H.Y., Knobelman C., Newman M.G., di Giovine F.S., Timms J., Duff G.W., Kornman K.S. (2000): Interleukin-1 genetic association with periodontitis in clinical practice. J Periodontol 71 (2), 156-163

Mc Fall, W.T. Jr. (1982): Tooth Loss in 100 treated Patients With Periodontal Disease. A Long-Therm Study. J Periodontol 53, 539-549

Mc Guire, M.K. \& Nunn, M.E. (1996): Prognosis Versus Actual Outcome.

III. The Effectiveness of Clinical Parameters in Accurately Predicting Tooth Survival. J Periodontol 67, 666-674

Mc Leod, D.E., Lainson, P.A., Spivey, J.D (1997): The effectiveness of periodontal treatment as measured by tooth loss. J Am Dent Assoc 128, 316-324

Mealey, B.L. (2006): Periodontal disease and diabetes: A two way street. J Am Dent Assoc 137, 26-31

Melcher; A.H. (1985): Cells of periodontium: their role in the healing of wounds. Ann R Coll Surg Engl 67, 130-131

Mercando, F.B., Marshall, R.I., Klestov, A.C., Bartold, P.M. (2001): Relationship between rheumatoid arthritis and periodontitis. J Periodontol 72, 779-787 
Michalowicz, B. S., Ronderos, M., Camara-Silva, R., Contreras, A., Slots, J. (2000): Human Herpesviruses and Porphyromonas gingivalis Are Associated With Juvenile Periodontitis. J Periodontol 71 (6), 981-988

Micheelis, W., Hoffmann, Th., Holtfreter, B., Kocher, Th., Schroeder, E. (2008): Zur epidermiologischen Einschätzung der Parodontitislast in Deutschland - Versuch einer Bilanzierung. Dtsch Zahnärztl Z 63, 464-472

Miley D.D., Garcia M.N., Hildebolt C.F., Shannon W.D., Couture R.A., Aderson Spearie C.L., Dixton D.A., Langenwalter E.M., Mueller C., Civitelli R., (2009): Cross-Sectional Study of Vitamin D and Calcium Supplementation Effects on Chronic Periodontitis. J Periodontol 80, 1433-143

Mullally, B.H., Linden, G.J. (1996): Molar furkation involvenemt associated with Cigarette smoking in periodontal referrals.

J Clin Periodontol 23, 658-661

Murray, P.A. (1994): Periodontal disease in patients infected by human immunodeficiency Virus. Periodontol 2000 6, 50-67

Müller, H.P. Parodontologie ,Thieme Verlag Stuttgart (2001)

Nishida M., Grossi S.G., Dunford R.G., Ho A.W., Trevisan M., Genco R. (2000a): Dietary Vitamin $\mathrm{C}$ and the Risk for Periodontal Disease. J Periodontol 71, 1215-1223

Nishida M., Grossi S.G., Dunford R.G., Ho A.W., Trevisan M., Genco R. (2000b): Calcium and the Risk for Periodontal Disease. J Periodontol 71, 1057-1066

Nishida, N., Yamamoto, Y., Tanaka, M., Maeda, K., Kataoka, K., Nakayama, K. Morimoto, K., Shizukuishi, S. (2006): Association between passive smoking and salivary markers related to periodontitis.

J Clin Periodontol 33, 717-723 
Nosal, G., Scheidt, M.J., O’Neil, R., van Dyke, T.E. (1991): The penetration of large solution into the periodontal pocket during ultrasonic instrumentation.

J Periodontol 62, 554-557

Nyman, S., Lindhe, J.,Rosling, B. (1977): Periodontal surgery in plaque-infected dentitions. J Clin Periodontol 10, 240- 249

O'Leary, T.J. (1986): The Impact of Research on Scaling and Root Planing.

J Periodontol 57, 69-75

Orkin, D.A., Reddy, J., \& Bradshaw, D. (1987): The relationship of the position of crown margins to gingival health.

J Prosthet Dent 57, 421-42

Oosterwaal, P.J.M.,Matee, M.I., Mikx, F.H.M., van't Hof, M.A., Renggli, H.H. (1987): The effect of subgingival debriment with hand and ultrasonic instruments on the subgingival microflora. J Clin Periodontol 14, 528-533

Österberg, T., Mellström, D. (1986): Tobacco smoking: a major risk factor for loss of teeth in three 70-year-old cohorts.

Community Dent Oral Epidemiol 14, 367-370

Page, R.C. (1986): Gingivitis. J Clin Periodontol 13, 345-355

Page, R.C. (1991): The role of inflammatory mediators in the pathogenesis of Periodontal disease. J Periodontal Res 26, 230-242

Page, R.C. \& Kornman, K.S (1997): The pathogenesis of human periodontitis: a Introduktion. Periodontol 2000 14, 9-11

Palacios C., Joshipura K.J., Willett W.C. (2009): Nutrition and health: guidlines for dental practitioners. Oral Dis 15, 369-381 
Palmqvist, S., Sjödin, B. (1987): Alveolar bone levels in a geriatric Swedish population. J Clin Periodontol 14, 100-104

Parsell, D.E., Streckfus, C.F., Stewart, B.M., \& Buchanan, W.T. (1998): The effect of amalgam overhangs on alveolar bone height as a function of patient age and overhang width. Oper Dent 23, 94-99.

Pepelassi, E.A., Diamanti-Kipioti, A. (1997): Selction of the most accurate method of conventional radiography fort he assessment of periodontal osseous destruction. J Clin Periodontol 24, 557-567

Pepelassi, E.A., Tsiklakis, K., Diamanti-Kipioti, A. (2000): Radiographic detection and assessment of the periodontal endoosseous defects J Clin Periodontol 27, 224-230

Petersilka, G.J., Flemming, T.F. (1999): Subgingivale Wurzeloberflächenbearbeitung Mit Schall- und Ultraschaschalliscalern. Parodontologie 3, 233-244

Petersilka, G.J., Flemming, T.F. (2005): Schall- und Ultraschall in der Parodontitistherapie. Gemeinsame Stellungnahme der DGZMK und der DGP. Dtsch Zahnärztl. Z 60 (6)

Pihlstrom, B. L. (2001): Periodontal risk assessment, diagnosis and treatment planning. Periodontol 2000 25, 37-58

Pitiphat, W., Merchant, A.T., Rimm, E.B., Joshipura, K.J. (2003): Alcohol Consumption Increases periodontitis Risk. J Dent Res 82, 509-513

Plagmann, H.C.: Lehrbuch der Parodontologie. Carl Hanser Verlag München Wien 1998, 41-447

Preber, H. \& Bergström, J. (1986): The effect of non-surgical treatment on periodontal pockets in smokers and non-smokers. J Clin Periodontol 13, 319- 323 
Pretzl, B., Kaltschmitt, J., Kim, T.-S., Reitmeir, P., Eickholz, P. (2008):

Tooth loss after periodontal therapy. 2: tooth-related factors.

J Clin Periodontol 35, 175-182

Proye, M.P., Polson, A.M. (1982): Effect of root surface alternations on periodontal healing. I. Surgical denudation. J Clin Periodontol 9, 428-440

Reddy, M.S., Geurs, N.C., Jeffcoat, R.L., Proskin, H., Jeffcoat, M.K. (2000):

Periodontal Disease Progression, J Periodontol 71, 1583-1590

Reynolds, M.A., Lavigne, C.K., Minah, G.E., Suzuki, J.B. (1992): Clinical effects of simultaneous ultrasonic scaling and subgingival irrigation with chlorhexidine. Mediating influence of periodontal probing depth.

J Clin Periodontol 19,595-600

Rohner, F., Cimasoni, P., Vuagnat, P. (1983): Longitudinal radiographical study on the rate of alveolar bone loss in patients of a dental school. J Clin Periodontol 10, 643-651

Rosania, A.E., Low, K.G., McCormick, C.M., Rosania, D.A. (2009): Stress, Depression, Cortisol, and Periodontal Disease. J Periodontol 80, 260-266

Rosling, B., Serino, G., Hellström, M-K., Socransky, S.S., Lindhe, J. (2001):

Longitudinal periodontal tissue alternations during suppertive therapie. Findings from subjects with normal and high suscepibility to periodontal disease. J Clin Periodontol 28, 241-249

Salvi, G.E., Lawrence, H.P., Offenbacher, S., \& Beck, J.D. (1997): Influence of risk factors on the pathogenesis of periodontitis. Periodontology 2000 14, 173-201

Saygun, I., Kubar, A., Özdemir, A., Yapar, M., Slots, J. (2004): Herpesviral-bacterial interrelationsship in aggressive periodontitis. J Periodontal Res 39, 207-212 
Scabbia, A., Cho, K.S., Sigurdsson, T.J., Kim, C.K., Trombelli, L. (2001): Cigarette Smoking Negatively Affects Healing Response Following Flap Debriment Surgery. J Periodontol 72, 43-49

Schätzle, M., Lang, N.P., Anerud, A., Boysen, H., Bürgin, W., Löe, H. (2001):

The influence of margins of restorations on the periodontal tissues over 26 years. J Clin Periodontol 28, 57-64

Schätzle, M., Loe, H., Burgin, W., Anerud, A., Boysen, H., \& Lang, N.P. (2003):

Clinical course of chronic periodontitis. I. Role of gingivitis.

J Clin Periodontol 30, 887-901

Schmidt, A.M., Weidman, E., Lalla, E., Shi Du Jan, Hori, O., Cao, R., Brett, J.G., Lamster, I.B. (1996): Advanced glycation endproducts (AGE's) induce oxidant stress in the gingiva: a potential mechanism underlying accerelated periodontal disease associated with diabetes.

J Periodontal Res 31, 508-515

Schroeder H.E.: Pathologie oraler Strukturen, Zähne, Pulpa, Parodont, Karger Verlag Basel 1997

Schwarz, F., Aoki, A., Becker, J., Sculean, A. (2008): Laser application in nonsurgical periodontal therapy: a systematic review.

J Clin Periodontol 35, 29-44

Sculean, A., Schwarz, F., Berakdar, M., Romanos, G.E., Brecx, M., Willershausen, B., Becker, J. (2004): Non-surgical periodontal treatment with a new ultrasonic device (Vector ${ }^{\mathrm{TM}}$-ultrasonic system) or hand instruments.

J Clin Periodontol 31, 428-433

Serino, G., Rosling, B., Ramberg, P., Socransky, S.S., Lindhe, J. (2001): Initial outcome and long-term effect of surgical and non-surgical treatment of davanced periodontal disease. J Clin Periodontol 28, 910-916 
Sheiham, A. (1991): Public health aspects of periodontal diseases in Europe. J Clin Periodontol 18, 362-369

Sheiham, A., Netuveli, G. S. (2002): Periodontal diesases in Europe. Periodontol 2000 29, 104-121

Ship, J.A., Beck, J.D. (1996): Ten-year longitudinal study of periodontal attachment loss in healthy adults.

Oral Surg Oral Med Oral Pathol Oral Radiol Endod 81, 281

Slots, J., Contreras, A., (2000): Herpesviruses: a unifying causative factor in periodontitis? Oral Microbiol Immunol 15(5), 277-280

Slots, J.,Ting, M. (1999): Actinobacillus actinomycetemcomitans and Porphyromonas gingivalis in human periodontal disease: occurrence and treatment. Periodontol 2000 20, 82-121

Smart, G.J., Wilson, M., Davies, E.H., Kieser, J.B. (1990): The assessment of ultrasonic root surface debriment by determination of residual endotoxin levels. J Clin Periodontol 17, 174-178

Smulow, J.B., Turesky, S.S., Hill, G.R. (1983): The effect of supragingival plaque removal on anaerobic bacteria in deep periodontal pockets.

J Am Dent Assoc 107, 737-742

Steinsvoll, S., Herlofson, B.B. (2006): Oral manifestations in HIV infection. Tidsskr Nor Laegeforen 9, 1218-1221

Taggart, J.A., Palmer, R.M., Wilson, R.F. (1990): A clinical and microbiological comparison of the effect of water and $0,02 \%$ chlorhexidine as coolants during ultrasonic scaling and root planing.

J Clin Periodontol 17, 32-37 
Taylor, G.W., Burt, B.A., Becker, M.P., Genco, R.J., \& Shlossman, M. (1998):

Glycemic Control and Alveolar Bone Loss Progression in Type 2 Diabetes. Ann Periodontol 3, 30-39

Ting, M., Contreras, A., Slots, J. (2000): Herpesvirus in localized juvenile periodontitis. J Periodontal Res 35, 17-25

Torfason, T., Kiger, R., Selvig, K.A., Egelberg, J. (1979): Clinical improvement of Gingival conditions following ultrasonic versus hand instrumentation of periodontal pockets. J Clin Periodontol 6, 165-176

Trombelli, L., Cho, K.S., Kim, C.K.,Scapoli, C. Scabbia, A. (2003): Impaired healing Response of periodontal furkation defects following flap debriment surgery in smokers. A controled clinical trial. J Clin Periodontol 30, 81-87

Umeda, M., Chen, C., Bakker, I., Contreras, A., Morrison, J.L., Slots, J. (1998):

Risk indicators for harboring periodontal pathogens.

J Periodontol 69, 1111-1118

van der Velden, U. (1984): Effect of age on the periodontium.

J Clin Periodontol 11, 281-294

van Volkinburg, J.W., Green, E., Armitage, G.C. (1976): The nature of root surfaces after curette, cavitron and alpha-sonic instrumentation.

J Periodontal Res 11, 374-381

van Winkelhoff, A. J., de Graaff, J. (1991): Microbiology in the management of destructive periodontal disease. J Clin Periodontol 18, 406-410

Vettore, M.V., Leao, A.T.T., Monteiro da Silva, A.M., Quintanilha, R.S., Lamarca, G.A. (2003): The relationship of stress and anxiety with chronic periodontitis. J Clin Periodontol 30, 394-402 
Wactawski-Wende, J. (2001): Periodontal Disease and Osteoporosis: Association and Mechanisms. Ann Periodontol 6, 197-208

Wagaiyu, E. G., Ashley, F.P. (1991): Mouthbreathing, lip seal and upper lip coverage and their relationship with gingival inflammation in 11-14 year-old schoolchildren. J Clin Periodontol 18, 698-702

Walmsley, A.D., Laird, W.R.E., Williams, A.R. (1984): A Model System to Demonstrate the Role of Cavitational Activity in Ultrasonic Scaling. J Dent Res 63, 1162-1165

Withers, J.A., Brunsvold, M.A., Killoy, W.J., \& Rahe, A.J. (1981): The relationship of palato-gingival grooves to localized periodontal disease.

J Periodontol 52, 41-44

Wolff, L., Dahlén, G., Aeppli, D., (1994): Bacteria as risk markers for periodontitis. J Periodontol 65 (5 Suppl), 498-510

Wood, W.R., Greco, G.W., Mc Fall, W.T. Jr. (1989): Tooth Loss in Patients With Moderate Periodontitis After Treatment and Long-Therm Maintenance Care. J Periodontol 60, 516-520

Yamamoto, Y., Nishida, N., Tanaka, M., Hayashi, N., Matsuse, R., Nakayama, K., Morimoto, K., Shizukuishi, S. (2005): Association between passive and active smoking evaluated by salivary cotinine and periodontitis. J Clin Periodontol 32, 1041-1046

Yki-Järvinen, H., Sammalkorpi, K., Koivisto, V.A., Nikkilä, E.A. (1989): Severity, Duration, and Mechanisms of Insulin resistance during Acute Infections. J Clin Encocrinol Metab 69, 317-323

Zaher, C-A., Hachem, J., Puhan, M-A., Mombelli, A. (2005): Interest in periodontology and preferences for treatment of localized gingival recessions. J Clin Periodontol 32, 375-382 
Zitterbart, P.A. (1987): Effectiveness of ultrasonic scalers: a literature review. Gen Dent 35, 295-297

Zybutz, M., Rapoport, D., Laurell, L., Persson, G.R. (2000): Comparisons of clinical and radiographic measurements of inter-proximal veritcal defects before ans 1-year after surgical treatments.

J Clin Periodontol 27, 179-186. 


\section{Danksagung}

Herrn Prof. Dr. med. dent. Rainer F. Mausberg möchte ich für die Möglichkeit zur Durchführung und Betreuung meiner Arbeit herzlichst danken. Ganz besonderer Dank gilt Herrn Dr. med. dent. Ziebolz für die tatkräftige Unterstützung und Betreuung.

Frau Lange aus der Medizinischen Statistik der Universität Göttingen möchte ich für die zahlreichen Hilfestellungen im Rahmen dieser Dissertation danken.

Herrn Dr. med. dent. Peter Kröncke und seinem Praxisteam in meiner ehemaligen Praxis möchte ich speziellen Dank aussprechen, für die Unterstützung bei der Patientensuche und Betreuung, was nicht selbstverständlich war. Nicht zuletzt ein Dankeschön an alle Patienten, die an dieser Untersuchung teilgenommen haben. 


\section{Curriculum Vitae}

Ich, Michael Wieslaw Jablonski, bin am 08. Dezember 1980 in Ratibor, Kreis Kattowitz / Polen (Oberschlesien) geboren. Konfession römisch katholisch. Meine Mutter, Irmgard Jablonski, geb. Jeremias, ist am 13. Juni 1957 in Ratibor geboren und von Beruf Dipl.-Zahntechnikerin. Mein Vater, Wieslaw Jablonski, verstarb am 24. Oktober 1996.

Meine schulische Ausbildung begann 1987/89 in Ratibor, am 03. Feb. 1989 war meine Einreise in die Bundesrepublik Deutschland, die zweite Klasse beendete ich in der Volksschule Denkendorf (bei Ingolstadt/Bayern). Darauf besuchte ich 1989/90 die Volksschule in Bad Neustadt / an der Saale und beendete dieses dritte Schuljahr an der Volksschule in Landsberg am Lech. Daraufhin folgte der Umzug nach Minden (Westfalen), wo ich meine Grundschulausbildung, in der Grundschule Dützen/Haddenhausen 1990/1991 beendete. Von 1991 bis 97 besuchte ich die Kurt-Tucholsky-Gesamtschule in Minden, die ich mit dem Erwerb der Fachoberschulreife abschloss. Anschließend besuchte ich, ebenfalls in der KurtTucholsky-Gesamtschule, die gymnasiale Oberstufe, die ich mit dem Erwerb des Abiturs am 30. Juni 2000 verließ. Nach meiner Schulzeit folgte mein Wehrdienst und freiwilliger Dienst vom 01. Juli 2000 in der Marineversorgungsschule List auf Sylt und ab dem 05. Oktober 2000 in der Marinewaffenschule in Eckernförde, wo ich als Versorgungsgast bis zu meinem Ausscheiden am 30. September 2001 tätig war. Ab dem 01 . Oktober 2001 begann mein Studium der Zahnheilkunde an der GeorgAugust-Universität in Göttingen, welches ich am 07. Dezember 2006 mit dem Staatsexamen beendete. Mein beruflicher Werdegang begann am 01. Februar 2007 in der Zahnarztpraxis von Dr. Peter Kröncke in Minden, als Vorbereitungsassistent. Ab September 2008 startete meine zusätzliche Tätigkeit in der Überweiserpraxis für Digitale Volumentomografie, ebenfalls in Minden. Am 01. September 2009 begann meine Weiterbildung zum Fachzahnarzt für Oralchirurgie in der Gemeinschaftspraxis Prof. Dr. Dr. Ralf Schmidseder und Dr. Frank Schmidseder in Frankfurt am Main. 